\title{
Trace metal accumulation in decapods and its use in monitoring the marine environment
}

\author{
Annie Graham
}

A thesis submitted to Victoria University of Wellington in partial fulfilment of the requirements for the degree of Master of Science in Marine Biology.

Victoria University of Wellington

April 2019 


\section{Abstract}

Coastal habitats are susceptible to severe contamination due to their exposure to both marine and terrestrial inputs, many of which contain toxic heavy metals. Trace metals in the marine environment can have severe impacts on the health of coastal ecosystems, as even those with essential functions can be toxic at high concentrations, and non-essential elements can cause impairment of biological functions even at low levels.

It is important to understand the chemistry of New Zealand's marine environment, in order to successfully monitor any changes to the chemical profile of the environment from anthropogenic pollutants. Biological indicators are a useful tool for monitoring ecosystem health, and the impact of human activity on the environment. Crustaceans fulfil all the criteria of being good environmental indicators, as well as having a range of feeding strategies, and being present at multiple trophic levels. The aim of this research was to 1) investigate spatial variation and the effect of urbanisation in trace metal concentration in two native decapod species, Heterozius rotundifrons and Petrolisthes elongatus, which cooccur but feed at different trophic levels; and 2) examine how essential and nonessential trace metals are accumulated into different body tissues of the decapod Jasus edwardsii, a significant cultural and fishery species.

To assess spatial variation and trophic level differences between decapods, baseline data of the concentrations of thirty trace metals was collected and analysed from both species at three sites in the Wellington region. Little variation was found between the sites, despite their differences in proximity to urban development, but significant differences were found between species, with the consumer $H$. rotundifrons having higher concentrations of most trace metals than the filter feeder $P$. elongatus.

To assess trace metal accumulation into tissues of $J$. edwardsii, an experiment was run exposing juveniles to water doped with an elevated copper and neodymium treatment. Copper was preferentially accumulated into the organ tissue, as was expected for an essential element. Neodymium was accumulated differentially into organ and exoskeleton tissue depending on the treatment, with specimens in the elevated treatment taking it up into the shell rather than the 
organs. A second experiment was also run to investigate whether moulted exoskeletons would passively absorb copper from their environment, which was shown to be the case.

This research aids in understanding the importance of multiple species monitoring, as trace element accumulation was shown to be highly variable depending on species and metals, and contributes valuable geochemical data on native New Zealand species, which have been little studied in this context. 


\section{Acknowledgments}

This thesis is dedicated to my grandparents, and Great Uncle Peter, for instilling in me a love of nature and the sea.

I would particularly like to thank my supervisors, Nicole Phillips, Kareen Schnabel, and Monica Handler for their endless support and guidance, without which this thesis could not have been achieved.

Many thanks also go to the CAIME team at NIWA Wellington and Victoria University: Richard Wysoczanski, Rachael Peart, Grace Frontin-Rollett, and Andrea Davies for assisting me in any way they could; and to other NIWA personnel: Jeff Forman and Dean Stotter who provided the crayfish used for this research, and Lisa Northcote and Helen Bostock for their geology expertise. Thanks also to the VUCEL technicians and the Phillips lab group for their advice and helping me with lab work and statistics, and to Bruce Charlier for the use of the geology lab and microbalance.

Finally, many thanks go to my family and friends, especially to my parents, Mary and Charlie Graham, and my siblings Charles, Hugh, and Moragh, for their constant love and support throughout my education; and to Chanelle Seabrook and Andrew Mason, for their encouragement and assistance in all aspects of this thesis.

The funding for this thesis was provided by NIWA and Victoria University through a Ministry of Business, Innovation, and Employment grant for the CAIME project. 


\section{$\underline{\text { Table of Contents }}$}

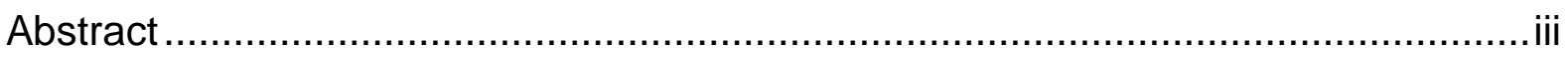

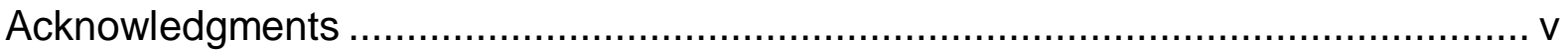

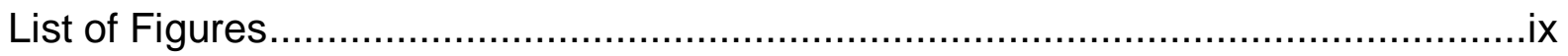

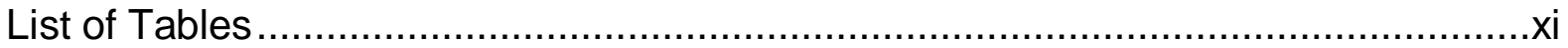

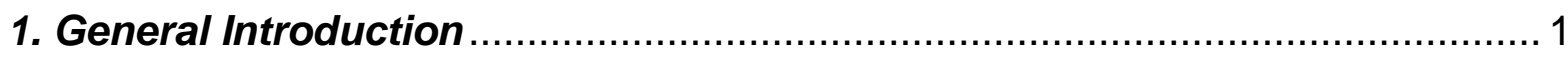

Monitoring metals in the environment............................................................ 1

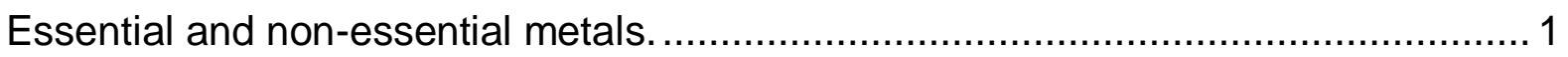

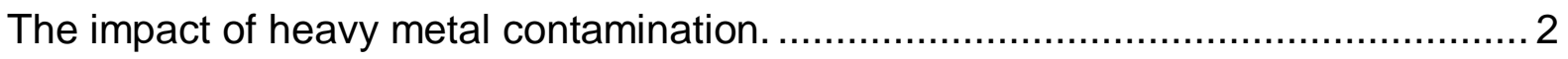

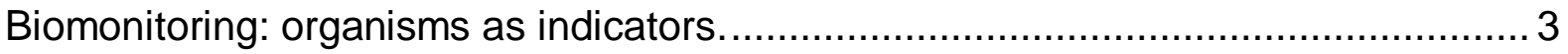

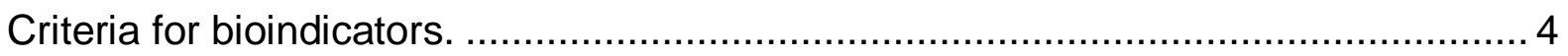

Crustaceans as indicators of marine environmental change (CAIME) ...................... 5

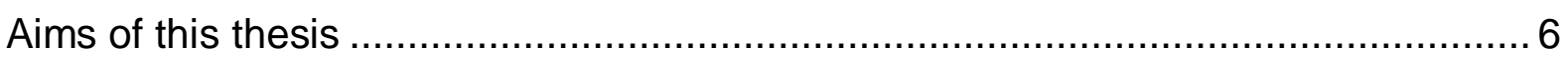

2. Baseline Data Collection and Spatial and Trophic Variation in Trace

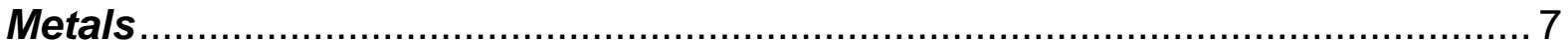

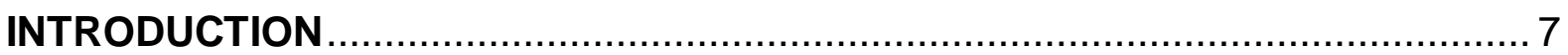

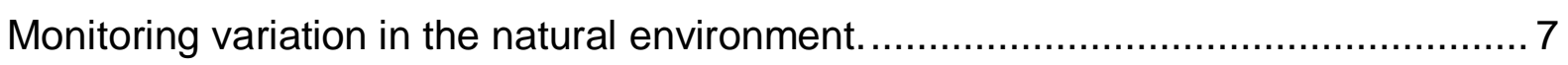

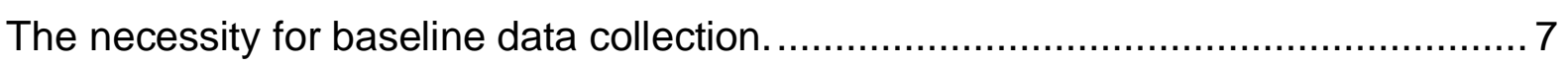

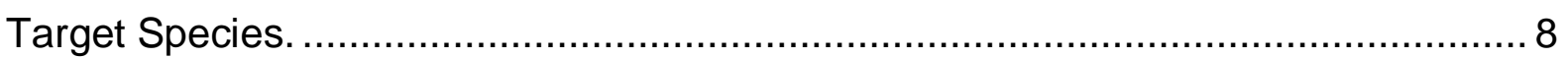

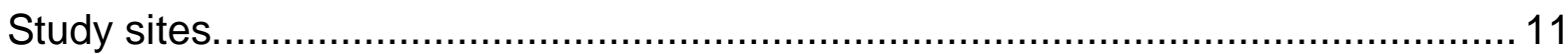

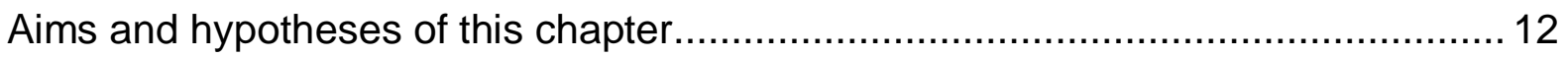

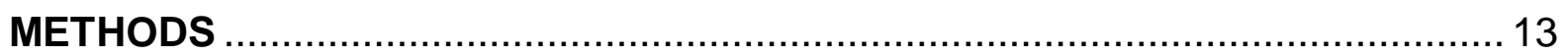

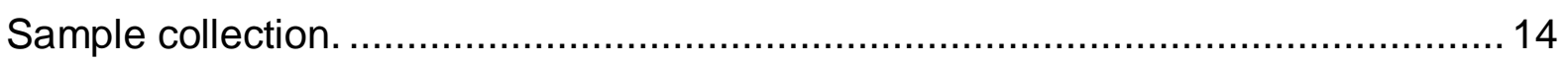

Cleaning, drying, and weighing decapod samples. .......................................... 15

Chemical processing of decapod samples........................................................ 16

Mass spectrometer analysis.......................................................................... 18

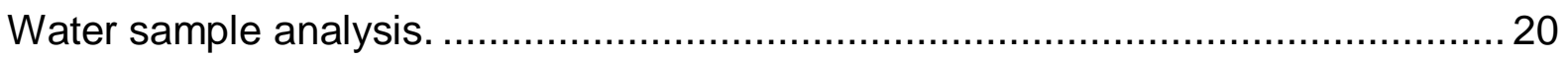

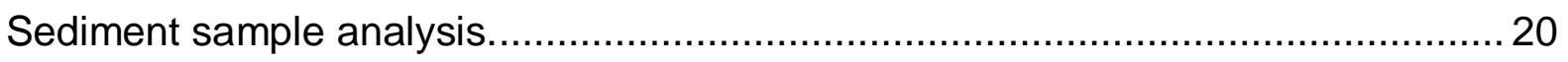

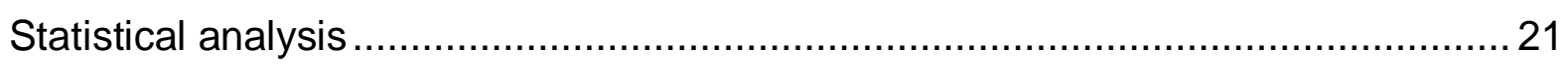

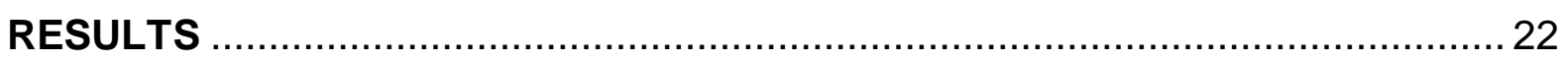

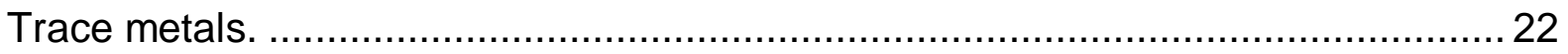

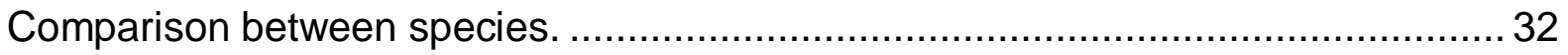

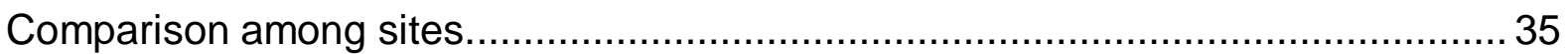


Interactions between site and species.

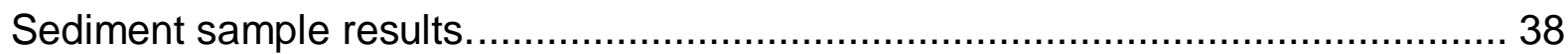

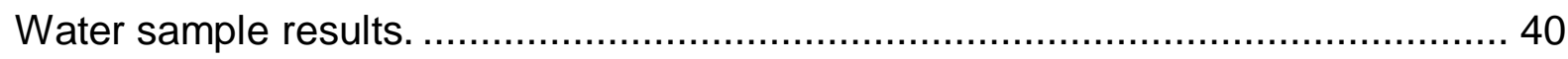

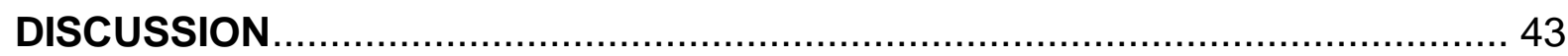

Comparison of concentrations of metals between species. .............................. 43

Comparison between concentrations of metals in decapods between different sites. 45

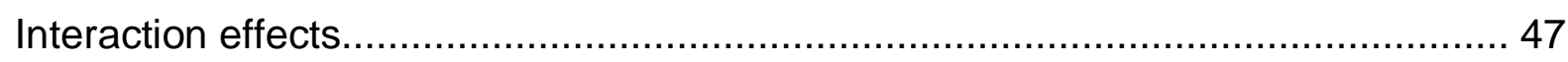

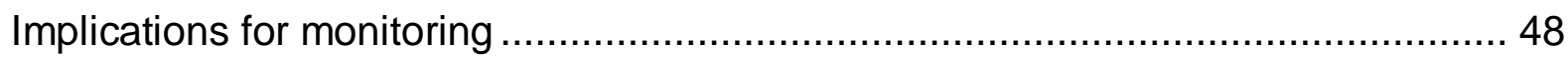

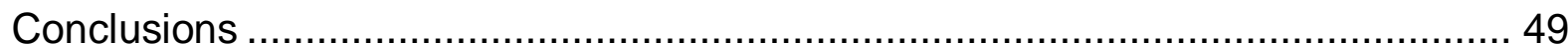

3. Uptake of trace metals into different tissue types of Jasus edwardsii. ....... 51

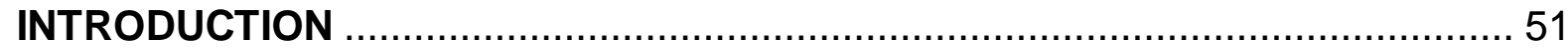

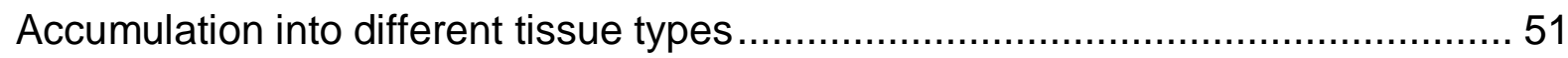

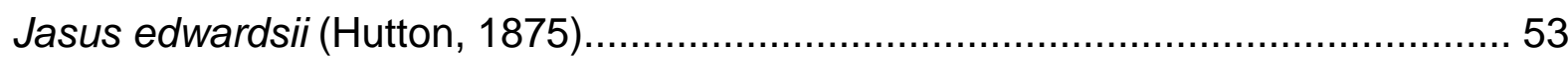

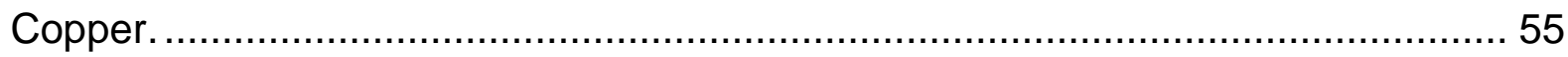

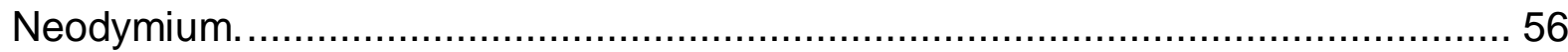

Aims and hypotheses of this chapter. ......................................................... 57

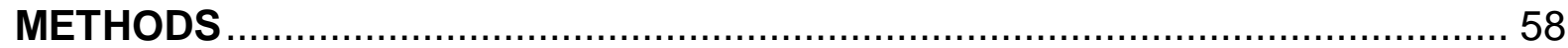

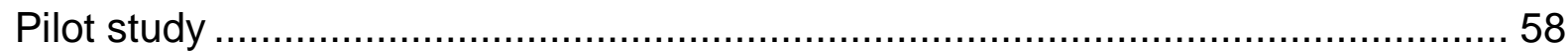

Maintenance of Jasus edwardsii juveniles.............................................. 59

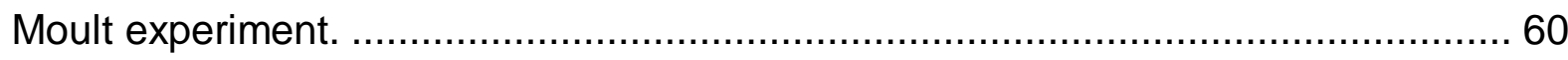

Jasus edwardsii doping experiment. ............................................................ 60

Cleaning, drying, and weighing decapod samples........................................ 61

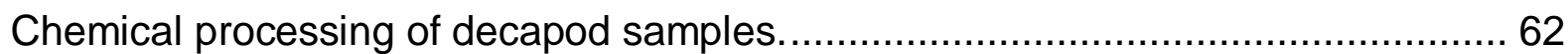

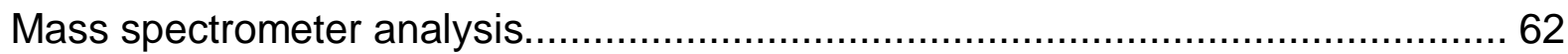

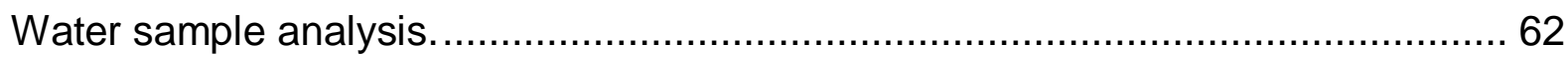

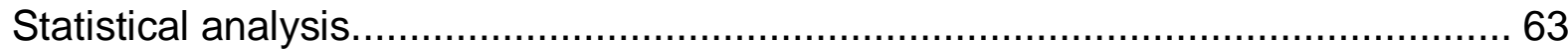

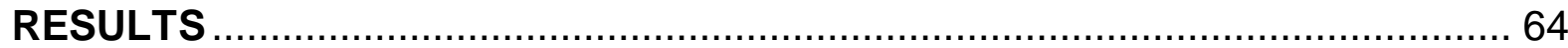

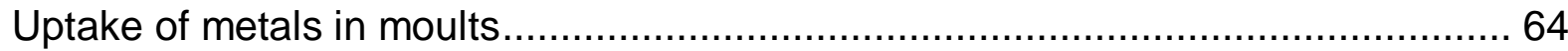

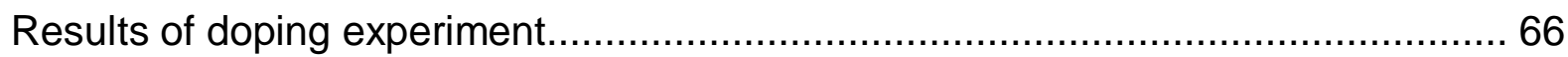

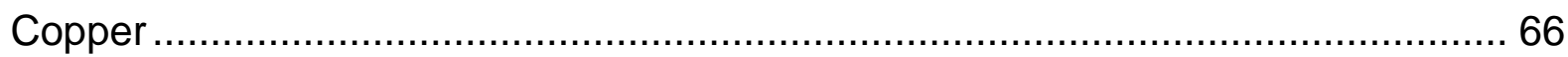

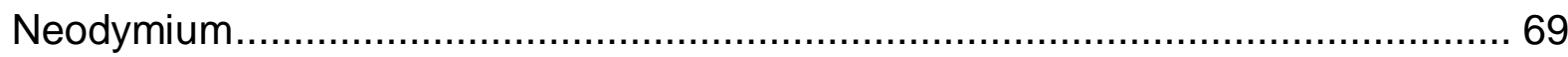

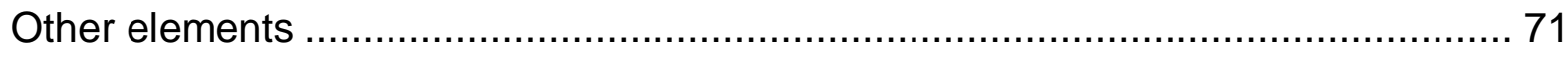

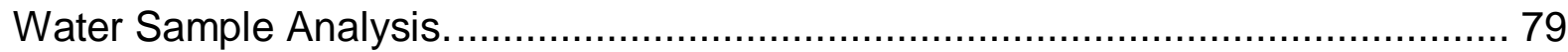


DISCUSSION

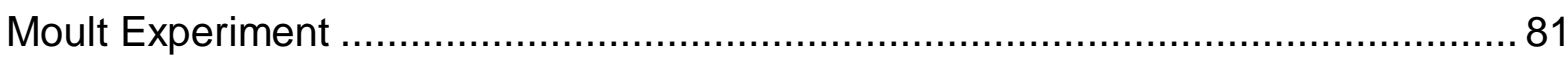

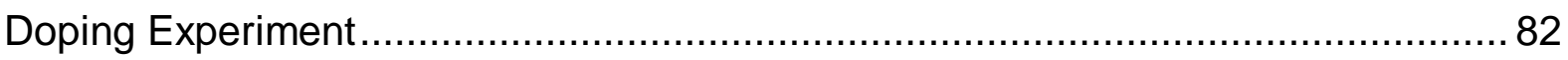

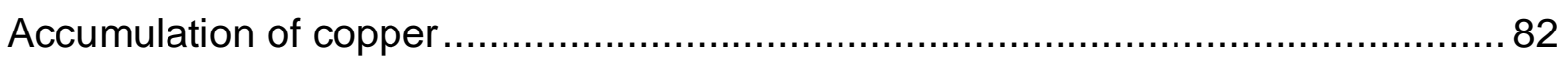

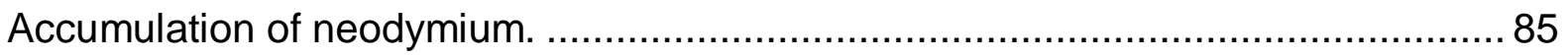

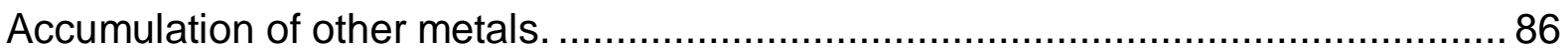

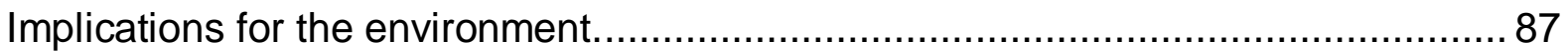

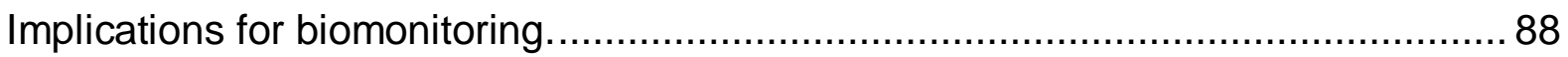

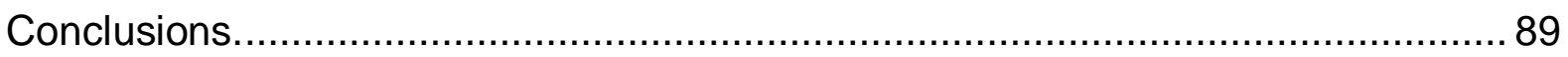

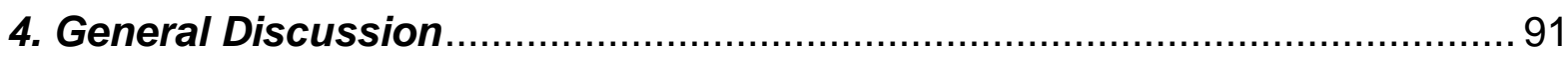

Implications of this research for the New Zealand environment. ............................91

Implications of this research for biomonitoring. .................................................. 92

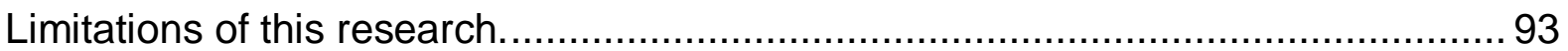

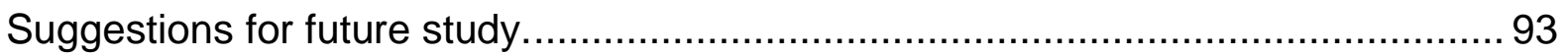

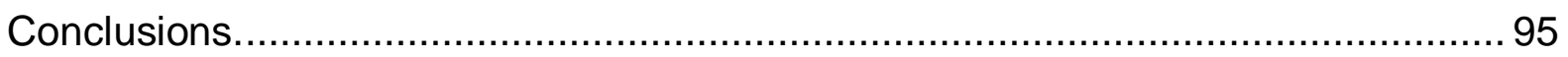

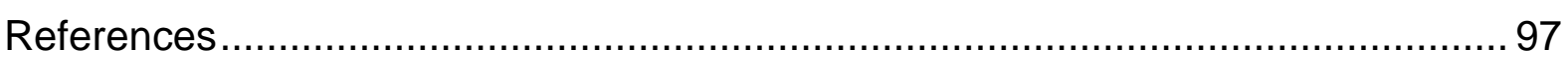




\section{List of Figures}

Figure 2.1. Heterozius rotundifrons in its habitat on the New Zealand rocky shore

Figure 2.2. Petrolisthes elongatus in its habitat on the New Zealand rocky shore

Figure 2.3. Map of the three sites of interest in the greater Wellington region

Figures 2.4A-D. Mean concentrations of metals in PPM (+/- SE) in different species.

Figure 2.5. Mean cadmium concentration in PPM (+/- SE) at three sites, for both species combined.

Figure 2.6. Mean copper concentration in PPM (+/- SE) at three sites, for both

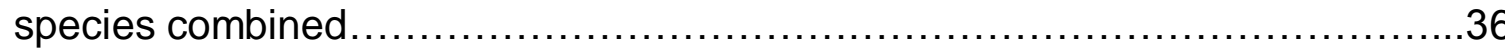

Figure 2.7. Mean titanium concentration in PPM (+/- SE) at three sites, for both

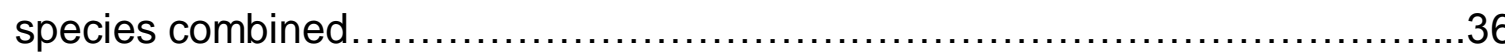

Figure 2.8. Mean molybdenum concentration in PPM (+/- SE) at three sites......37

Figure 2.9. Mean zinc concentration in PPM (+/- SE) at three sites. .38

Figure 2.10 A and B. Mean trace element concentrations in PPB in water samples from three locations.

Figure 2.11. Mean scandium concentration in PPB in water samples from three locations.

Figure 3.1 A and B. Juvenile Jasus edwardsii at A) a few months after puerulus stage and B) one year after....

Figure 3.2. NIWA collection sites for Jasus edwardsii.

Figure 3.3. Logged concentrations of PPM (+/- SE) of various metals in Jasus edwardsii moults exposed to water doped with two concentrations of copper....65

Figure 3.4. Mean concentration in PPM (+/- SE) of copper in Jasus edwardsii moults exposed to water doped with two concentrations of copper.

Figure 3.5. Mean copper concentrations in PPM (+/- SE) in three different tissue types, for copper/neodymium treatment samples and control samples.

Figure 3.6. Mean copper concentrations in PPM (+/- SE) in three different tissue types for baseline samples and control samples. 
Figure 3.7. Mean neodymium concentrations in PPM (+/- SE) in three different tissue types for copper/ neodymium treatment samples and control samples....70

Figure 3.8. Mean neodymium concentrations in PPM (+/- SE) in three different tissue types for baseline samples and control samples.

Figure 3.9. Mean caesium concentrations in PPM (+/- SE) in three different tissue types for $\mathrm{J}$. edwardsii juveniles exposed to an elevated copper/neodymium treatment, and baseline and control samples.

Figure 3.10. Mean rubidium concentrations in PPM (+/- SE) in three different tissue types for $J$. edwardsii juveniles exposed to an elevated copper/neodymium treatment, and baseline and control samples.

Figure 3.11. Mean manganese concentrations in PPM (+/- SE) in three different tissue types for $J$. edwardsii juveniles exposed to an elevated copper/neodymium treatment, and baseline and control samples. .76

Figure 3.12. Mean iron concentrations in PPM (+/- SE) in three different tissue types for $J$. edwardsii juveniles exposed to an elevated copper/neodymium treatment, and baseline and control samples.

Figure 3.13. Mean lead concentrations in PPM (+/- SE) in three different tissue types for $J$. edwardsii juveniles exposed to an elevated copper/neodymium treatment, and baseline and control samples.

Figure 3.14. Mean concentrations of five metals in PPM (+/- SE), in three different tissue types for $J$. edwardsii juveniles exposed to an elevated copper/neodymium treatment, and baseline and control samples.

Figure 3.15. Mean scandium concentration in PPB in water samples from four locations

Figure 3.16 A and B. Mean trace element concentrations in PPB in water samples from four locations 


\section{List of Tables}

Table 2.1. Trace elements measured at three resolutions by ICP-MS ............19

Tables 2.2i-xxx. Two-way ANOVA results for the effects of species and site and the interaction on the concentration of metals in decapods.

Table 2.3. Percentage composition of sediment type at each site and adjacent rivers

Table 3.1. Two-way ANOVA tables for copper results............................67

Table 3.2. Two-way ANOVA tables for neodymium results........................69

Tables 3.3i-x. Two-way ANOVA results for the effects of treatment and tissue type and the interaction on the concentration of metals in Jasus edwardsii.......71 



\section{General Introduction}

\section{Monitoring metals in the environment.}

Contamination by heavy metals such as lead, copper, and iron is a major threat to coastal habitats. Heavy metals are naturally occurring from weathering of rocks, volcanic activity, and other natural phenomena; however, anthropogenic activity can add to the heavy metal load through agricultural activity, mining, urban run-off, waste disposal, and industrialisation (Maffucci et al., 2005; Company et al., 2011; Walker \& Grant, 2015). As coastal habitats are exposed to both terrestrial and marine sources of contamination, they are highly susceptible to pollution, posing a serious threat to the health of organisms and communities. Metals also tend to have long half-lives and are not biodegradable; heavy metals remain in the environment for a long time, increasing the risk of detrimental effects (El Gammal et al., 2016).

Monitoring studies and programs measure trace metals to assess the health of the environment. Trace elements, including metals, are those that are present in systems in minute amounts, and may accumulate and magnify through the food web. Bioaccumulation, taking up of nutrients and contaminants into body tissues; and biomagnification, when elements increase in concentration as they move up the food web; can have serious effects on consumers' health and organism interactions. Monitoring of heavy metals is important for managing natural fluctuations in the environment, particularly in sensitive areas where there are naturally elevated amounts of trace metals, and anthropogenic sources of heavy metal pollution (Bonsignore et al., 2018; Moura et al., 2018).

\section{Essential and non-essential metals.}

Many metals have important biological roles in organisms, including in metabolic and enzymatic functioning, respiratory processes, as a component of blood or haemolymph, or to enable growth (White \& Rainbow, 1985; Ma et al., 2012; Manimaran et al., 2012; Goretti et al., 2016; Ragi et al., 2017). These are referred 
to as essential or bioactive elements. However, even bioessential elements like zinc, calcium, and copper have the potential to be toxic if they exceed threshold levels (Marsden \& Rainbow, 2004; Lemos et al., 2013; Wang \& Wang, 2016).

Not all metals fulfil a biological purpose. Many, like lead, cadmium, and chromium, are non-essential elements, which are present in the natural environment, but can be extremely toxic even at very low levels (Ragi et al., 2017). Non-essential elements are sometimes, but not always, taken up like essential elements, though are thought to be less well-regulated (McMeans et al., 2007; Tomlinson et al., 2014; Kobayashi et al., 2016). The thesis examines both essential and non-essential metals, and whether these are accumulated differently into decapods.

\section{The impact of heavy metal contamination.}

Metal pollutants can have a severe effect on marine organisms. Heavy metal toxicity can lead to impairment of many biological functions, including reproductive and feeding processes, increased mortality, cellular and DNA damage, and disruption to protein synthesis (Fingerman et al., 1996; Jakimska et al., 2011; Gotze et al., 2014; Ward et al., 2015). Metal contamination causes damage to proteins and lipids, DNA degradation, disruption to enzymatic, mitochondrial and metabolic processes, and changes to regulatory functions that control important physiological processes (Fingerman et al., 1996; Mochida et al., 2011; Giacomin et al., 2014). These processes include respiration, growth, and osmoregulation, and affect individual organisms, their populations, and communities, as impaired physiological processes can lead to changes in mortality, reproduction, predator-prey dynamics, and feeding rate (Jakimska et al., 2011; Pang et al., 2012). Exposure to the metals cadmium, copper and zinc showed disruption to the endocrine system of three species of fiddler crabs, and Daphnia, affecting neurological function, reproduction, moulting, and the ability to regenerate limbs (Fingerman et al., 1996). Other organisms, including the amphipod Leptocheirus plumulosus, and the polychaete worm Neanthes arenaceodentata are similarly affected by exposure to metal contamination (Ward 
et al., $2015 \mathrm{a}$ and b). Prolonged exposure to copper in laboratory experiments showed decreased reproduction, growth, and survival rates (Ward et al., 2015 a and $b$ ). These physiological effects can have wider ecological impacts, as metals may accumulate through food webs and altered rates of reproduction, feeding, and growth can affect predator/prey and trophic dynamics (Lefcort et al., 1999; Soto-Jimenez et al., 2011).

The effects of metal contamination are influenced by a range of factors - the presence of hydrocarbons, synergistic reactions with other elements, and the concentration of dissolved organic matter can all increase toxicity (Stark et al., 2003, Cebrian \& Uriz, 2007; Giacomin et al., 2013). Toxicity is also affected by salinity and temperature, so it is important to study a range of systems and geographic sites. Understanding how metal pollution affects different organisms and ecosystems is essential, as waterways continue to be contaminated and in the face of global warming (Bryant et al., 1985; Gomiero \& Viarengo, 2014; Deruytter et al., 2015).

\section{Biomonitoring: organisms as indicators.}

A comprehensive knowledge of how pollution affects organisms and their communities is necessary for management of ecosystems, fisheries and human health (Brix et al., 2010; Sary \& Mohammadi, 2012; Qiu, 2015; Arulkumar et al., 2017; Liu et al., 2017; Ragi et al., 2017). Monitoring methods include measurement of environmental data, e.g. water and sediment characteristics, temperature, salinity, and biomonitoring (Chou et al., 2003; Walker et al., 2013; Walker \& Grant, 2015).

Biomonitoring is measuring the uptake of nutrients and trace elements into animals and plants, as a reflection of the abundance of these elements in the environment (Alikhan et al., 1990). Trace elements are any elements, including heavy metals, which are present in small amounts in an organism. The present thesis will focus on trace metals, as they have serious ecological impacts, as outlined above. Living organisms used in biomonitoring are known as biological indicators (or bioindicators), and integrate a range of ecological information, 
making them a useful tool for monitoring ecosystem health and the impact of human activity on the environment (de Souza et al., 2017; Puig et al., 2017).

\section{Criteria for bioindicators.}

Organisms selected as biological indicator species tend to have long lifespans, are relatively sedentary, large, and abundant, have a range of life history strategies, and are ecologically important (MacFarlane et al., 2000; Chou et al., 2003; Yap et al., 2004). Crustaceans fulfill all of these criteria, and are commonly used as bioindicators in freshwater and marine environments (Fukunaga \& Anderson, 2011; Liu et al., 2017; Bertrand et al., 2018).

Decapods have been identified globally as effective and reliable indicators of ecosystem health. They fulfil many of the criteria for good environmental indicators - they are relatively abundant, large, have long lives and a range of life strategies, and are present at multiple trophic levels (MacFarlane et al., 2000; Chou et al., 2003). They are able to bioregulate essential elements, however, some species cannot excrete some metals, like cadmium, which is extremely toxic and the inability to regulate it enables it to be measured for monitoring (Nunez-Noguiera et al., 2012). Crustaceans are also often important members of aquatic communities and considered keystone species, in both freshwater and marine systems (Silliman \& Bertness, 2002; Smart et al., 2002; Eddy et al., 2014; Kuklina et al., 2014). Keystone species are particularly important to monitor as they have a disproportionate influence on their community. They can act as predators and prey, and many are used for human consumption, which makes them valuable for economic purposes and human health.

The diverse group of decapods commonly referred to as crayfish or lobsters have been popular subjects for contamination studies, due to their abundance, bioindicator potential, and ecological and economical importance. Freshwater crayfish like Cambarus bartoni and Procambarus clarkii are commonly used for investigating bioaccumulation into different tissue types and the harmful effects of contaminants on decapods (Alikhan et al., 1990; Wei \& Yang, 2016). The cellular processes of marine organisms have not been as widely studied as those of 
freshwater species, which presents a gap in the literature, as many marine species that have only recently come into focus in these studies are important for fisheries and ecosystems (Morcillo et al., 2016).

\section{Crustaceans as indicators of marine environmental change (CAIME)}

The present study is part of a three year Ministry of Business, Innovation, and Employment funded study, run by the National institute of Water \& Atmospheric Research (NIWA) and Victoria University of Wellington. This study, Crustaceans As Indicators of Marine Environmental change (CAIME), aims to monitor the marine environment and assess any human-induced changes, and develop a method to monitor changes using trace metal uptake in crustaceans.

The CAIME project has three main objectives to achieve these goals, by developing a baseline inventory of Crustacea in New Zealand waters, assessing bioaccumulation through doping and preservation studies, and assessing environmental changes due to ocean acidification. The present thesis fits into the first two objectives, by adding to the baseline data collection, and undertaking a doping experiment. 


\section{Aims of this thesis}

This thesis will explore the uptake of trace metals by common coastal decapod species. This will aid in investigating how decapods accumulate metals, whether they can serve as indicators of environmental change, and what implications this has for biomonitoring.

There are two specific objectives by which this aim will be achieved:

- Investigating spatial variation in heavy metal concentration across two coastal decapod species that co-occur but feed at different trophic levels and on different organic matter sources.

- Examining how two metals are accumulated in one decapod species, the New Zealand crayfish, and comparing how these metals are taken up into different body tissues. 


\section{Baseline Data Collection and Spatial and Trophic Variation in Trace Metals}

\section{INTRODUCTION}

\section{Monitoring variation in the natural environment.}

It is important to consider how trace metals affect different trophic levels and transfer through communities, but trophic interactions are highly variable and still relatively under-studied (Lefcort et al., 1999; Soto-Jimenez et al., 2011). An integrated approach to investigating ecosystem health is imperative, which includes a variety of species and contaminants, to ensure a thorough understanding of how different metals affect organisms, from the response of individual organisms at a cellular level, to trophic transfer of metals through ecosystems (Al-Subiai et al., 2011; Sabullah et al., 2015).

Natural environments are variable across geographic ranges, and a range of time scales, with short and long-term fluctuations from weather and significant natural events like bushfires and flooding affecting local communities and their inhabitants (Jenkins, 2013; Burton et al., 2016; Peraza-Castro et al., 2016). This can be compounded by anthropogenic impacts, from rapid changes through pollution, mining, and the effects of agriculture and urbanisation, to long-term impacts such as climate change and ocean acidification (Grinham et al., 2014; Baker et al., 2016; Stockdale et al., 2016; Zaharescu et al., 2016).

\section{The necessity for baseline data collection.}

Baseline data collection is a critical requirement for monitoring and further understanding ecosystems, especially when monitoring efforts include bioindicators, as they are affected by a range of variables (Edgar et al., 2004; Jenkins 2013; Gardner et al., 2016). Continuous baseline data collection allows researchers to assess long time scales and the impact of contamination both before and after impacts, which is necessary for robust statistical testing and effective management of the environment (Edgar et al., 2004; Jenkins, 2013). 
For a baseline dataset to be comprehensive it must use multiple species. Species-specific differences may lead to different results as accumulation rates and uptake patterns vary between species (Rainbow \& Luoma, 2011). The need for comprehensive baseline datasets has been emphasised by ecological monitoring of vulnerable or changing environments, such as for ecosystem restoration and in assessment of species populations for conservation of rare or native species (Downs et al., 2011; Venter \& Conradie, 2015; Gardner et al., 2016). Problems have been identified where there is a need for improved management of species, for example in fisheries, but a lack of robust baseline data limits how effective policy and management tools (Pais et al., 2012).

In order to collect a broad dataset that can address the variation between species at different trophic levels, different contaminants, and the effect of urbanisation and natural geographic variation, this chapter measures thirty trace metals in similar species which exist at different trophic levels but do not predate each other, yet occupy the same habitat. Measuring such a large number of elements gives an in-depth collection of geochemical data, and enables a more comprehensive analysis than most trace metal studies, which look at only four or five elements. This chapter also looks at three sites to examine geographic variation and the effect of agriculture and urbanisation on the chemical profile of these species.

\section{Target Species.}

Two common New Zealand coastal decapod crustaceans were chosen for this research, the big-handed crab Heterozius rotundifrons and the false crab Petrolisthes elongatus. 


\section{Heterozius rotundifrons (A. Milne-Edwards, 1867)}

Heterozius rotundifrons, commonly known as the "big handed" or "freeze" crab, is a small endemic crab, found on rocky shores around New Zealand. Its common names are both derived from the males' singular large claw, and from their response to being disturbed, which is to extend their legs and claws and stop moving (Hazlett \& Bach, 2010). Heterozius rotundifrons is found throughout the intertidal zone, often under larger rocks where water has pooled, where it shelters amongst the smaller cobbles. It has sandy yellow legs with a dark grey body, which disguises it well amongst rocks. Its legs are short and thick, and its body is around $20-30 \mathrm{~mm}$ wide and oval to diamond shaped. The number of individuals that aggregate in one place is variable, but the male-female ratio is about 1:1 (Hazlett et al., 2005). This species is an omnivorous scavenger, feeding on algae and debris (McLay, 1988).

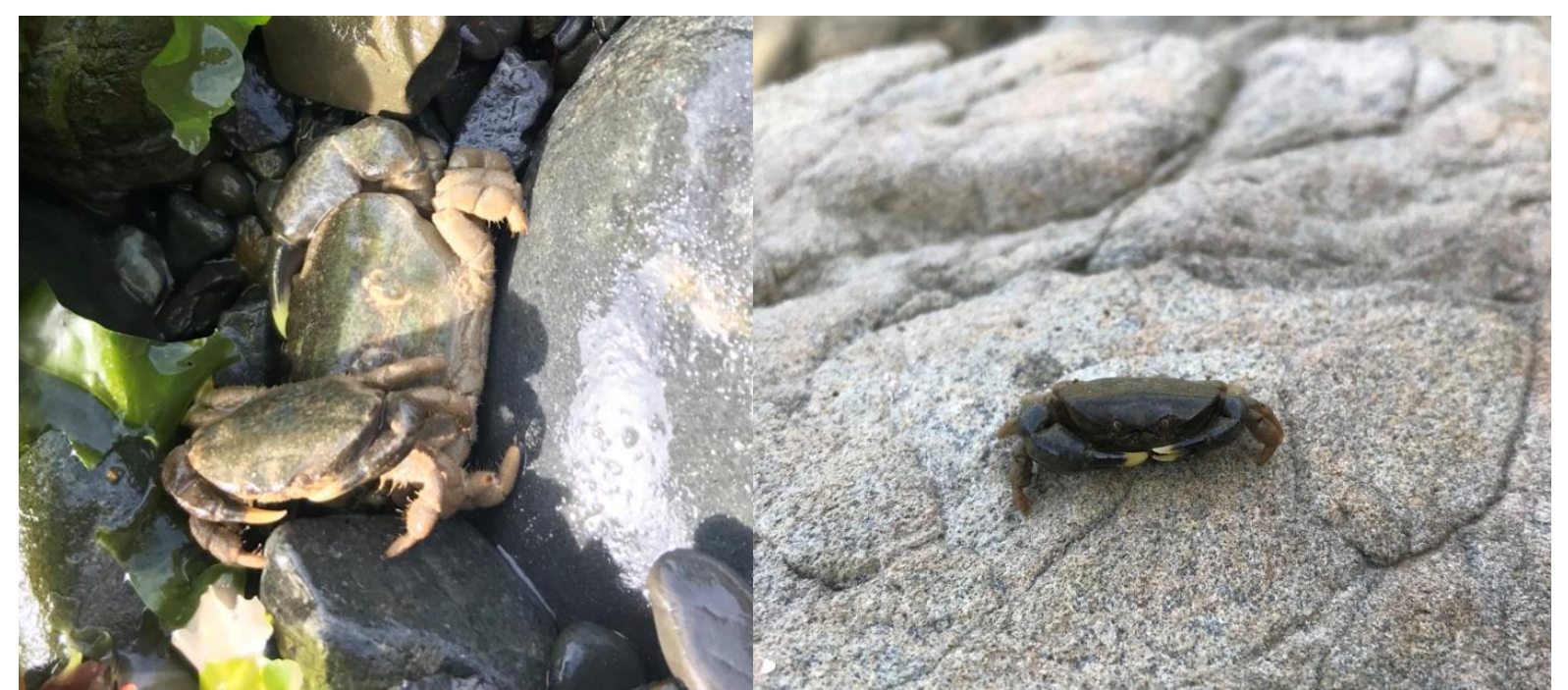

Figure 2.1 Heterozius rotundifrons in its habitat on the New Zealand rocky shore 


\section{Petrolisthes elongatus (H. Milne Edwards, 1837)}

Petrolisthes elongatus, commonly known as the "porcelain" or "half" crab, is also a small native crab, inhabiting rocky beaches around New Zealand. It is dark blue-green in colour, with a round, flat carapace up to about one centimetre across. It has three pairs of walking legs, and large flattened claws. When disturbed, it flattens itself against the substrate and moves quickly to shelter. Petrolisthes elongatus is found throughout the intertidal zone, under large rocks. It is primarily a filter feeder (McLay, 1988).

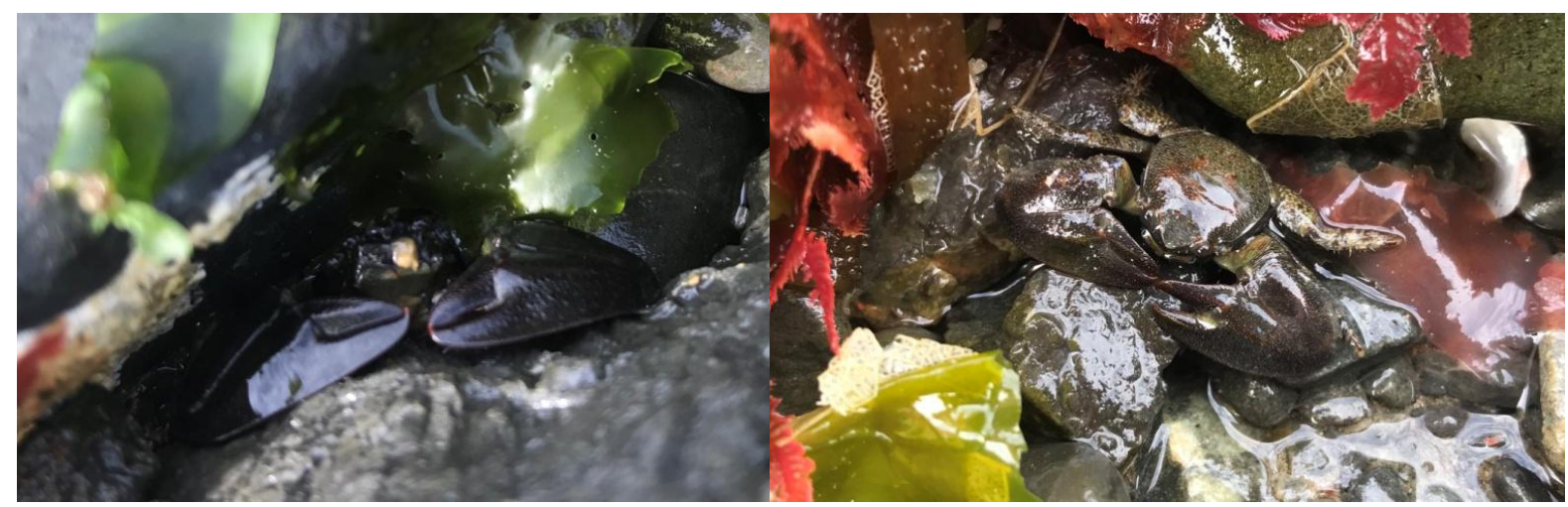

Figure 2.2. Petrolisthes elongatus in its habitat on the New Zealand rocky shore.

\section{Rationale for selection of these species.}

These species are suitable target organisms for this study for the following reasons: It is important to include native species in ecological studies, as they are usually specifically adapted to the local environment and are often the focus of management and recovery programs (Bertrand et al., 2018). These species are highly abundant, so many individuals can be analysed without impacting the population; and their wide distribution range makes them ideal for baseline data collections.

Heterozius rotundifrons and Petrolisthes elongatus co-occur throughout their range and are often found under the same rocks (McLay, 1988). As they occupy the same habitat, but feed at different trophic levels, they offer a valuable opportunity to investigate any potential differences or biomagnification of elements between trophic levels, and across geographic locations. Trophic level research provides a valuable assessment of how heavy metals affect 
communities as well as singular species (Borrell et al., 2016; Briand et al., 2018). Primary consumers, including filter-feeders, have been found in numerous studies to accumulate large concentrations of trace metals due to having direct contact with metal particles, and their low rates of excretion (Cid et al., 2010; Jara-Marini et al., 2013; Caro et al., 2015; Schaller \& Planer-Friedrich, 2017).

\section{Study sites.}

\section{Geography and geology of sites.}

The geology of the Wellington region is dominated by greywacke, with areas of limestone, mudstone, and sandstone (Begg \& Johnston, 2000; Lee \& Begg, 2002). These rock types predominantly consist of silicate minerals and calcium carbonate, and are dominated by silica, aluminium, calcium, and to lesser extents potassium, iron, manganese and titanium. Other elements that are present, including trace metals, only exist in small amounts in these rocks and their derived sediments, and are expected to be relatively homogeneous across these sites, as the rock types in the Wellington region, and in the study locations here, are primarily of the same origin (Begg \& Johnston, 2000; Lee \& Begg, 2002). The coarseness of sediment also influences the availability of contaminants in a location. Grain size data are increasingly used to measure the quality of aquatic environments, as the physiochemical properties of sediments, including size and composition, influence whether and how long trace elements are retained in the system (Guner, 2010; Khrisna \& Mohan, 2013; Zaaboub et al., 2014; Bravo et al., 2016). Fine grain sediment, in the mud fraction, generally has higher levels of contaminants due to its larger surface area and adsorption capabilities.

Due to the geology of the region, any significant differences in the trace metal profiles of these three sites would be expected to be the result of contamination from other sources, such as fertiliser, road and urban runoff, rather than from natural geological variation. Proximity to urban areas can increase the uptake of trace metals into organisms (Gundacker, 2000). 


\section{Aims and hypotheses of this chapter.}

This chapter aims to collect baseline data on the trace element chemistry of decapod species for two purposes. It will investigate spatial variation in trace element concentration between three sites, and assess whether there is evidence for significant anthropogenic effects on the trace metal chemistry of decapods at these locations, and it will examine the variation in trace metal chemistry of species at different trophic levels.

The hypotheses of this chapter are twofold. The first is that there will be significant differences between the trace element concentrations of the two species, with the majority of higher concentrations being in the filter feeder Petrolisthes elongatus. The second working hypothesis is that there will be differences in element concentrations between sites, as they differ in their proximity to different anthropogenic sources of contamination. Tarakena Bay is expected to be more affected by urbanisation than the other two sites, which are more agricultural. 


\section{METHODS}

\section{Site information.}

The three sites chosen for this study are all exposed, rocky beaches in the greater Wellington region (Figure 2.3).

- Wharehou Bay (4112'59.6"S, $\left.174^{\circ} 42^{\prime} 09.1 " \mathrm{E}\right)$, at Makara, is a semi-rural beach on the west coast of Wellington. It is surrounded by farmland, however is only a short drive from the city, and has a small settlement. It is very popular with visitors, especially at weekends, and can get very busy, with cars driving onto Makara Beach, leading to potential pollutants running off into the water. There is also a small river that flows through farmland into Makara Beach, across the bay from Wharehou Bay.

- Tarakena Bay (4120'32.8"S, 174²49'07.9"E), on Wellington's south coast, is the most urban site in this study. It is a short distance from the airport, and although there are few buildings by the beach itself, the road is busy and there are suburban areas nearby, potentially leading to contamination from residential and road runoff. There is also a waste water treatment plant discharge pipe one kilometre around the bay, at Moa Point.

- Tora Point $\left(41^{\circ} 30^{\prime} 16.5^{\prime \prime S}, 175^{\circ} 31^{\prime} 44.8^{\prime \prime} \mathrm{E}\right)$ is an isolated rural site on the east coast, in the southern Wairarapa district. There are few houses, although the road can be reasonably active at times, and a river flows to Tora Beach, a few metres from the site. The surrounding coast is predominantly low-intensity sheep and beef farmland, with some clusters of houses. 


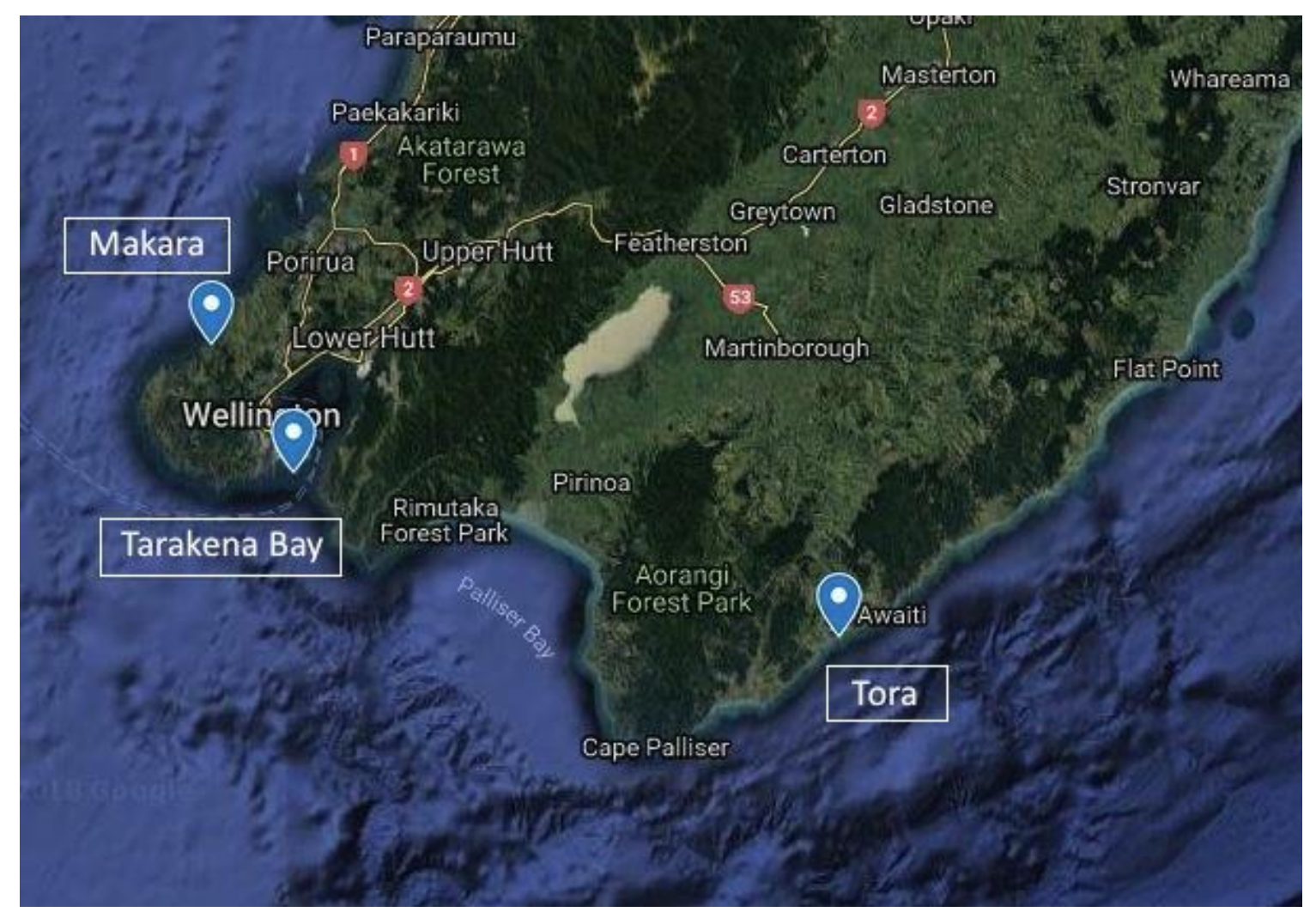

Figure 2.3. Map of the three sites of interest in the greater Wellington region. Map generated from Google Earth.

\section{Sample collection.}

To minimise the impact of storms and floods changing the natural chemical profile of the sediment and water, and to ensure the samples were representative, all samples were collected on fine, still days, at least one week after the last heavy rain. Samples were collected in winter (May-August) of 2018. The exact date of collection was variable depending on weather, tides, and accessibility to the sites.

Five individuals of each crab species were collected from three cobble beach sites in the greater Wellington region - Tarakena Bay on the south coast, Wharehou Bay at Makara on the west coast and Tora Point on the east coast. The animals selected were as close to the same size as possible, no individual was more than a few millimetres larger than the others. Specimens were collected at low tide and taken immediately to Victoria University Coastal Ecology Lab (VUCEL) to be frozen. 
On the same day if possible, or the next fine day, at least three days after periods of heavy rain, a seawater sample was taken from the deepest possible point in the collection area. An acid-washed bottle was rinsed with seawater three times at the site, and then filled with $100 \mathrm{~mL}$ of clear seawater, containing as little sediment as possible. To dissolve fine particles and to prevent dissolved elements from precipitating on the bottle walls, $1 \mathrm{~mL}$ of trace element grade 3 molar $\mathrm{HCl}$ was added to the seawater, and the samples were refrigerated until needed.

Sediment samples were also taken at each site. The samples collected were of the finest sediment at the site, which sometimes required collecting sediment from underneath the larger cobbles. $500 \mathrm{~g}$ per sample was collected and placed into ziplock bags, then frozen until analysis. At sites with river inputs, sediment samples were taken from the river mouth as well. At Tora, three samples were taken - one from the sampling site, and from Awhea River near Tora Point, as there was both soft muddy sediment and coarse sediment. Three samples were also taken at Makara, one from the sampling site, one from the river, and one from 50 metres from the sampling site, as this is closer to where the $H$. rotundifrons were found, and there are large metal structures rusting along the beach.

\section{Cleaning, drying, and weighing decapod samples.}

These processes took place in a sterile environment. All equipment and surfaces were cleaned with ethanol after each sample. All the equipment used was plastic, Teflon, or aluminium foil. Cleaning the samples took place in the dry lab at VUCEL, and weighing was done in the geochemistry laboratory at Victoria University of Wellington.

Three walking legs were extracted from each individual and placed in a Teflon vial. Deionised (DI) water was added, and the vial placed in an ultrasonic bath for 15 seconds. The DI water was removed using a pre-rinsed transfer pipette. This cleaning step was repeated twice more to remove seawater and any sediment or fine particles. 
The sample was placed into an aluminium foil drying boat, then into a larger aluminium foil tray with an aluminium foil lid to protect the samples from any potential particulate contamination. The samples were dried at $60^{\circ} \mathrm{C}$ for 90 minutes. Once dry, the drying boat and sample were placed in a ziplock bag and into a desiccator until they were weighed.

Samples were weighed on aluminium foil using a Mettler Toledo 5 decimal place balance. Weights were recorded after 30 seconds to allow for drift, and the samples were placed into clean, labelled $1.5 \mathrm{ml}$ plastic vials.

\section{Chemical processing of decapod samples.}

The chemical preparation of the dried samples for analysis took place in the geochemistry laboratory at Victoria University of Wellington.

The weighed samples were transferred into pre-cleaned Savillex beakers, and any material left in the sample vial was transferred using a clean epi-pipette containing ultrapure water to ensure quantitative transfer. A fresh pipette tip was used for every sample.

Nine drops of trace element grade $\mathrm{H}_{2} \mathrm{O}_{2}$ were added to the sample beakers, using a pre-rinsed transfer pipette. All pipettes were rinsed three times with ultrapure water. The beakers were left uncapped in the laminar flow hood for 20 minutes, with the lids placed on parafilm.

The uncapped samples were placed on a $70^{\circ} \mathrm{C}$ hotplate for 30 minutes and the temperature then increased to $80^{\circ} \mathrm{C}$, to ensure a controlled and gentle reaction. When minimal liquid was left in the beaker, the temperature was increased to $90^{\circ} \mathrm{C}$ until only foam was left, and the samples then left to cool with the caps on. A $0.5 \mathrm{~mL}$ aliquot of teflon-distilled $\mathrm{HNO}_{3}$ was added to the samples and placed uncapped on the hotplate at $110^{\circ} \mathrm{C}$ until dry. After this step was repeated the samples appeared to be fully dissolved. To ensure complete dissolution, $2-3 \mathrm{~mL}$ of Teflon distilled $6 \mathrm{M} \mathrm{HCl}$ was added to the samples, which were recapped and refluxed on a hotplate overnight at $110^{\circ} \mathrm{C}$. The samples were checked visually 
and the $\mathrm{HCl}$ was evaporated on the hotplate at $110^{\circ} \mathrm{C} .0 .5 \mathrm{~mL}$ of $\mathrm{HNO}_{3}$ was added to the samples again to remove all traces of chloride, the uncapped beakers placed on the hotplate at $110^{\circ} \mathrm{C}$ until dry, and then this step was repeated once more.

The samples could then be diluted for trace element analysis. There were three possible dilution steps depending on the weight of the sample, to obtain solutions representing a 2500 times dilution in $3 \% \mathrm{HNO}_{3}$. Dilutions were calculated on a weight basis using the dry sample weight, so that: final solution (mg)/sample weight $(\mathrm{mg})=2500$.

For samples weighing less than $\sim 5 \mathrm{mg}$ : A calculated volume of $3 \mathrm{M} \mathrm{HNO}_{3}$ was added to the sample beakers, and they were refluxed overnight. The beakers were left to cool for at least 30 minutes, and then the samples and $\mathrm{HNO}_{3}$ were weighed in pre-weighed $14 \mathrm{~mL}$ centrifuge tubes. Ultrapure water was added at four times the calculated volume of $\mathrm{HNO}_{3}$, the samples were weighed again, and the tubes centrifuged for 5 minutes at $2500 \mathrm{rpm}$.

Samples weighing between $\sim 5$ and 10mg: The same process was used as for $\sim 5 \mathrm{mg}$ samples, but with a pre-cleaned Nalgene bottle instead of a centrifuge tube. The sample solution was mixed by shaking the bottle, then $\sim 10 \mathrm{~mL}$ of the solution was transferred to a pre-cleaned centrifuge tube and centrifuged as above, ready for analysis.

Samples weighing over $\sim 10 \mathrm{mg}: 6.3 \mathrm{~mL}$ of $6 \mathrm{M} \mathrm{HNO}$ was pipetted into to the sample beaker, which was capped and refluxed overnight. The beakers were left to cool for at least 30 minutes, and then the samples and $\mathrm{HNO}_{3}$ were weighed in pre-cleaned Nalgene bottles. $18.8 \mathrm{~mL}$ of ultrapure water was pipetted into the Nalgene bottle and the weight recorded. An aliquot of the solution was pipetted into a pre-cleaned centrifuge tube and the weight recorded. A combination of $1 \%$ $\mathrm{HNO}_{3}$ and/or ultrapure water was added to bring the volume of solution in the tube to $10 \mathrm{~mL}$ of $3 \% \mathrm{HNO}_{3}$. The weight was recorded again, and the tubes centrifuged as above. 


\section{Mass spectrometer analysis.}

The samples were measured with a Thermo Scientific Element2 Inductively Coupled Plasma Mass Spectrometer (ICP-MS) in the School of Geography, Environment and Earth Sciences at Victoria University of Wellington.

The reagents used were trace metal grade, and all dilutions and cleaning of equipment used ultra-pure water. Final sample solutions used for analysis were in $3 \% \mathrm{HNO}_{3}$. Samples were introduced to the instrument using a self-aspirating $200 \mu \mathrm{l} / \mathrm{min}$ glass nebuliser attached to a cinnabar spray chamber. Take up time into the ICP-MS was 80 seconds, and there was a four minute rinse between each sample. $\mathrm{A} 3 \% \mathrm{HNO}_{3}$ solution was analysed after every third to fourth solution to measure background levels of the instrument.

A multi-element standard was made from certified single element standards, and used for calibration of the ICP-MS. Four dilutions of the standard (1x,2x, 20x and 40x) were analysed at the beginning and end of the analytical sequence to confirm the linearity of the instrument response. The dilution that best matched the signal intensity, measured as counts per second (CPS), of the samples was used to calibrate the sample solutions, and was run after every third to fourth sample in the sequence.

The instrument was tuned to optimise sample signal and signal stability, and to minimise generation of oxides. Three mass resolutions were used to measure the different element masses (Table 2.1). Data were obtained as CPS and converted to PPM using the calibration factor determined from the CPS response of the multi-element standard. 
Table 2.1. Trace elements measured at three resolutions by ICP-MS. The isotopes are in brackets.

\begin{tabular}{|c|c|}
\hline Low resolution & $\begin{array}{l}\text { Lithium (7Li) } \\
\text { Rubidium (85Rb) } \\
\text { Yttrium (89Y) } \\
\text { Niobium (93Nb) } \\
\text { Molybdenum 95(Mo) } \\
\text { Cadmium (111Cd) } \\
\text { Tin (118Sn) } \\
\text { Caesium (133Cs) } \\
\text { Barium (137Ba) } \\
\text { Lanthanum (139La) } \\
\text { Cerium (140Ce) } \\
\text { Neodymium (146Nd) } \\
\text { Samarium (147Sm) } \\
\text { Lead (208Pb) } \\
\text { Thorium (232Th) } \\
\text { Uranium (238U) }\end{array}$ \\
\hline Medium resolution & $\begin{array}{l}\text { Scandium (45Sc) } \\
\text { Titanium (47Ti) } \\
\text { Vanadium }(51 \mathrm{~V}) \\
\text { Chromium }(52 \mathrm{Cr}) \\
\text { Manganese }(55 \mathrm{Mn}) \\
\text { Cobalt }(59 \mathrm{Co}) \\
\text { Nickel }(60 \mathrm{Ni}) \\
\text { Copper }(63 \mathrm{Cu}) \\
\text { Zinc }(66 \mathrm{Zn})\end{array}$ \\
\hline High resolution & $\begin{array}{l}\text { Magnesium (25Mg) } \\
\text { Aluminium (27Al) } \\
\text { Calcium (44Ca) } \\
\text { Iron (56Fe) } \\
\text { Arsenic (75As) } \\
\text { Strontium (86Sr) }\end{array}$ \\
\hline
\end{tabular}

To further ensure accuracy, standard reference materials (SRMs) were also processed and analysed with the samples. The SRMs used for this study were NIST1566 (oyster tissue) from the US National Institute for Standards and Technology, and DORM-4 (fish protein) from the Canadian National Research Council, as these were the closest match for the decapod tissue. The SRMs have certified concentrations of elements, used as reference values, which are based on $250 \mathrm{mg}$ of material. As the samples used for the SRM analysis in this experiment weighed less than this $(50-80 \mathrm{mg})$, the results were expected to be more diverse in concentration, and greater deviation from the reference values. Despite this, most elements measured in the SRM analysis were within $1-15 \%$ of 
the reference value, and major elements, like copper, were within $1 \%$, so were considered accurate.

\section{Water sample analysis.}

The water sample analysis took place in the chemistry laboratory of the University of Otago, Dunedin. Samples were first filtered and then desalinised by passing through resin-exchange chemistry. Elements were then analysed using an ICP-MS instrument. An in-house seawater standard analysed over a period of time was used to evaluate analytical precision, and an SRM, NASS-7 (Seawater) from the Canadian National Research Centre, was used to evaluate accuracy. Most metals were within 1-10\% of certified values, with cadmium within $17 \%$. These data were used to define the uncertainties in the water sample measurements reported.

\section{Sediment sample analysis.}

The sediment samples were analysed by grain size in the geology laboratory at NIWA Wellington.

For all samples except the soft Awhea River sediment (Awhea River 1), at least $15 \mathrm{~g}$ of the sample were dried at $60^{\circ} \mathrm{C}$ overnight, and the dry weight recorded. The samples were then sieved through a series of mesh sizes $(2 \mathrm{~mm}, 1.6 \mathrm{~mm}$, $500 \mu \mathrm{m}, 125 \mu \mathrm{m}$ and $63 \mu \mathrm{m})$, and the amount of sample left in each sieve was weighed. These weights were recorded to determine the relative proportion of grain size in each sample. The samples, including Awhea River 1, were also run through a LS13-320 Laser Diffraction Particle Size Analyser to look more closely at the mud fraction of the sediment. Awhea River 1 was not measured with sieves as it was fine enough to run through the laser analyser alone. $6 \mathrm{~g}$ of the fine fraction of each sample were left in a washing solution, and placed in an ultrasonic bath for ten seconds at a time until all clumps of soft sediment had broken up. The sample was transferred into the laser analyser through a $1.6 \mathrm{ml}$ sieve to catch any organic matter or larger pieces of sediment, and the 
obscuration determined. Given the coarseness of the samples, it was considered acceptable when obscuration was above $2 \%$.

\section{Statistical analysis}

Data were tested to meet the assumptions of normality and equal variance in R3.5.1 (R Core Team, 2016), using R-Studio Version 1.1.456 (RStudio Team, 2018), for all data. When necessary, data were transformed by logging or taking the square root, to meet these assumptions. Two-way Analysis of Variance (ANOVA) tests were run in R-Studio for each of 30 elements with site and species as the main effects. Post hoc Tukey tests were run using the TukeyHSD function in the stats package, for any significant results.

Sediment data were run through Gradistat V8.0 (Blott 2010). Water data were analysed through comparison of trends in Excel. 


\section{RESULTS}

\section{Trace metals.}

Trace element levels for two species of decapods from three sites were resolved for thirty elements (Table 2.1). Significant differences between species were observed for twenty-one metals, and between sites for three metals (Tables 2.2i$\mathrm{xxx}$ ). In three cases there was a significant interaction between these factors.

Tables 2.2i-xxx. Two-way ANOVA results for the effects of species and site and the interaction on the concentration of metals in decapods. Significant $p$-values are in bold.

\section{i. Aluminium (Al)}

\begin{tabular}{|l|l|l|l|l|}
\hline Factor & DF & $\begin{array}{l}\text { Sum of } \\
\text { Squares }\end{array}$ & F-statistic & p-value \\
\hline Species & 1 & 215446 & 36.85 & $<0.0001$ \\
\hline Site & 2 & 18104 & 1.55 & 0.233 \\
\hline Species x Site & 2 & 2059 & 0.18 & 0.84 \\
\hline Error & 24 & & & \\
\hline
\end{tabular}

\section{ii. Arsenic (As)}

\begin{tabular}{|l|l|l|l|l|}
\hline Factor & DF & $\begin{array}{l}\text { Sum om } \\
\text { Squares }\end{array}$ & F-statistic & -value \\
\hline Species & 1 & 0.137 & 6.9 & 0.015 \\
\hline Site & 2 & 0.029 & 0.73 & 0.493 \\
\hline Species x Site & 2 & 0.095 & 2.4 & 0.112 \\
\hline Error & 24 & & & \\
\hline
\end{tabular}


iii. Barium (Ba)

\begin{tabular}{|l|l|l|l|l|}
\hline Factor & DF & $\begin{array}{l}\text { Sum of } \\
\text { Squares }\end{array}$ & F-statistic & p-value \\
\hline Species & 1 & 0.0127 & 0.5 & 0.486 \\
\hline Site & 2 & 0.07 & 1.39 & 0.269 \\
\hline Species $\times$ Site & 2 & 0.051 & 1.02 & 0.377 \\
\hline Error & 24 & & & \\
\hline
\end{tabular}

iv. Cadmium (Cd)

\begin{tabular}{|l|l|l|l|l|}
\hline Factor & DF & $\begin{array}{l}\text { Sum of } \\
\text { Squares }\end{array}$ & F-statistic & p-value \\
\hline Species & 1 & 0.001 & 0.03 & 0.874 \\
\hline Site & 2 & 0.595 & 8 & 0.002 \\
\hline Species x Site & 2 & 0.139 & 1.86 & 0.177 \\
\hline Error & 24 & & & \\
\hline
\end{tabular}

\section{v. Caesium (Cs)}

\begin{tabular}{|l|l|l|l|l|}
\hline Factor & DF & $\begin{array}{l}\text { Sum of } \\
\text { Squares }\end{array}$ & F-statistic & $p$-value \\
\hline Species & 1 & 0.0016 & 10.6 & 0.003 \\
\hline Site & 2 & 0.0005 & 1.57 & 0.228 \\
\hline Species x Site & 2 & 0.0002 & 0.62 & 0.548 \\
\hline Error & 24 & & & \\
\hline
\end{tabular}


vi. Calcium (Ca)

\begin{tabular}{|l|l|l|l|l|}
\hline Factor & DF & $\begin{array}{l}\text { Sum of } \\
\text { Squares }\end{array}$ & F-statistic & -value \\
\hline Species & 1 & $1.741^{\wedge} 9$ & 0.57 & 0.458 \\
\hline Site & 2 & $3.888^{\wedge} 9$ & 0.64 & 0.539 \\
\hline Species x Site & 2 & $1.491^{\wedge} 9$ & 0.24 & 0.786 \\
\hline Error & 24 & & & \\
\hline
\end{tabular}

vii. Cerium (Ce)

\begin{tabular}{|l|l|l|l|l|}
\hline Factor & DF & $\begin{array}{l}\text { Sum of } \\
\text { Squares }\end{array}$ & F-statistic & -value \\
\hline Species & 1 & 0.74 & 36.14 & $<\mathbf{0 . 0 0 0 1}$ \\
\hline Site & 2 & 0.0695 & 1.7 & 0.205 \\
\hline Species x Site & 2 & 0.014 & 0.35 & 0.71 \\
\hline Error & 24 & & & \\
\hline
\end{tabular}

viii. Chromium (Cr)

\begin{tabular}{|l|l|l|l|l|}
\hline Factor & DF & $\begin{array}{l}\text { Sum of } \\
\text { Squares }\end{array}$ & F-statistic & -value \\
\hline Species & 1 & 0.425 & 41.41 & $<\mathbf{0 . 0 0 0 1}$ \\
\hline Site & 2 & 0.0324 & 1.58 & 0.227 \\
\hline Species x Site & 2 & 0.0099 & 0.48 & 0.62 \\
\hline Error & 24 & & & \\
\hline
\end{tabular}


ix. Cobalt (Co)

\begin{tabular}{|l|l|l|l|l|}
\hline Factor & DF & $\begin{array}{l}\text { Sum of } \\
\text { Squares }\end{array}$ & F-statistic & p-value \\
\hline Species & 1 & 1.894 & 26.7 & $<0.0001$ \\
\hline Site & 2 & 0.0158 & 0.11 & 0.895 \\
\hline Species x Site & 2 & 0.057 & 0.4 & 0.674 \\
\hline Error & 24 & & & \\
\hline
\end{tabular}

x. Copper (Cu)

\begin{tabular}{|l|l|l|l|l|}
\hline Factor & DF & $\begin{array}{l}\text { Sum of } \\
\text { Squares }\end{array}$ & F-statistic & p-value \\
\hline Species & 1 & 1.127 & 47.38 & $<0.0001$ \\
\hline Site & 2 & 0.187 & 3.93 & $\mathbf{0 . 0 3 4}$ \\
\hline Species x Site & 2 & 0.077 & 1.62 & 0.219 \\
\hline Error & 24 & & & \\
\hline
\end{tabular}

xi. Iron (Fe)

\begin{tabular}{|l|l|l|l|l|}
\hline Factor & DF & $\begin{array}{l}\text { Sum of } \\
\text { Squares }\end{array}$ & F-statistic & p-value \\
\hline Species & 1 & 432 & 55.83 & $<\mathbf{0 . 0 0 0 1}$ \\
\hline Site & 2 & 26 & 1.68 & 0.208 \\
\hline Species x Site & 2 & 3.3 & 0.21 & 0.81 \\
\hline Error & 24 & & & \\
\hline
\end{tabular}


xii. Lanthanum (La)

\begin{tabular}{|l|l|l|l|l|}
\hline Factor & DF & $\begin{array}{l}\text { Sum of } \\
\text { Squares }\end{array}$ & F-statistic & $p$-value \\
\hline Species & 1 & 0.1495 & 30.12 & $<0.0001$ \\
\hline Site & 2 & 0.008 & 0.81 & 0.456 \\
\hline Species x Site & 2 & 0.0014 & 0.14 & 0.872 \\
\hline Error & 24 & & & \\
\hline
\end{tabular}

xiii. Lead (Pb)

\begin{tabular}{|l|l|l|l|l|}
\hline Factor & DF & $\begin{array}{l}\text { Sum of } \\
\text { Squares }\end{array}$ & F-statistic & p-value \\
\hline Species & 1 & 0.993 & 20 & 0.0002 \\
\hline Site & 2 & 0.227 & 2.28 & 0.124 \\
\hline Species x Site & 2 & 0.047 & 0.47 & 0.632 \\
\hline Error & 24 & & & \\
\hline
\end{tabular}

xiv. Lithium (Li)

\begin{tabular}{|l|l|l|l|l|}
\hline Factor & DF & $\begin{array}{l}\text { Sum of } \\
\text { Squares }\end{array}$ & F-statistic & p-value \\
\hline Species & 1 & 0.116 & 3.23 & 0.0849 \\
\hline Site & 2 & 0.071 & 0.99 & 0.386 \\
\hline Species $\times$ Site & 2 & 0.013 & 0.18 & 0.834 \\
\hline Error & 24 & & & \\
\hline
\end{tabular}


Xv. Magnesium (Mg)

\begin{tabular}{|l|l|l|l|l|}
\hline Factor & DF & $\begin{array}{l}\text { Sum of } \\
\text { Squares }\end{array}$ & F-statistic & p-value \\
\hline Species & 1 & 0.002 & 0.13 & 0.727 \\
\hline Site & 2 & 0.014 & 0.58 & 0.567 \\
\hline Species x Site & 2 & 0.006 & 0.24 & 0.79 \\
\hline Error & 24 & & & \\
\hline
\end{tabular}

xvi. Manganese (Mn)

\begin{tabular}{|l|l|l|l|l|}
\hline Factor & DF & $\begin{array}{l}\text { Sum of } \\
\text { Squares }\end{array}$ & F-statistic & -value \\
\hline Species & 1 & 0.046 & 0.42 & 0.523 \\
\hline Site & 2 & 0.439 & 1.99 & 0.158 \\
\hline Species x Site & 2 & 0.008 & 0.04 & 0.965 \\
\hline Error & 24 & & & \\
\hline
\end{tabular}

xvii. Molybdenum (Mo)

\begin{tabular}{|l|l|l|l|l|}
\hline Factor & DF & $\begin{array}{l}\text { Sum of } \\
\text { Squares }\end{array}$ & F-statistic & p-value \\
\hline Species & 1 & 0.0517 & 4.56 & $\mathbf{0 . 0 4 3}$ \\
\hline Site & 2 & 0.1797 & 7.93 & $\mathbf{0 . 0 0 2}$ \\
\hline Species x Site & 2 & 0.0699 & 3.08 & $\mathbf{0 . 0 0 6 4}$ \\
\hline Error & 24 & & & \\
\hline
\end{tabular}


xviii. Neodymium (Nd)

\begin{tabular}{|l|l|l|l|l|}
\hline Factor & DF & $\begin{array}{l}\text { Sum of } \\
\text { Squares }\end{array}$ & F-statistic & $p$-value \\
\hline Species & 1 & 0.133 & 29.24 & $<0.0001$ \\
\hline Site & 2 & 0.0043 & 0.48 & 0.624 \\
\hline Species x Site & 2 & 0.0007 & 0.08 & 0.923 \\
\hline Error & 24 & & & \\
\hline
\end{tabular}

xix. Nickel (Ni)

\begin{tabular}{|l|l|l|l|l|}
\hline Factor & DF & $\begin{array}{l}\text { Sum of } \\
\text { Squares }\end{array}$ & F-statistic & p-value \\
\hline Species & 1 & 1.895 & 48.24 & $<0.0001$ \\
\hline Site & 2 & 0.041 & 0.52 & 0.6 \\
\hline Species x Site & 2 & 0.0088 & 0.11 & 0.894 \\
\hline Error & 24 & & & \\
\hline
\end{tabular}

Xx. Niobium (Nb)

\begin{tabular}{|l|l|l|l|l|}
\hline Factor & DF & $\begin{array}{l}\text { Sum of } \\
\text { Squares }\end{array}$ & F-statistic & p-value \\
\hline Species & 1 & 0.0576 & 34.56 & $<0.0001$ \\
\hline Site & 2 & 0.0097 & 2.92 & 0.073 \\
\hline Species x Site & 2 & 0.0005 & 0.15 & 0.86 \\
\hline Error & 24 & & & \\
\hline
\end{tabular}


xxi. Rubidium (Rb)

\begin{tabular}{|l|l|l|l|l|}
\hline Factor & DF & $\begin{array}{l}\text { Sum } \\
\text { Squares }\end{array}$ & F-statistic & -value \\
\hline Species & 1 & 0.277 & 59.02 & $<\mathbf{0 . 0 0 0 1}$ \\
\hline Site & 2 & 0.021 & 2.25 & 0.127 \\
\hline $\begin{array}{l}\text { Species } \\
\text { SiteSpecies } \\
\text { Site }\end{array}$ & 2 & 0.021 & 2.19 & 0.134 \\
\hline Error & 24 & & & \\
\hline
\end{tabular}

xxii. Scandium (Sc)

\begin{tabular}{|l|l|l|l|l|}
\hline Factor & DF & $\begin{array}{l}\text { Sum of } \\
\text { Squares }\end{array}$ & F-statistic & -value \\
\hline Species & 1 & 0.0114 & 14.2 & $\mathbf{0 . 0 0 0 9}$ \\
\hline Site & 2 & 0.001 & 0.7 & 0.505 \\
\hline Species x Site & 2 & 0.0001 & 0.07 & 0.93 \\
\hline Error & 24 & & & \\
\hline
\end{tabular}

xxiii. Strontium (Sr)

\begin{tabular}{|l|l|l|l|l|}
\hline Factor & DF & $\begin{array}{l}\text { Sum } \\
\text { Squares }\end{array}$ & F-statistic & $p$-value \\
\hline Species & 1 & 0.0688 & 9.4 & $\mathbf{0 . 0 0 5 3}$ \\
\hline Site & 2 & 0.0008 & 0.06 & 0.944 \\
\hline Species x Site & 2 & 0.01 & 0.7 & 0.505 \\
\hline Error & 24 & & & \\
\hline
\end{tabular}


xxiv. Tin (Sn)

\begin{tabular}{|l|l|l|l|l|}
\hline Factor & DF & $\begin{array}{l}\text { Sum of } \\
\text { Squares }\end{array}$ & F-statistic & $p$-value \\
\hline Species & 1 & 0.0199 & 1.06 & 0.313 \\
\hline Site & 2 & 0.0098 & 0.26 & 0.77 \\
\hline Species x Site & 2 & 0.086 & 2.3 & 0.122 \\
\hline Error & 24 & & & \\
\hline
\end{tabular}

xxv. Titanium (Ti)

\begin{tabular}{|l|l|l|l|l|}
\hline Factor & DF & $\begin{array}{l}\text { Sum of } \\
\text { Squares }\end{array}$ & F-statistic & p-value \\
\hline Species & 1 & 37.43 & 58.55 & $<0.0001$ \\
\hline Site & 2 & 4.89 & 3.82 & $\mathbf{0 . 0 3 6}$ \\
\hline Species x Site & 2 & 0.55 & 0.43 & 0.656 \\
\hline Error & 24 & & & \\
\hline
\end{tabular}

xxvi. Thorium (Th)

\begin{tabular}{|l|l|l|l|l|}
\hline Factor & DF & $\begin{array}{l}\text { Sum of } \\
\text { Squares }\end{array}$ & F-statistic & p-value \\
\hline Species & 1 & 0.474 & 12.23 & $\mathbf{0 . 0 0 1 9}$ \\
\hline Site & 2 & 0.0086 & 0.11 & 0.896 \\
\hline Species x Site & 2 & 0.047 & 0.6 & 0.554 \\
\hline Error & 24 & & & \\
\hline
\end{tabular}


xxvii. Uranium (U)

\begin{tabular}{|l|l|l|l|l|}
\hline Factor & DF & $\begin{array}{l}\text { Sum of } \\
\text { Squares }\end{array}$ & F-statistic & $p$-value \\
\hline Species & 1 & 1.373 & 46.56 & $<0.0001$ \\
\hline Site & 2 & 0.058 & 0.98 & 0.39 \\
\hline Species x Site & 2 & 0.037 & 0.62 & 0.545 \\
\hline Error & 24 & & & \\
\hline
\end{tabular}

xxviii. Vanadium (V)

\begin{tabular}{|l|l|l|l|l|}
\hline Factor & DF & $\begin{array}{l}\text { Sum of } \\
\text { Squares }\end{array}$ & F-statistic & -value \\
\hline Species & 1 & 1.097 & 59.37 & $<0.0001$ \\
\hline Site & 2 & 0.086 & 2.31 & 0.12 \\
\hline Species x Site & 2 & 0.0098 & 0.26 & 0.77 \\
\hline Error & 24 & & & \\
\hline
\end{tabular}

xxix. Yttrium (Y)

\begin{tabular}{|l|l|l|l|l|}
\hline Factor & DF & $\begin{array}{l}\text { Sum of } \\
\text { Squares }\end{array}$ & F-statistic & -value \\
\hline Species & 1 & 0.0612 & 37.66 & $<0.0001$ \\
\hline Site & 2 & 0.004 & 1.18 & 0.324 \\
\hline Species x Site & 2 & 0.0006 & 0.19 & 0.827 \\
\hline Error & 24 & & & \\
\hline
\end{tabular}


xxx. Zinc (Zn)

\begin{tabular}{|l|l|l|l|l|}
\hline Factor & DF & $\begin{array}{l}\text { Sum of } \\
\text { Squares }\end{array}$ & F-statistic & $p$-value \\
\hline Species & 1 & $<0.0001$ & 0.02 & 0.895 \\
\hline Site & 2 & 0.0046 & 0.44 & 0.647 \\
\hline Species x Site & 2 & 0.113 & 10.94 & $\mathbf{0 . 0 0 0 4}$ \\
\hline Error & 24 & & & \\
\hline
\end{tabular}

\section{Comparison between species.}

Of the twenty-one metals that were significantly different between species, seventeen were higher in Heterozius rotundifrons, and the mean concentration of many of these was over twice that of the concentration in Petrolisthes elongatus (Figures 2.4A-D). In comparison, the four metals that were higher in $P$. elongatus were only slightly higher in concentration, with the exception of copper, which was more than double the mean of copper in $H$. rotundifrons (Figures 2.4A-D).

Of the elements that were not significantly different between species, most were non-essential. However, some essential elements, like magnesium and calcium, were also not significantly different between the species (Figure 2.4A). 


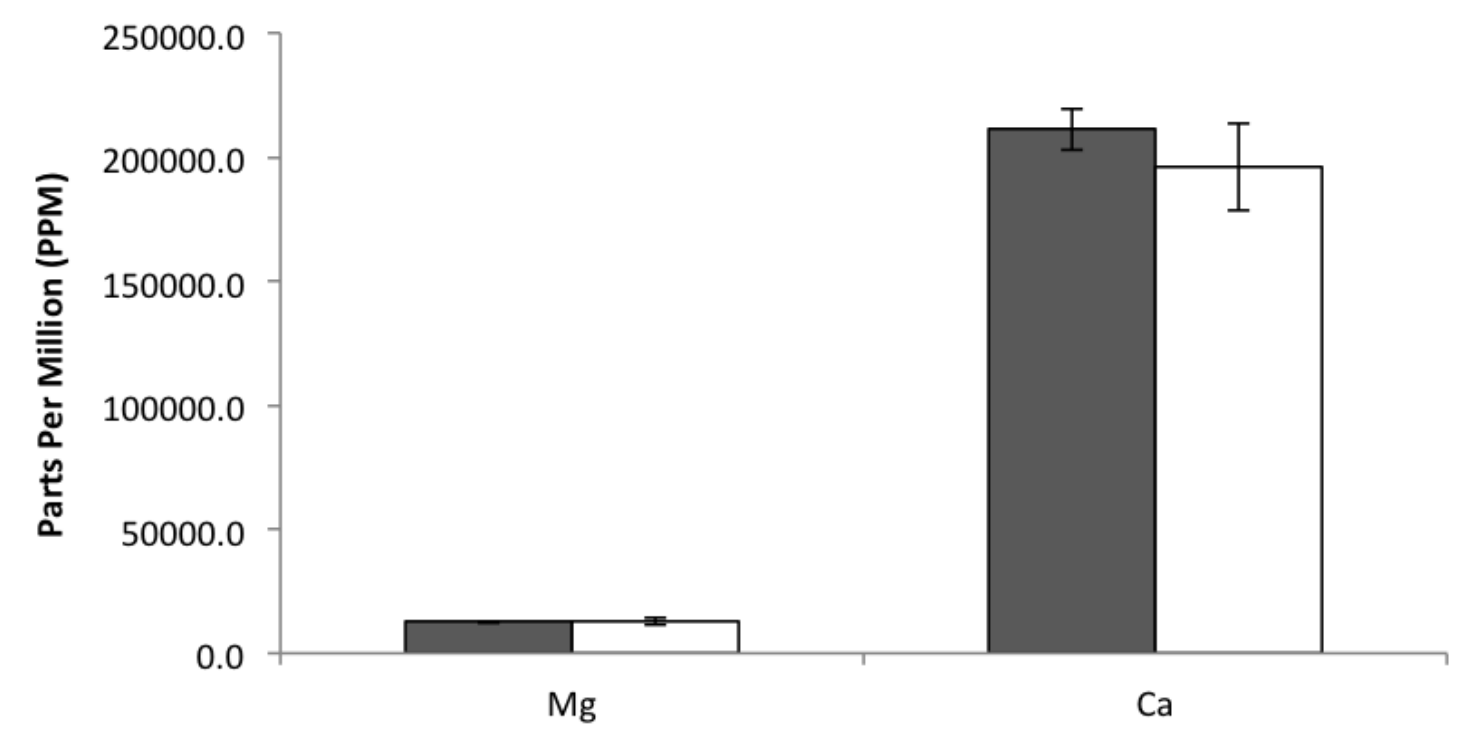

A

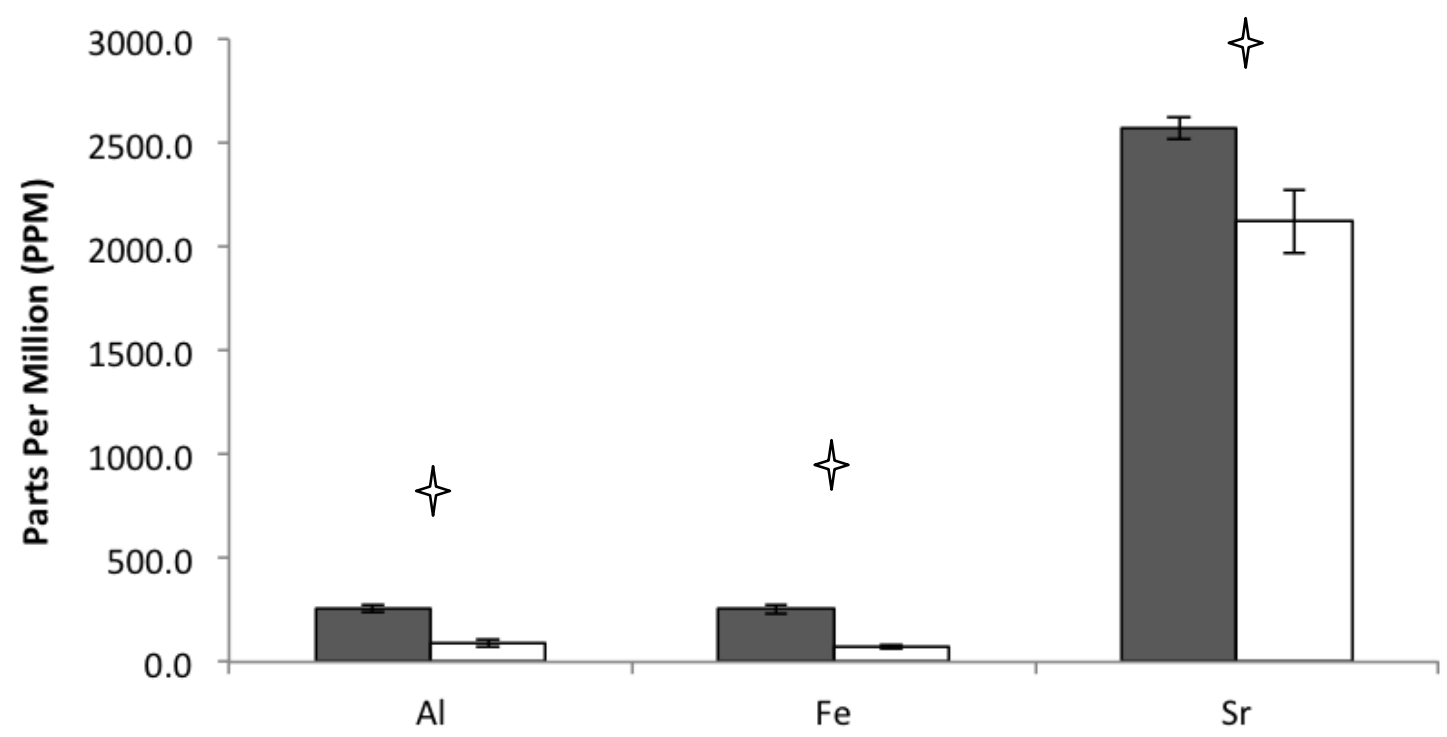

B 


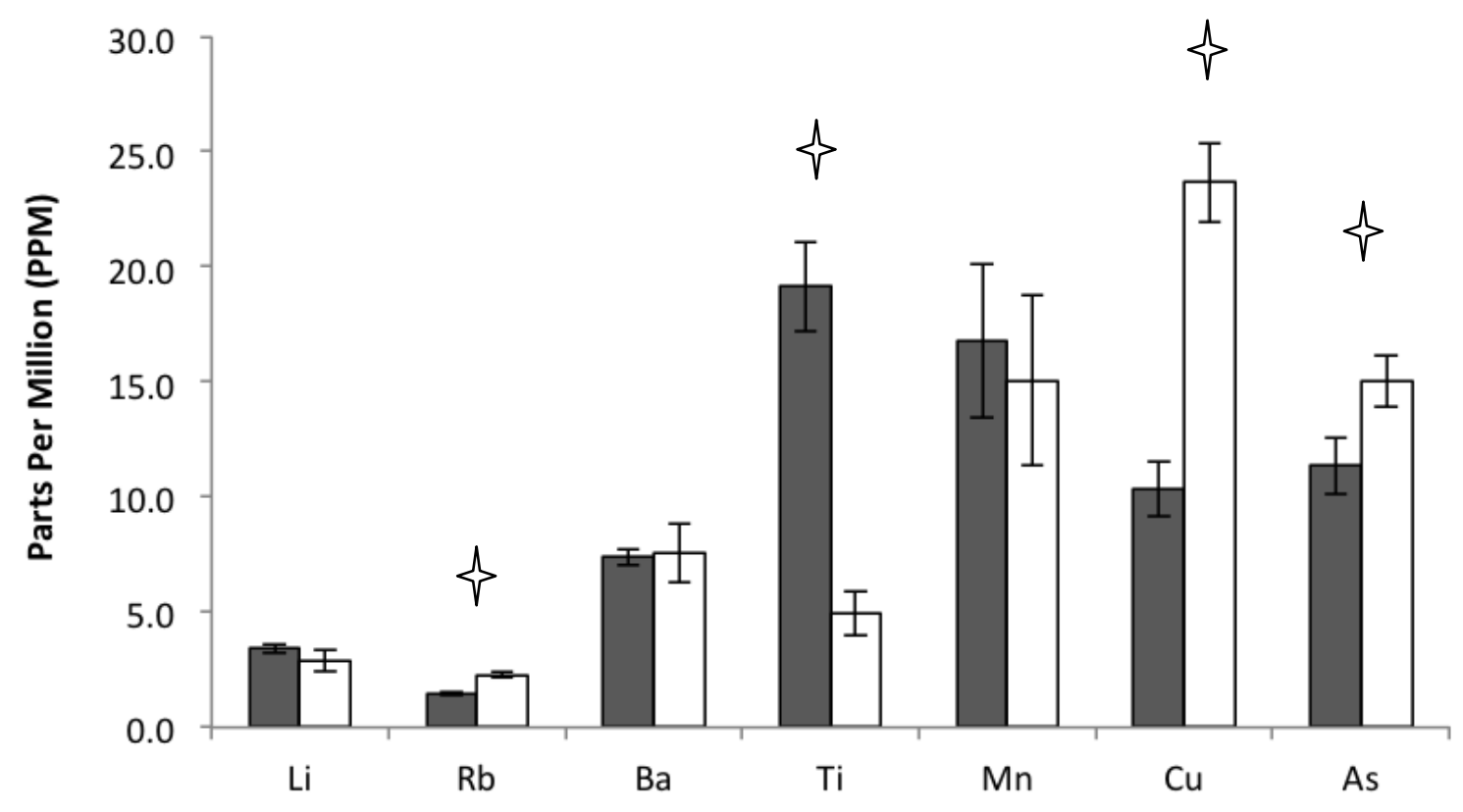

C

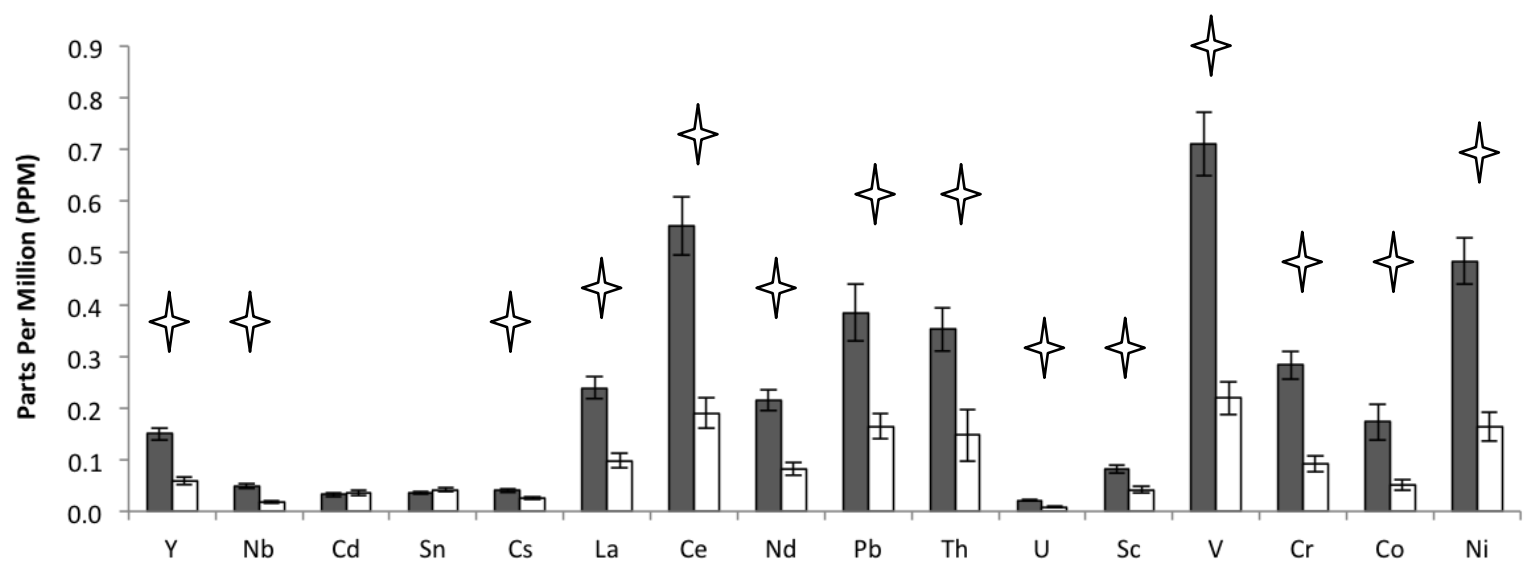

D

Figures 2.4A-D. Mean concentrations of metals in PPM (+/- SE) in different species, excluding those measured that had a significant interaction (Mo and $\mathrm{Zn}$ ). Metals are grouped in the plots based on PPM range for ease of viewing. $n=15$ for each species. Dark grey bars $=$ Heterozius rotundifrons, white bars $=$ Petrolisthes elongatus. Stars indicate a significant difference. 


\section{Comparison among sites.}

Three of the thirty elements were significantly different between sites. Cadmium was significantly higher in samples from Tora compared to both Tarakena Bay and Makara (Figure 2.5), while Tarakena Bay and Makara were not significantly different from each other. Tora samples also contained significantly more copper than those from Makara (Figure 2.6) but neither were different from the Tarakena Bay samples. Animals from Tora contained significantly less titanium than those from Tarakena Bay (Figure 2.7). Neither Tora nor Tarakena Bay were significantly different from Makara for titanium.

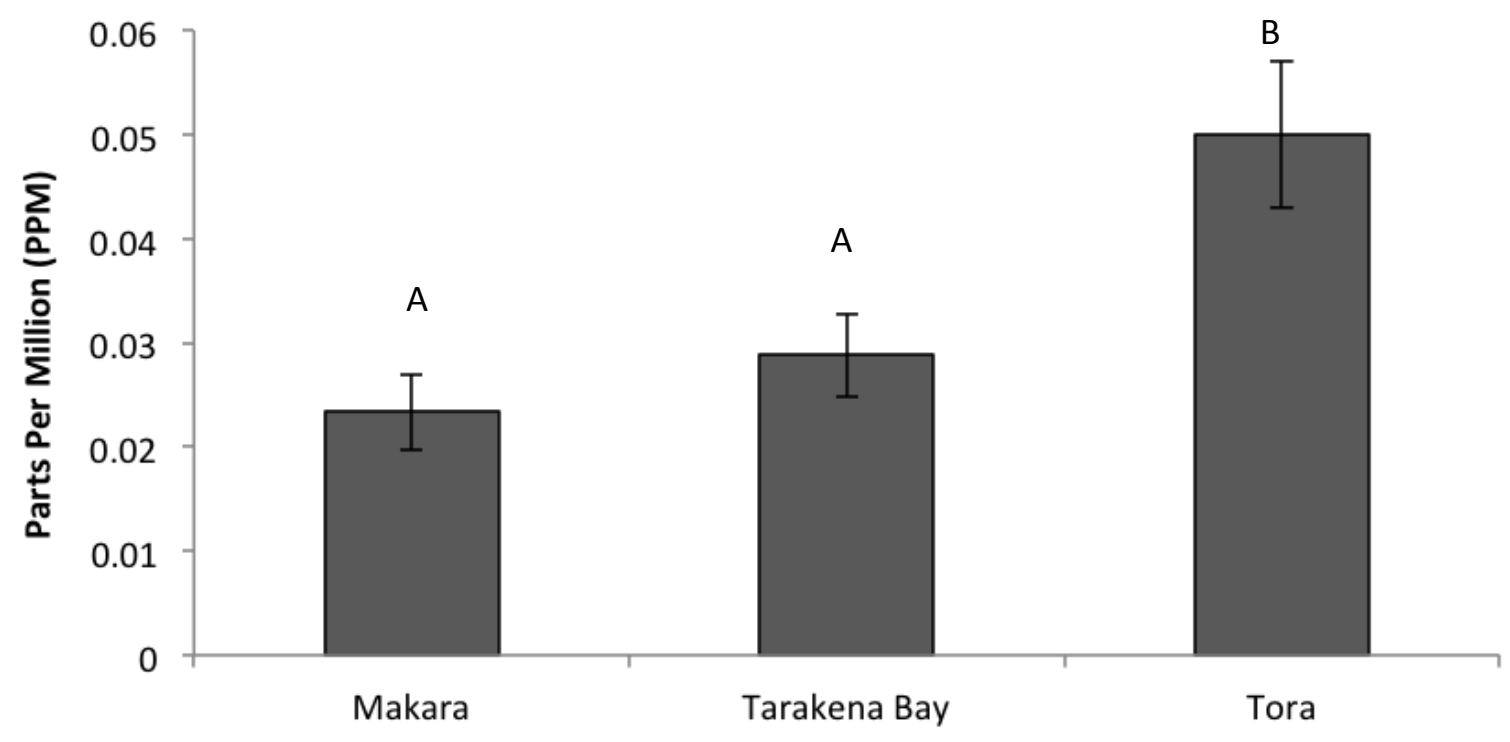

Figure 2.5. Mean cadmium concentration in PPM (+/- SE) at three sites, for both species combined. The same letter indicates the sites are statistically the same. $n=10$ (5 per species) for each site. 


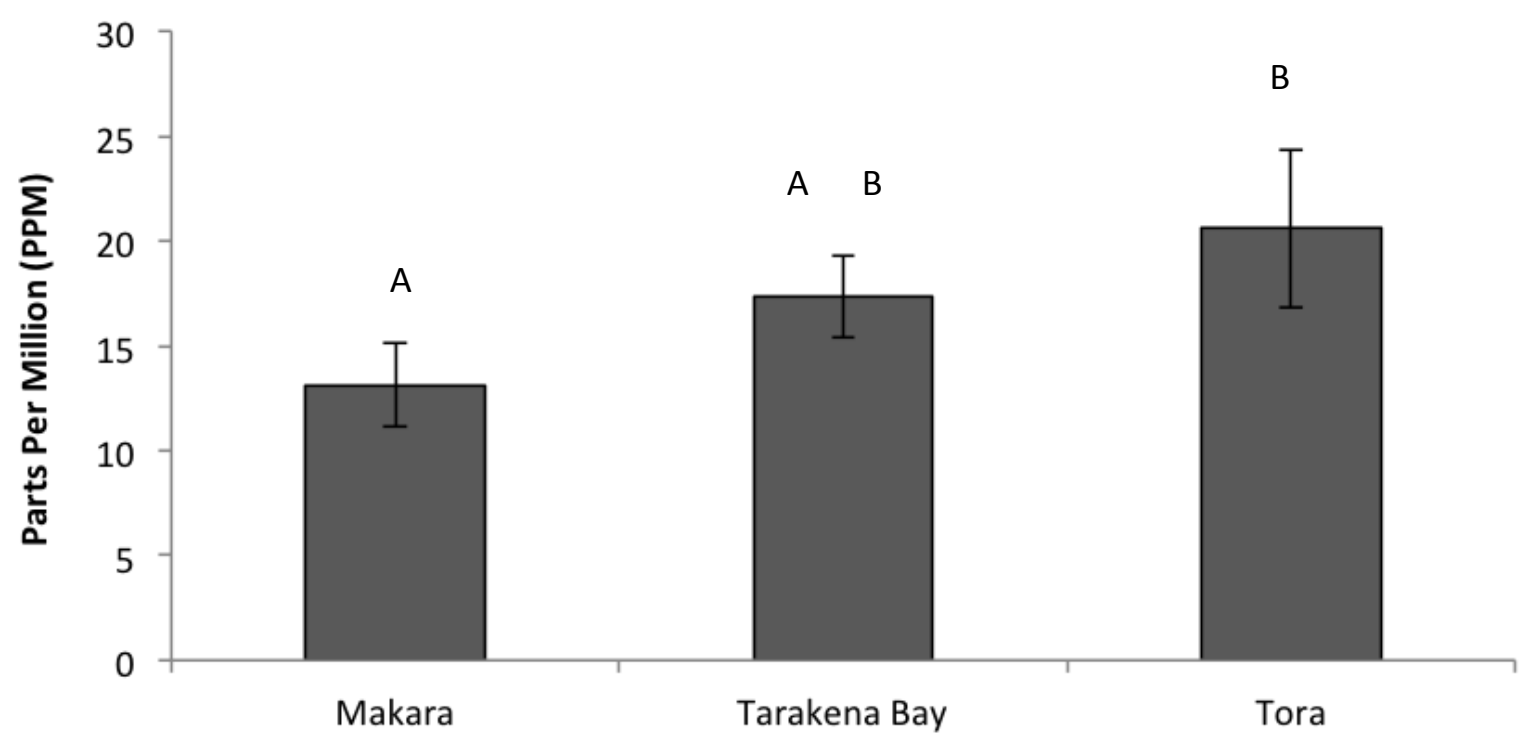

Figure 2.6. Mean copper concentration in PPM (+/- SE) at three sites, for both species combined. The same letter indicates the sites are statistically the same. $n=10$ (5 per species) for each site.

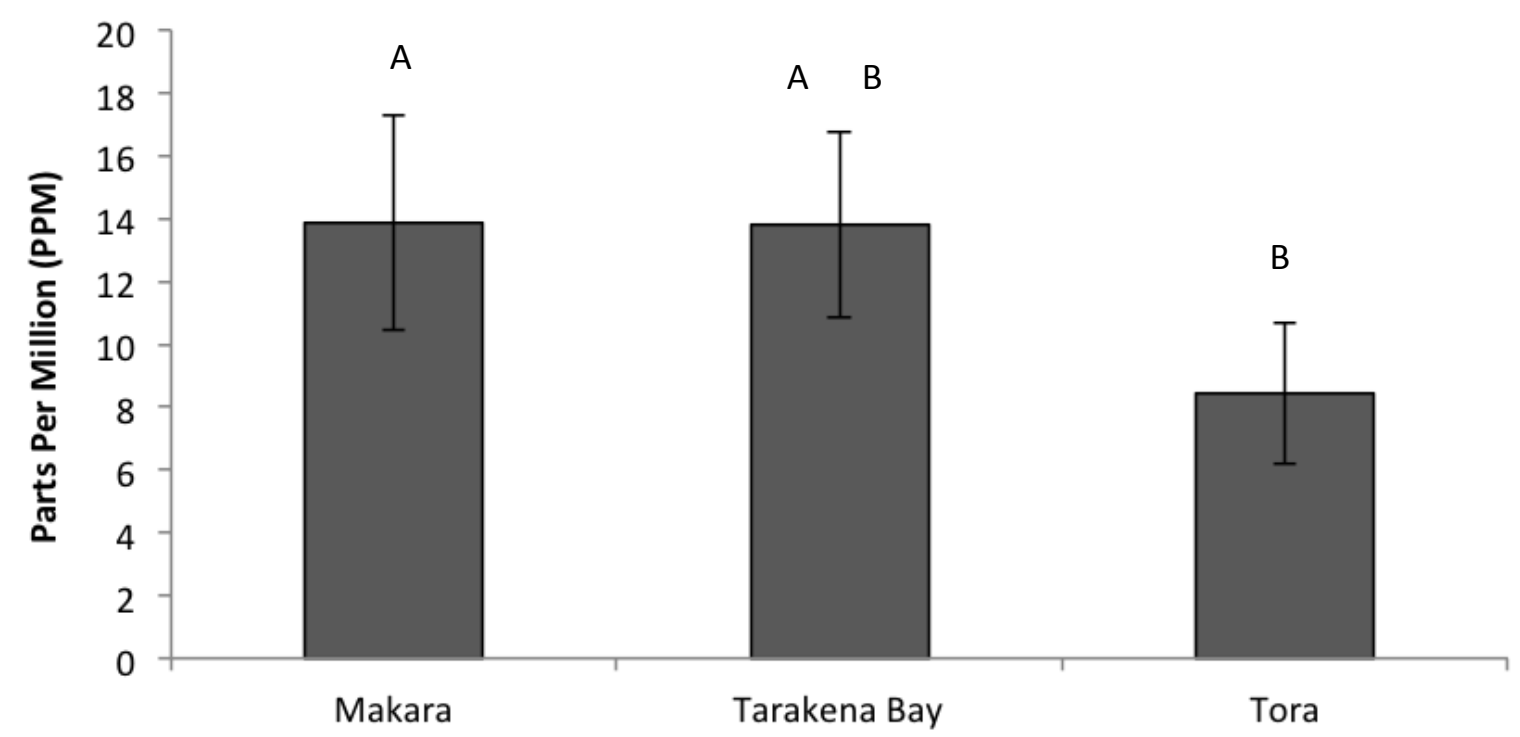

Figure 2.7. Mean titanium concentration in PPM (+/- SE) at three sites, for both species combined. The same letter indicates the sites are statistically the same. $n=10$ (5 per species) for each site. 


\section{Interactions between site and species.}

There was a significant interaction between the effects of species and site for zinc and molybdenum (Table 2.2xvii, 2.2xxx). The interaction for molybdenum likely arose due to differing patterns between species and sites (Figure 2.8). Heterozius rotundifrons from Tarakena Bay were highest in Mo, but $P$. elongatus from Tora contained more Mo than the other sites. The interaction for zinc arose in the same way, $\mathrm{Zn}$ being highest at Tarakena Bay for $H$. rotundifrons specimens and lowest for $P$. elongatus, and Tora being highest in zinc for $P$. elongatus and lowest for $H$. rotundifrons (Figure 2.9).

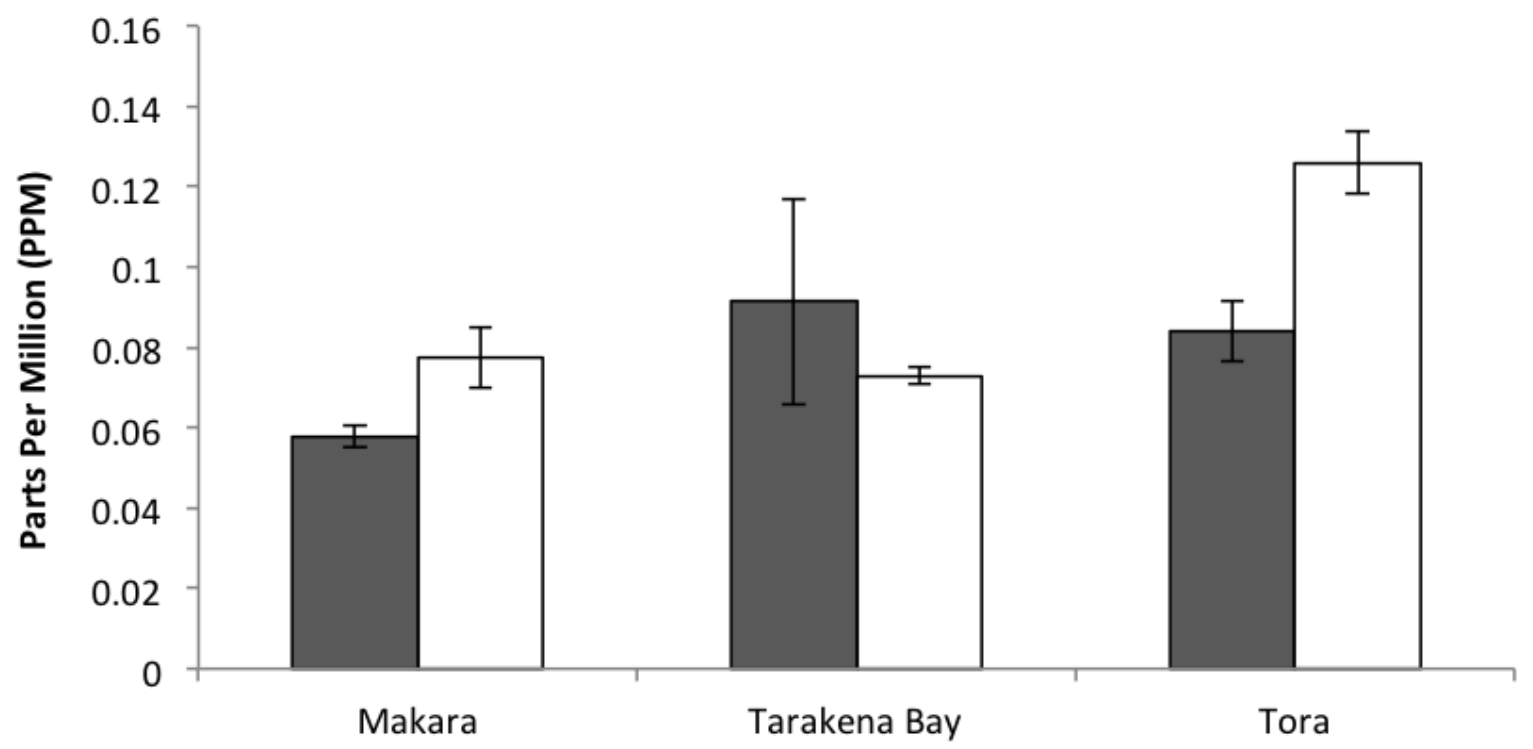

Figure 2.8. Mean molybdenum concentration in PPM (+/- SE) at three sites. $n=5$ of each species at each site. Dark grey bars= Heterozius rotundifrons, white bars= Petrolisthes elongatus. 


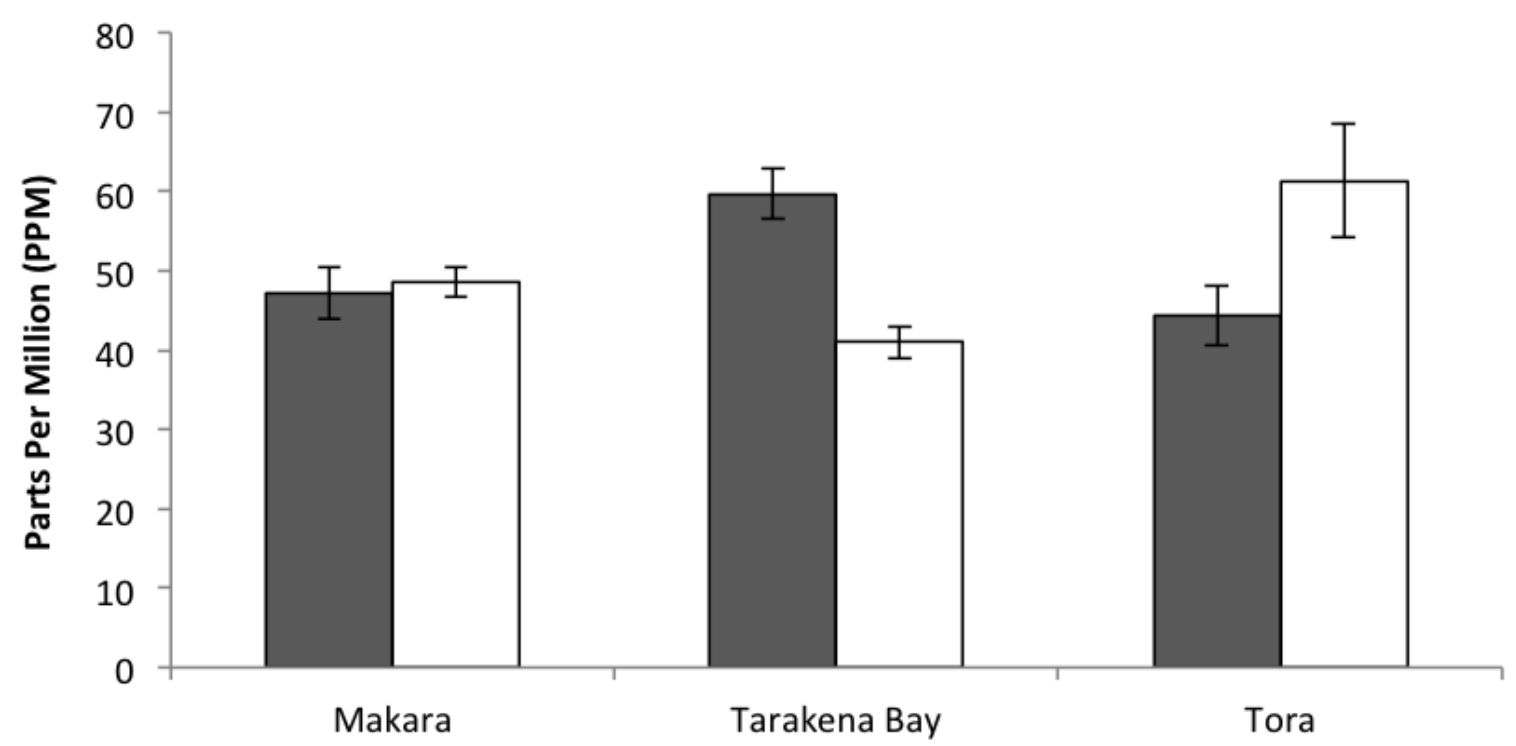

Figure 2.9. Mean zinc concentration in PPM (+/- SE) at three sites. $n=5$ of each species at each site. Dark grey bars $=$ Heterozius rotundifrons, white bars $=$ Petrolisthes elongatus.

\section{Sediment sample results.}

The grain size analysis indicated that all of the sites for this study consisted of gravel and coarse sand, with little fine sediment (Table 2.3). The one exception was the Awhea River, adjacent to the Tora Point site, which has two main sediment types, coarse sand and silt. The sample Awhea River 1 was the only sample from which the majority of the sediment was from the mud fraction. 
Table 2.3. Percentage composition of sediment type at each site and adjacent rivers.

\begin{tabular}{|c|c|c|c|c|c|c|c|}
\hline $\begin{array}{l}\text { Sediment } \\
\text { Type }\end{array}$ & $\begin{array}{l}\text { Makara } \\
\text { Beach } \\
1\end{array}$ & $\begin{array}{l}\text { Makara } \\
\text { Beach } \\
2\end{array}$ & $\begin{array}{l}\text { Makara } \\
\text { River }\end{array}$ & $\begin{array}{l}\text { Tora } \\
\text { Point }\end{array}$ & $\begin{array}{l}\text { Awhea } \\
\text { River } 1\end{array}$ & $\begin{array}{l}\text { Awhea } \\
\text { River } 2\end{array}$ & $\begin{array}{l}\text { Tarakena } \\
\text { Bay }\end{array}$ \\
\hline $\begin{array}{l}\text { Fine } \\
\text { Gravel }\end{array}$ & - & - & - & - & - & - & - \\
\hline $\begin{array}{l}\text { Very } \\
\text { Fine } \\
\text { Gravel }\end{array}$ & 14.73 & 17.23 & 19.6 & 7.82 & - & 22.76 & 7.45 \\
\hline $\begin{array}{l}\text { Very } \\
\text { Coarse } \\
\text { Sand }\end{array}$ & 31.95 & 32.4 & 28.55 & 20.91 & - & 32.36 & 16.28 \\
\hline $\begin{array}{l}\text { Coarse } \\
\text { Sand }\end{array}$ & 40.75 & 40.02 & 39.26 & 43.52 & - & 39.94 & 38.49 \\
\hline $\begin{array}{l}\text { Medium } \\
\text { Sand }\end{array}$ & 7.06 & 6.63 & 7.95 & 18.3 & - & 4.45 & 25.56 \\
\hline $\begin{array}{l}\text { Fine } \\
\text { Sand }\end{array}$ & 3.46 & 2.93 & 3.85 & 8.75 & 1.16 & 0.49 & 11.85 \\
\hline $\begin{array}{l}\text { Very } \\
\text { Fine } \\
\text { Sand }\end{array}$ & 0.73 & 0.24 & 0.4 & 0.2 & 14.29 & - & 0.07 \\
\hline $\begin{array}{l}\text { Very } \\
\text { Coarse } \\
\text { Silt }\end{array}$ & 0.31 & 0.14 & 0.08 & 0.14 & 26.6 & - & 0.06 \\
\hline $\begin{array}{l}\text { Coarse } \\
\text { Silt }\end{array}$ & 0.3 & 0.13 & 0.07 & 0.11 & 22.33 & - & 0.06 \\
\hline $\begin{array}{l}\text { Medium } \\
\text { Silt }\end{array}$ & 0.31 & 0.13 & 0.09 & 0.1 & 16.84 & - & 0.07 \\
\hline Fine Silt & 0.22 & 0.09 & 0.07 & 0.07 & 10.52 & - & 0.06 \\
\hline $\begin{array}{l}\text { Very } \\
\text { Fine Silt }\end{array}$ & 0.15 & 0.06 & 0.05 & 0.06 & 6.88 & - & 0.04 \\
\hline Clay & 0.01 & 0.01 & 0.02 & 0.02 & 1.37 & - & 0.02 \\
\hline
\end{tabular}




\section{Water sample results.}

The range of elements that were able to be measured in seawater is lower than what was able to be analysed in the animals, due to the standards used in the analysis and the range of element concentrations.

The relative concentrations of cadmium and copper in the seawater samples from each site were consistent with the results of the animal analyses - Cu was higher in water from Tora than at either of the other sites, and Makara had the lowest concentration, although the differences were less extreme in the water samples than the animals (Figures 2.5, 2.6; 2.10A\&B). Cd was higher in the sample from Tora, and lowest in Tarakena Bay, and the concentration ratio between the sites was similar to that in the crabs.

Titanium was not consistent with the animal results (Figures 2.7, 2.10B). Titanium was too high to measure successfully at Tora and Makara. It can be inferred from this that there is a greater concentration of titanium at Tora and Makara than at Tarakena Bay.

There were also some other differences seen between the water samples and the animal results. Lead, cobalt, yttrium, vanadium, zinc, and nickel were all higher at Tora, yet none showed significant site differences in the animal results (Table 2.2, Figure 2.10A\&B). The mean concentrations of these elements were higher in the crabs than the seawater however, which suggests that they are accumulated in the animal (Figures 2.4D, 2.10A\&B). 


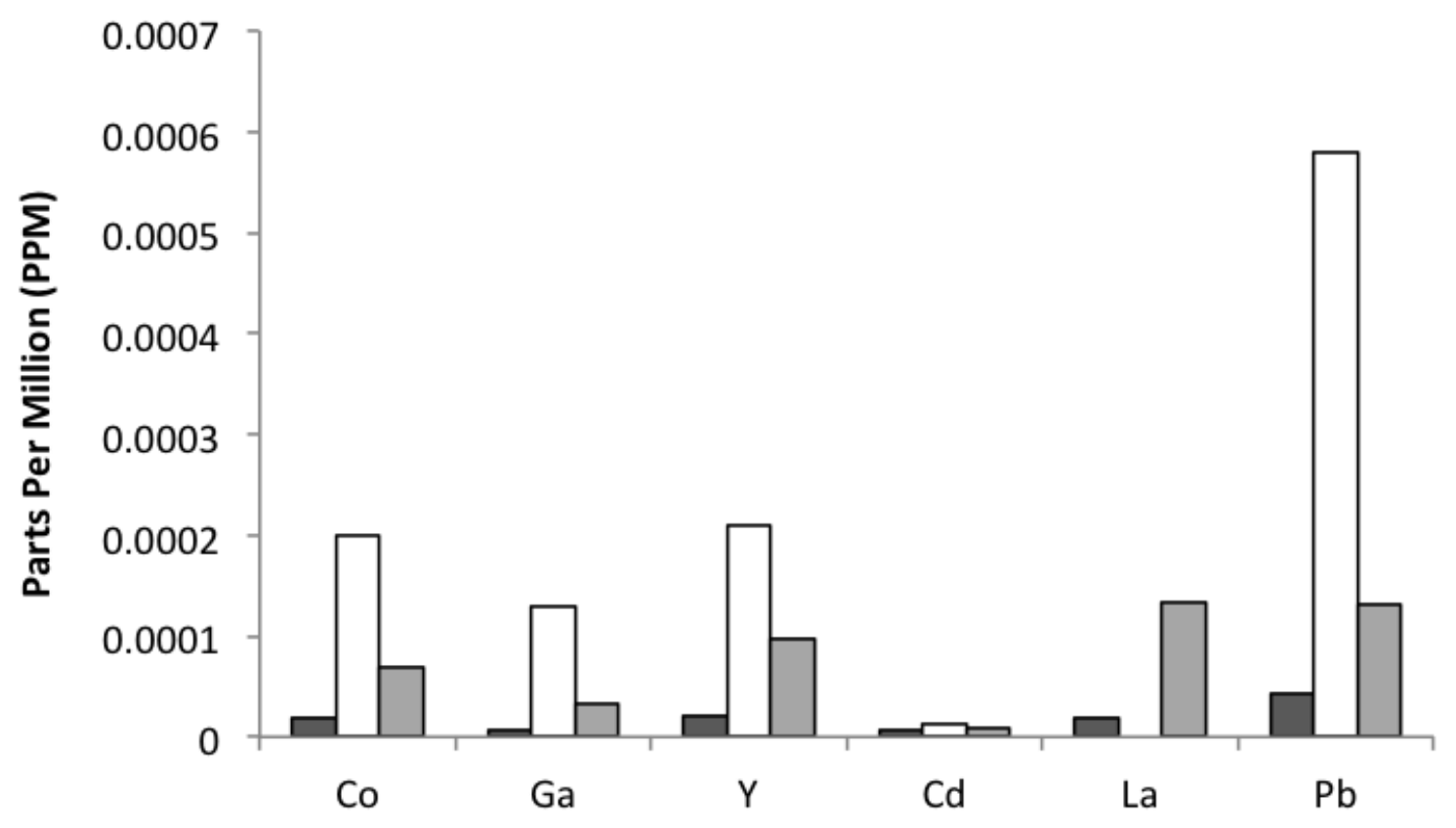

A

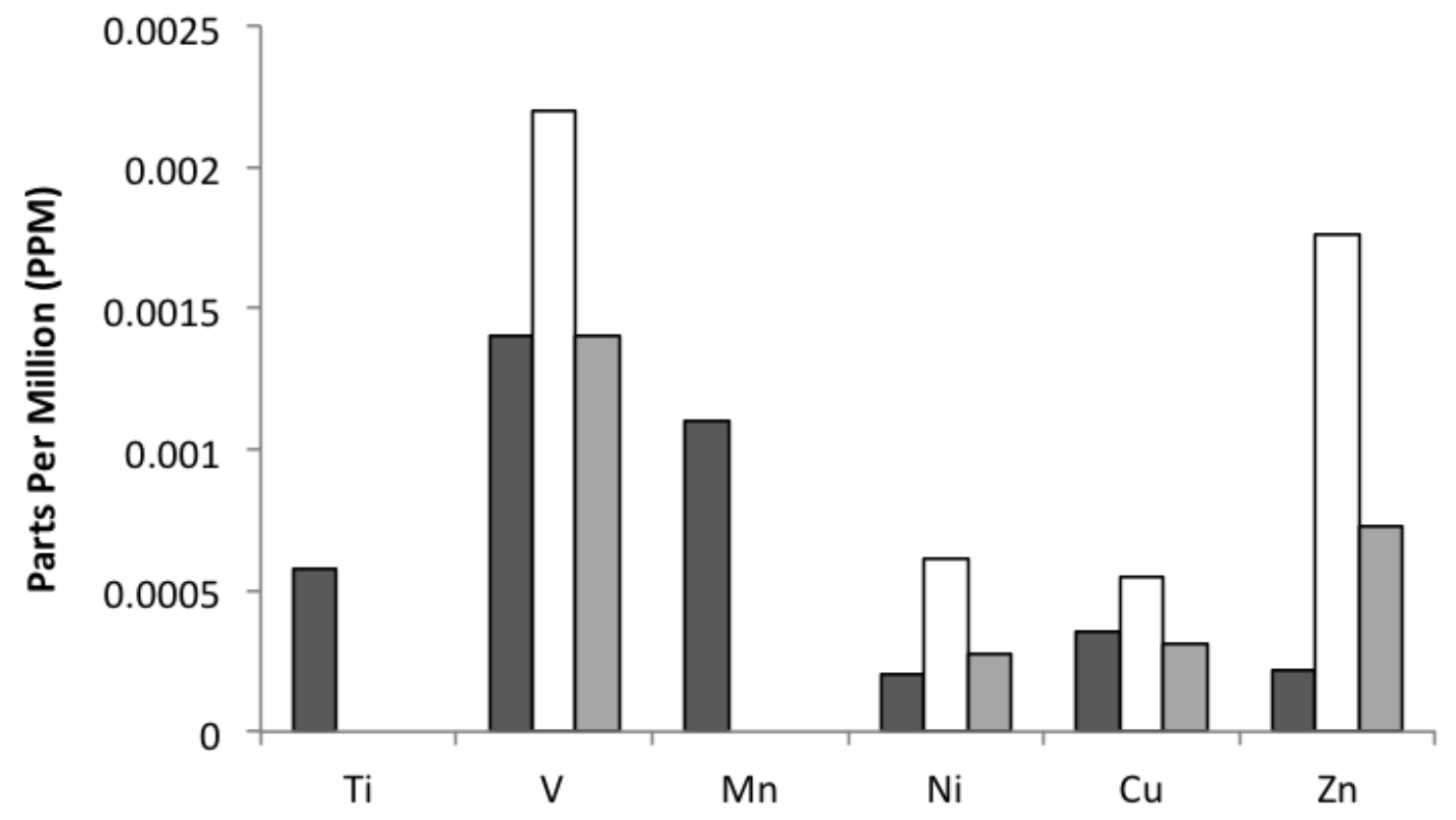

B

Figure 2.10 A and B. Mean trace element concentrations in PPB in water samples from three locations. Dark grey bars= Tarakena Bay, white bars= Tora, light grey bars= Makara. Absence of a bar indicates the concentration was too high to be accurately measured. 


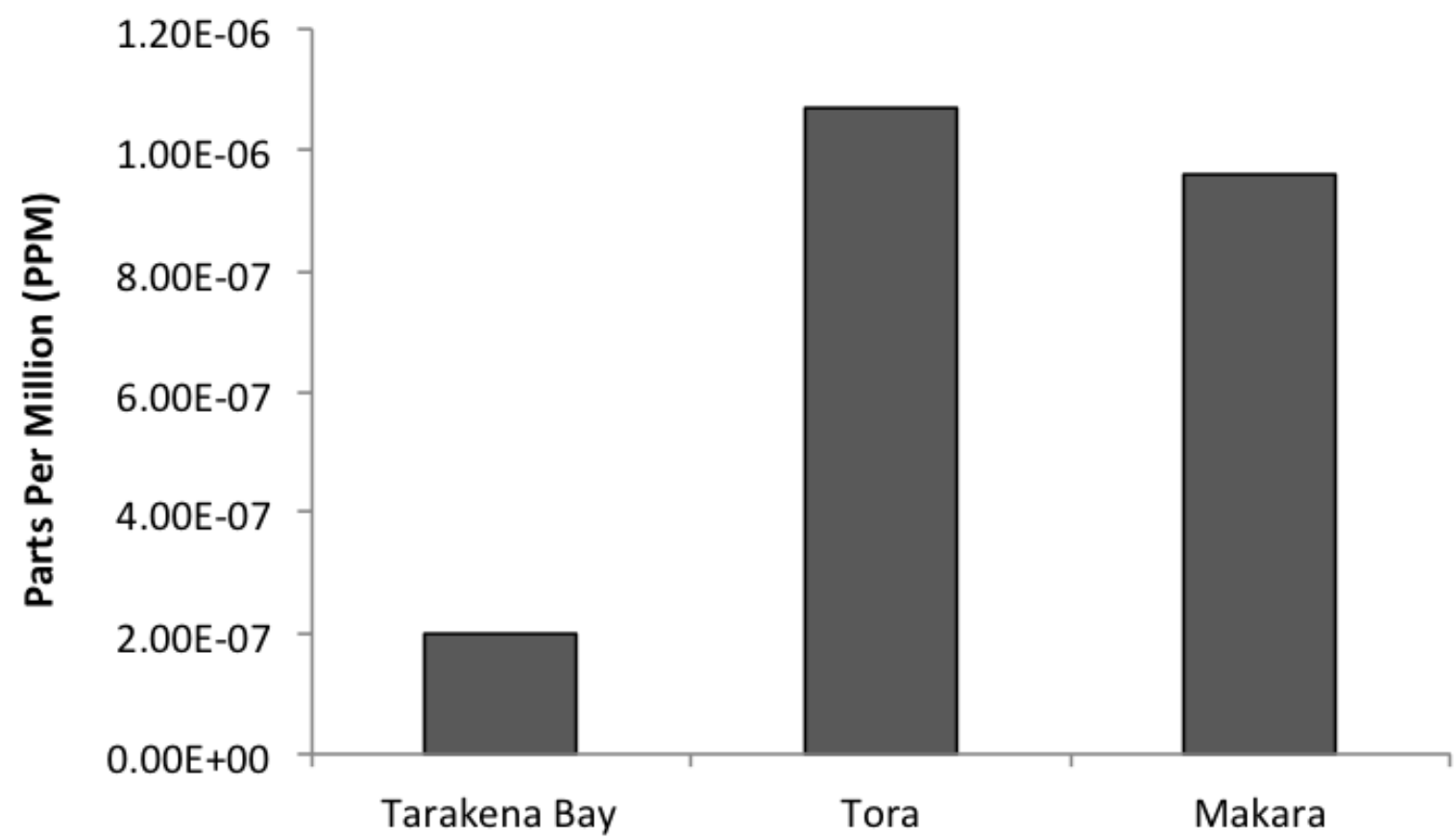

Figure 2.11. Mean scandium concentration in PPB in water samples from three locations. 


\section{DISCUSSION}

\section{Comparison of concentrations of metals between species.}

The results of this research indicate that $H$. rotundifrons and $P$. elongatus have the ability to be used for monitoring the environment, as they show accumulation of trace metals. The hypothesis that there would be species differences in trace metal concentration was supported, as twenty-one out of thirty elements were significantly different between species. However, Petrolisthes elongatus was hypothesised to have higher concentrations of metals due to it being a filter feeder. This was not supported, as only four of the twenty-one significant metals were higher in $P$. elongatus. In general, accumulation has been found to be high in filter feeders, as they absorb nutrients directly from the environment, hence their common use as bioindicators (Fukunaga \& Anderson, 2011; Liu et al., 2017).

The trace metals that were higher in $P$. elongatus were copper, rubidium, caesium, and arsenic. Of these, only copper is known to be bioessential. Rubidium and caesium are rare-earth metals that have no known biological role, but are taken up in a similar way to potassium, and are sometimes substituted for it (Relman 1956; Vinichuk et al., 2011; Tomlinson et al., 2014; Kobayashi et al., 2016). Potassium was not analysed in this study, but it could be expected that it would also have been higher in $P$. elongatus than in $H$. rotundifrons, due to the trends seen in Cs and Rb. Potassium is an important essential element, so it may be valuable to include in future studies. Arsenic has been thought to have a biological role, as evidence has been found in studies of some mammals, however this is not confirmed, and many compounds of arsenic are highly toxic (Uthus, 1992; Bou-Alayan et al., 1995; Cui et al., 2011). Crustaceans tend to have higher arsenic concentrations than other organisms as they are bottomdwelling, and sediment usually contains more arsenic than water (Bou-Alayan et al., 1995; Alonso-Hernandez et al., 2012). As $P$. elongatus is a bottom-dwelling filter-feeder, it has the opportunity to take up arsenic from fine particles in its diet as well as from direct contact with the sediment. 
Both essential and non-essential elements were higher in $H$. rotundifrons. It is an omnivorous scavenger, occupying a higher trophic level than $P$. elongatus. Animals that occupy higher trophic levels have sometimes been found to have greater concentrations of nutrients and metals due to bioaccumulation through the food chain (Wang \& Rainbow, 2000; Wang \& Ke, 2002; Rainbow et al., 2006). As stated above, it was expected that $P$. elongatus would accumulate higher concentrations of trace metals due to it being a filter feeder. The small amount of fine sediment at these sites may account for this unexpected result. Sediment is an indirect contributor to contamination, as it supplies pollutants to the water column, from which they are taken up (Briand et al., 2018). Filter feeders take up metals from suspended sediment when they feed, but, as the sites used for this research were relatively low in fine sediment, $P$. elongatus may have had less nutrients and metals available relative to what $H$. rotundifrons could take up from its scavenging diet.

\section{Results of other trophic level studies.}

It is difficult to directly compare the results of different biomonitoring studies due to the extremely variable nature of such research, and this study is unusual in that it looks at two similar species, while most trophic studies use a range of organisms from different classes. Despite the difficulty in comparison of these studies, they are useful for understanding of bioaccumulation and biomagnification (Rainbow \& Smith, 2010). Environmental factors alter the behaviour of trace metals in trophic networks, and different species' abilities to bioregulate and detoxify can influence the transfer of trace elements in one system, while another may be affected in other ways (Hao et al., 2013). Trophic level studies in other marine systems show considerable variation in their results. Some fail to find any significant evidence of differences between levels (Hao et al., 2013; Borrell et al., 2016). Others, however, had results that reflect those of this study. Research on a coral reef system showed that omnivorous and carnivorous consumers had higher levels of trace elements compared to organisms at lower trophic levels, much like Heterozius rotundifrons and Petrolisthes elongatus (Briand et al., 2018). The uptake of trace metals from diet is a highly important pathway, and the results of this study, as well as others, 
indicate that it may contribute more to accumulation of trace elements in animals and through trophic levels than direct uptake from the environment (Weeks \& Rainbow, 1993; Nunez-Noguiera et al., 2006; Pastorinho et al., 2009; Briand et al., 2018).

\section{Comparison between concentrations of metals in decapods between different sites.}

Given the similar geology of the sites, it is not unexpected that the trace element concentrations between the three locations are largely similar, with only a few significant site differences. However, the geographical differences between sites were expected to have some effect on the metal concentrations in the animals, as the level of agricultural and urban impact varies between each site. This hypothesis was supported in part, with cadmium, titanium, and copper the only metals to differ in concentration in the crab specimens between sites.

Sediment and water from each site were analysed to investigate whether these could explain the observed differences in metal concentrations between locations, and to gain a deeper understanding of the habitat. Analyses in other bioindicator studies have shown that elevated concentrations of metals in animals are reflected in sediment (Weinstein et al., 1992). However, the level of contaminants in sediment is dependent on grainsize, as coarse sand and gravel does not retain metals as well as finer sediments can. The lack of sediment in the mud fraction for these sites is typical of exposed areas, where fine material cannot accumulate with high-energy wave action. Organisms in these environments, such as the target species of this work, are more likely to pick up significant amounts of nutrients and metals from the water, rather than the substrate, as physiochemical properties of sediment influence their uptake into organisms, and metal contaminants are less readily taken up from coarse sediment (Gundacker, 2000; Signa et al., 2017). In these environments, fine sediment remains suspended in the water column, and its composition is likely to be reflected in water sample analysis. For this reason, at these sites seawater is more likely than sediment to influence the chemical composition of the animals, which is partially supported by the results from the location analysis. 
Cadmium was significantly higher in the animals at Tora Point than at either Tarakena Bay or Makara. The same pattern was seen in the water samples from these sites. Cadmium is a by-product of phosphate fertilisers, which are used along the Tora coast and surrounding farmland. Run-off from these fertilisers may result in slightly higher cadmium concentrations at Tora Point. Cadmium is an extremely toxic metal and cannot be excreted by crustaceans, which makes them ideal organisms to use when monitoring Cd (Nunez-Noguiera et al., 2012). It is possible that the fine sediment in the Awhea River could carry contaminants to the sea from farms and other anthropogenic sources, which may account for the elevated metals seen at Tora.

Copper was significantly higher in Tora animals than those from Makara, and this was reflected in the water samples. As the Wellington region is similar in its geology, and Tora is isolated from potential sources of copper from urbanisation, the origin of these elevated levels are so far unclear, but ICP-MS analysis of the sediment could provide some insight. Although copper levels were not extremely high, it is a toxic pollutant, so it is important to monitor, and potentially investigate further the reasons for this significant difference in future studies (Fingerman et al., 1996; Ward et al., 2015).

The mean concentration of titanium was very similar between Makara and Tarakena Bay, but significantly lower at Tora than at Makara. Tora was not significantly different from Tarakena Bay, despite how close it was in concentration to Makara. This suggests that the difference between mean $\mathrm{Ti}$ concentrations is slight. This is understandable, as although titanium is an abundant metal, most naturally occurring titanium is in mineral deposits, and as the sites in this study are geologically similar, it is not expected that one would be enriched with titanium (Buettner \& Valentine 2012). The titanium results of the water samples are not reflected in the animal results, in which Tora specimens had lower concentrations of titanium than specimens from either of the other sites. This discrepancy between the animal results and water samples was unexpected since the sediment composition indicates that any differences between sites are likely to be due to the chemical composition of the seawater. Some organisms, such as dinoflagellates and ascidians, have an affinity for Ti; 
however there is currently limited evidence of a biological role (Buettner \& Valentine 2012). Bioregulation and offloading of excess metals may explain why there are such differences between the concentrations of titanium between animals and seawater at certain sites. If levels of titanium are higher than at other sites, as suggested by the water sample results, they might exceed what is safe and usable by the animals. In this case, Ti would be offloaded by excretion or moulting, which could result in lower concentrations of $\mathrm{Ti}$, as seen in Tora animals.

The relatively few differences in metal concentrations between sites indicates that they are not particularly affected by agricultural or urban runoff, possibly due to their relative isolation, and exposure to strong wave action which disperses contaminants. It would be valuable for future study to further investigate the effects of urbanisation by including sites that are in lower energy environments, closer to potential sources of runoff, or are known to be polluted. Further study of coastal invertebrates in areas with more variable geology may show more significant differences by location, and further research should expand the study area to be more widespread across the species ranges. This is being addressed by the CAIME project for a variety of crustacean species.

\section{Interaction effects}

There were interaction effects between the effects of location and species for zinc and molybdenum. This means that these factors depend on each other and therefore cannot be discussed separately. Further analysis on zinc and molybdenum would be beneficial, as they are essential elements, as well as having severe toxic effects at high concentrations. The differing patterns could be due to interactions with other metals at the sites - some metals influence the levels of others due to synergistic and interactive effects (Liao et al., 2018). Molybdenum has a relationship with copper (Suttle, 1974; Wang et al., 2016). Enzymes containing molybdenum are found in almost all organisms, and have a number of important functions, including roles in nitrogen-fixing in plants and metabolic enzyme activation in animals. High levels of molybdenum can inhibit 
copper uptake, and it is used as a treatment for copper toxicity in many animals (Kusum et al., 2010; Morgan et al., 2014). Although the patterns seen in these results do not clearly reflect an interaction between $\mathrm{Cu}$ and Mo, bioaccumulation depends on a number of factors, so further investigation may be useful.

\section{Implications for monitoring}

Baseline data are invaluable for monitoring the environment, as they provide a starting point for comparative studies and enables researchers and environmental managers to observe how the ecosystem changes. This research has identified that there is variation even between similar species, which highlights the importance of using multiple species as bioindicators. This methodology is used worldwide and is considered a simple and effective tool for monitoring the environment. It provides a great deal of information, and can be used not only for assessing environmental health, but also in understanding trophic dynamics and interactions between different metals.

This methodology is not without its flaws - during the statistical analysis for this study, the problem arose that it was not possible to separate out the differences between elements accumulated in the shell and in the muscle tissue. Certain metals are known to be more prevalent in certain tissue types, and the levels of these can vary greatly between individuals due to variation in moulting cycles and other natural factors (Weeks et al., 1992; Pratoomchat et al. 2002). This could lead to confounding results, as what may appear to be variation in certain elements could be simply due to individuals having recently moulted. This is an important factor to consider for monitoring, as it may cause inaccurate interpretation of data, and is addressed in the second chapter of this thesis.

It is noted throughout the literature that due to accumulation of metals into certain organs, it is important to consider that tissue types may differ in their reflection of environmental quality (Alikhan et al., 1990; Suarez-Serrano et al., 2010). The majority of studies favour using adult animals as bioindicators, which may not provide a full picture of the environment and it is beneficial to focus on other life stages to understand if accumulation or ability to bioregulate changes with growth 
(Alikhan et al., 1990). Juvenile and adult organisms alike are affected by pollutants, suffering apoptosis in tissues where they accumulate, increased mortality and slower moulting (Greco et al., 2001; Khan et al., 2006; Wang et al., 2014). It is important to undertake comprehensive research with a range of variables, including different age classes and tissue types, to better understand how populations may be affected by pollution.

The variation in metal concentration between the two decapod species analysed for this research emphasises the importance of using a range of species for biomonitoring (Jara-Marini et al., 2013). Although the animals were of similar size and were collected from the same sites, in most cases from within one metre of each other, the majority of metals that were significantly higher in one species were different by a considerable margin. This stresses what has been highlighted by other studies of this nature - trace metal uptake is so variable, even between similar species, that it is difficult to make generalisations about patterns of accumulation (Jara-Marini et al., 2013). For monitoring purposes, this means that to use bioindicator species to depict environmental quality, it is crucial to use a range of species from different trophic levels, and to consider the effects of factors like seasonality, age, and food source.

This research represents the collection of baseline data for the Wellington region, and an investigation into uptake of metals into animals in different trophic levels, it also is a part of the larger CAIME project. Inclusion in this project means that the results of this work will contribute to a larger dataset of baseline information, and the questions that have arisen can be addressed by future studies.

\section{Conclusions}

Trace element analysis is a valuable monitoring tool, as it provides a wealth of data which can be used for a range of purposes, and is an effective measure of ecosystem health. This chapter of this thesis contributed to a baseline dataset of decapod information, and assessed spatial and trophic level differences in trace element chemistry. Urbanisation was expected to have an influence on the site comparison results, however this was not seen, likely due to the exposed nature 
of the sites and the lack of fine sediment. This study emphasised the complexity of trophic level variation in bioaccumulation patterns, and highlighted the need for multiple species to be used in biomonitoring studies. 


\section{Uptake of trace metals into different tissue types of Jasus edwardsii.}

\section{INTRODUCTION}

\section{Accumulation into different tissue types}

The accumulation of trace elements in organisms varies across tissues, which is important to consider when using biomonitors. Elements are taken up by crustaceans differentially across tissue types. The organs tend to accumulate contaminants at a faster rate than other tissues, as they are taken up to be used in biological processes or detoxified in the hepatopancreas (Paganini \& Bianchini, 2009; Martins et al., 2011; Sogiento et al., 2013). The hepatopancreas is where metabolic and detoxification processes occur, and studies usually find that this is where the highest concentration of metals is accumulated (Soedarini et al., 2012; Goretti et al., 2016).

Some metals are preferentially accumulated in other tissues. Calcium is particularly associated with the exoskeleton, as it is required to build new shells. Neodymium binds with chitin structures, causing it to be taken up into exoskeletons (Roberts et al., 2012). Other elements, like copper, are found at different concentrations in the shell depending on what stage of their moult cycle the animal is in (Pratoomchat et al., 2002). The shell is also used to offload excess nutrients and metals. In some decapod species, such as fiddler crabs, elements that are excessively high in concentration are accumulated into the exoskeleton and then discarded through the moulting process (Bergey \& Weis, 2007). Muscle tissue however, tends to be low in natural concentrations of metals (Soedarini et al., 2012; Mazlum et al., 2016).

Muscle tissue is often used in environmental monitoring studies, as it is the food source of other animals and of humans, and is therefore ecologically and economically important. However, it is naturally comparatively low in heavy metal concentration, so analysing this tissue includes a bias (Soedarini et al., 2012). Detoxification processes usually protect muscle tissue from accumulating dangerous levels of toxins, therefore using muscle as a guideline for monitoring 
may not be an accurate depiction of the true levels of contaminants in the environment. Variation in the natural chemical profile of different tissue types from moult cycles and other factors is therefore important to consider when conducting research on trace element uptake.

Moulted shells may also passively take up excess metals from their environment. The chitin derivative chitosan takes up contaminants from water and other mediums, and has a number of commercial applications for sequestration of heavy metals. Chitosan is highly porous, water soluble and binds with negatively charged molecules (Osifo et al., 2009). In laboratory tests, it has been found to remove over $90 \%$ of copper ions from animal effluent, and as it can be made into a range of materials it is a potential remediation material for wastewater (Osifo et al., 2009; Mohanasrinivasan et al., 2014). The chitosan used for research is usually derived from shrimp exoskeletons, however as the key factor is that they are chitin, it is expected that many crustacean species could be a source. Jasus edwardsii exoskeletons are primarily made of a chitin-protein matrix (Jack et al., 2011). Since the aim of this research is to investigate uptake of trace elements into living animals, it is important to find out whether passive absorption of metals into moulted exoskeletons takes place.

When bioindicator species are used for environmental monitoring, the organ tissue, usually the hepatopancreas but sometimes the gill, is often used in preference to the muscle. However, because metal concentrations often vary by tissue type, this may give a biased picture of trace elements in the environment (Guner, 2007; Beeram et al., 2012). Analyses of animals that have economic value as a food source, such as large decapods and fish, often will only target muscle tissue, because it is what is eaten and therefore has consequences for human health (Hao et al., 2013). This tends to be lower in toxic metals until the concentration becomes too high for the organs to detoxify. For bioindicator species to be effective, and to protect ecosystem health, it is important to analyse different tissues, and understand bioaccumulation of both essential and nonessential elements.

In this chapter I examine how two metals, copper and neodymium, are taken up into juveniles of the spiny lobster Jasus edwardsii. I examine how these metals 
are accumulated into different body tissues, which aids in understanding how biomonitoring results can be biased if only certain tissue types are analysed, and how this important species is affected by contaminants.

\section{Jasus edwardsii (Hutton, 1875)}

The species selected for this section of the study was Jasus edwardsii, also known as crayfish, red rock lobster and southern rock lobster. This is a species of spiny lobster native to New Zealand and Australia, and is a highly valuable commercial species, with important fisheries in both countries (Chiswell \& Booth, 2008; Chiswell \& Booth, 2017). In New Zealand, it is also has great cultural significance to Māori and is a popular recreational fishing species.

Jasus edwardsii have been the focus of many studies in New Zealand and Australia, especially concerning population dynamics, diet, and settlement of larvae, as they have one of the longest larval stages of any crustacean (Chiswell \& Booth, 2017). The phyllosoma larvae live in the open ocean for up to two years and go through 11 larval stages (Chiswell \& Booth, 2008). Following the phyllosoma stage, they undergo a significant metamorphosis from the flat-bodied transparent larvae into a post-larval puerulus, which is a transparent miniature of an adult crayfish, and actively swim at night to settle near the coast on rocky reefs at depths less than 15 metres (Booth, 1989; Hinojosa et al., 2016; Lorelai Garcia-Echauri \& Jeffs, 2018). The puerulus then moults into a juvenile that resembles the adult, and is able to scavenge on shellfish and small fish, and feed on algae (Figure 2.1). The juvenile stage was the focus of this study. 


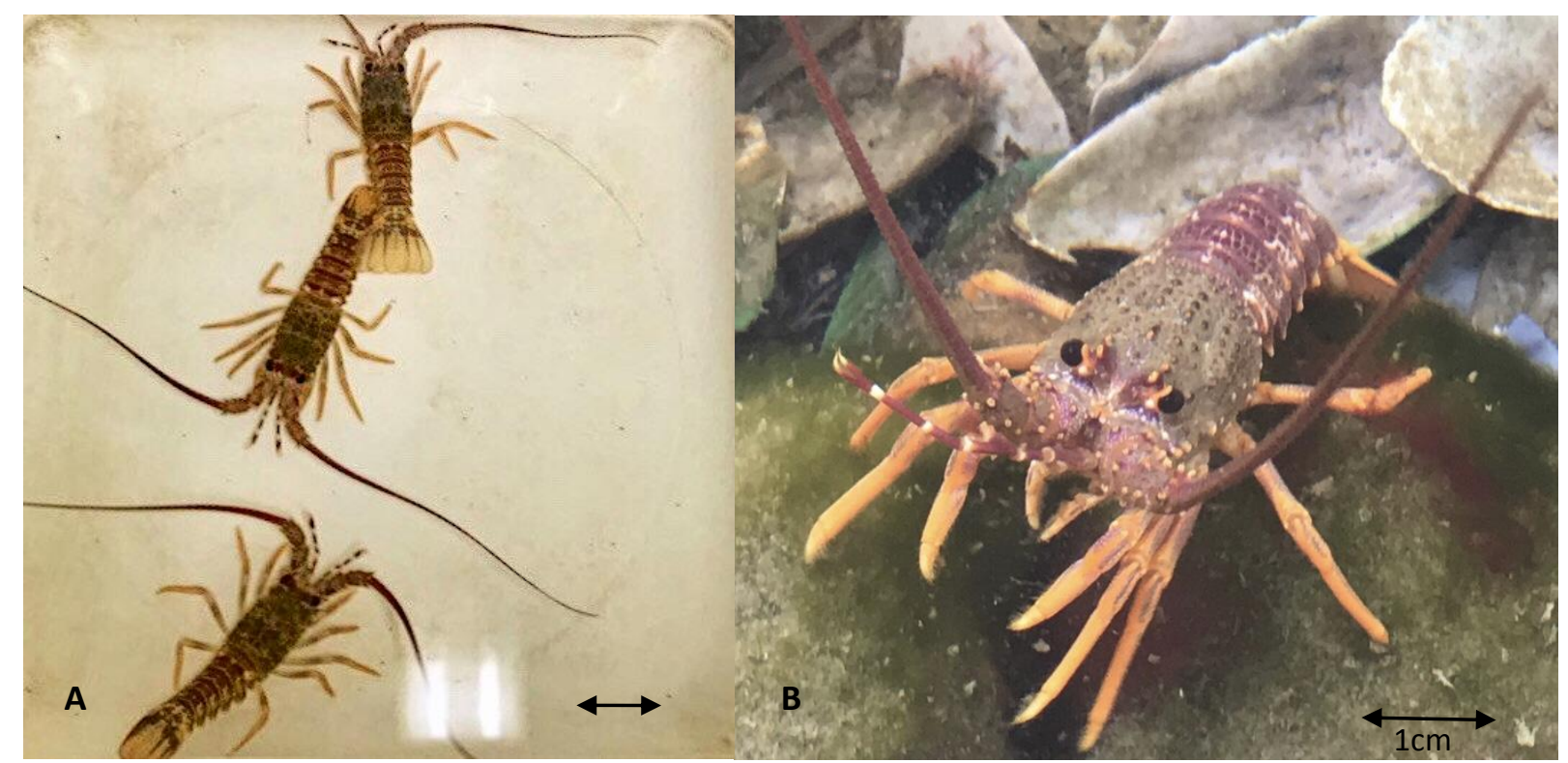

Figure 3.1 A and B. Juvenile Jasus edwardsii at A) a few months after puerulus stage and $B$ ) one year after.

Spiny lobsters have been studied around the world, in a wide range of contexts. Like J. edwardsii, many species are important for fisheries, so there is an incentive for having an in-depth understanding. The variety of research is immense, focusing on topics from the impact of marine reserves, fishery dynamics, and larval growth, to predation responses, and population genetics (Babucci et al., 2010; Frisch \& Hobbs, 2011; Gristina et al., 2011; Kay et al., 2012; Jensen et al., 2013; Celi et al., 2015; Kikuchi et al., 2015; Stanley et al., 2015). Trace element research is less common, although has been undertaken for several studies (Fukushima et al., 2001; Maharajan et al., 2011; Maharajan et al., 2012; Loflen et al., 2018). Jasus edwardsii has not been the subject of many trace element studies, although trace element markers have been used in population structure research (Jack et al., 2011). Uptake of pathogenic toxins into the hepatopancreas has been studied, but what little work has been done on heavy metal uptake has focused on muscle tissue, as Jasus edwardsii is a critical commercial species (Fabris et al., 2006; McLeod et al., 2018). For fishery purposes, and for the conservation of the species, it is important that the population is well understood and in good health. Extending the body of research into how J. edwardsii is impacted by exposure to contaminants, is crucial, as puerulus and juvenile crayfish in particular settle and develop on rocky reefs close to shore, and have the potential to be exposed to contaminants that could hinder their development or increase mortality. The majority of work on this and 
related species has used adult specimens, and while this is important from many perspectives, it is crucial not to focus solely on mature animals, as juveniles and larvae are critical to the success of the species, and may respond differently to adults when exposed to contamination.

\section{Copper.}

The heavy metal copper was chosen for this study because it is a bioessential element that is toxic above certain levels, is abundant in oceanic systems, and is commonly included in contamination studies and environmental monitoring as it is a common pollutant. It is also particularly important to crustaceans, as it is an essential component of haemolymph (Depledge \& Bjerregaard, 1989; Maharajan et al., 2011). Copper plays a significant role for all organisms, particularly in metabolic processes, respiration and enzyme functioning (White \& Rainbow, 1985; Soegianto et al., 1999; Manimaran et al., 2012; Goretti et al., 2016). However, at levels that exceed the ability of animals to bioregulate it can be severely toxic (Manimaran et al., 2012; Giacomin et al., 2014; Gomiero \& Viarengo, 2014). At high concentrations, copper exposure can decrease growth, survival, and reproduction in amphipods, and it decreases reproductive rates in other crustaceans, and growth and survival of polychaetes (Fingerman et al., 1996; Ward et al., 2015a; Ward et al., 2015b). Larvae are extremely sensitive to heavy metal exposure - copper is one of the most toxic elements to larvae, especially for bivalves (His et al., 1999). The toxicity of copper is thought to be due to the tendency of $\mathrm{Cu}^{2+}$ ions to bind to bioessential molecules, which may affect the function of proteins and cause formation of Reactive Oxygen Species, which are severely toxic (Maharajan et al., 2011). Copper has detrimental effects even at sublethal levels, and as it is relatively abundant and readily taken up by organisms, it is extremely important to monitor copper concentrations in the environment (Maharajan et al., 2011). 


\section{Neodymium.}

The rare earth element neodymium was chosen for this study because it is less abundant in oceanic systems, and less studied in a bioaccumulation context, therefore it is not known if it is regulated by organisms. It is increasingly used in oceanographic and geological analyses, through which it has been found that some organisms, like Foraminifera, take up neodymium into calcite structures (Roberts et al., 2012).

Although some rare earth elements (REEs) have biological functions, many, including neodymium, are not well studied in this regard (Huang et al., 2011). The ability of most REEs to be bioregulated, and how they are taken up and distributed in organisms is unknown, and it is unclear what the threshold is for impacting the health of organisms and the environment. It is therefore important to understand how REEs are accumulated, in order to be able to monitor negative effects and determine what safe levels may be. Rare earth metals are a popular mining product, and have many uses in technology, such as in the manufacture of batteries and computer hardware (Rim et al., 2013). The extraction of REEs, and their many uses in technological production are a major source of pollution, although much of the contamination is due to associated chemical runoff. However, studies on human health have determined that REEs by themselves can have a negative impact on organisms (Huang et al., 2010; Huang et al., 2011; Zha et al., 2011).

Copper and neodymium were chosen as the only two metals for the doping study to allow for examination of uptake without the possibility of interaction from increased concentrations of other metals causing confounding results. Neodymium and copper were not expected to interact with each other due to the large natural difference in concentration, and this natural ratio was preserved in the doping experiment. 


\section{Aims and hypotheses of this chapter.}

This chapter had two aims. First, it examined whether moulted exoskeletons that are exposed to elevated levels of copper take it up from their environment. Second, it examined whether there is a significant response in metal concentration for $J$. edwardsii that has been exposed to elevated levels of copper and neodymium, and whether these metals are taken up selectively into different tissue types.

It was hypothesised that there would be significantly more copper absorbed by moults exposed to a high copper concentration $(200 \mu \mathrm{g} / \mathrm{L})$ than those exposed to the low concentration $(20 \mu \mathrm{g} / \mathrm{L})$, or in the control group.

It was also hypothesised that there would be no significant difference between the overall copper concentration of control samples and the samples in the $20 \mu \mathrm{g} / \mathrm{L}$ copper treatment, but that there would be a difference between the tissue types for copper, with more copper expected to be taken up into the organs for bioregulation. For neodymium, it was hypothesised that there would be a significant difference in overall concentration between the controls and the treated samples, but not between tissue types, as the concentration was not expected to be high enough to require bioregulation in the organs. 


\section{METHODS}

\section{Pilot study}

Before this research began, I ran a pilot study to ensure the $\mathrm{J}$. edwardsii juveniles could be successfully kept in the lab, and to determine an appropriate dosage of copper. An acceptable dosage was considered one that would not harm the animals, but would be high enough to observe significant uptake of copper by the dosed animals.

The pilot study used low concentrations of copper, in keeping with those used for similar work on juveniles (Maharajan et al., 2012). The majority of studies use adult animals, which are more tolerant to higher concentrations (Bardeggia \& Alikhan, 1991; Truchot \& Rtal, 1998). Some research conducted on juveniles of other crustacean species used concentrations above 100 $\mathrm{g} / \mathrm{L}$, however these studies were concerned with assessing detrimental effects of copper, while the present study was aiming only to monitor sub-lethal accumulation of metals (Soegianto et al., 1999; Khan \& Nugegoda, 2007). Analysis of the pilot study samples showed that even the highest concentration, $20 \mu \mathrm{g} / \mathrm{L}$ of copper, did not show significant accumulation between shell and muscle tissue, nor between control and dosed animals after four weeks of exposure.

This result determined what concentration of copper would be used for this thesis. As it was known that $20 \mu \mathrm{g} / \mathrm{L}$ would not impair the animals, it was decided that this concentration should be used in case a higher one was harmful, and also because the experiment was planned to run longer than the pilot. A higher dosage of $200 \mu \mathrm{g} / \mathrm{L}$ was also used, as it is one order of magnitude higher than the low concentration, and was theorised that it would show more significant accumulation than the control samples. Organ tissue was not used in the pilot study due to the difficulty in dissecting juvenile crayfish without crushing fragile tissue. Because the pilot study results showed no difference between shell and muscle tissue, and studies indicate that copper is accumulated first in the hepatopancreas, I decided to examine organ tissue for analysis in the main experiment as well. 


\section{Maintenance of Jasus edwardsii juveniles.}

Puerulus and juvenile stage Jasus edwardsii were provided by NIWA. These were collected using Booth crevice collectors close to the shore (Phillips \& Booth, 1994). The animals were collected in July 2018 as part of NIWA's monthly surveys at Castlepoint $\left(40^{\circ} 54^{\prime} 04.4^{\prime \prime S}, 176^{\circ} 13^{\prime} 47.3^{\prime \prime E}\right)$ and Riversdale

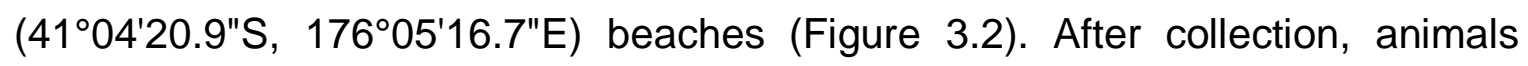
were housed at VUCEL, and their moults collected and frozen. Prior to the doping experiment, the specimens were kept in a tank with a continual supply of filtered seawater (FSW) and fed three times a week with Mytilus edulis collected from Scorching Bay beach in Wellington. They were kept in this tank for two months, to allow as much growth as possible, in order to make dissection easier and have more tissue for analysis. The juveniles were grown until they were about $5-8 \mathrm{~cm}$ long. The mussels were also kept at VUCEL in a tank supplied with raw seawater. A FSW sample was also collected; to ensure the metal concentration of the water was low and that elevating the levels of some elements would not cross a threshold of toxicity.

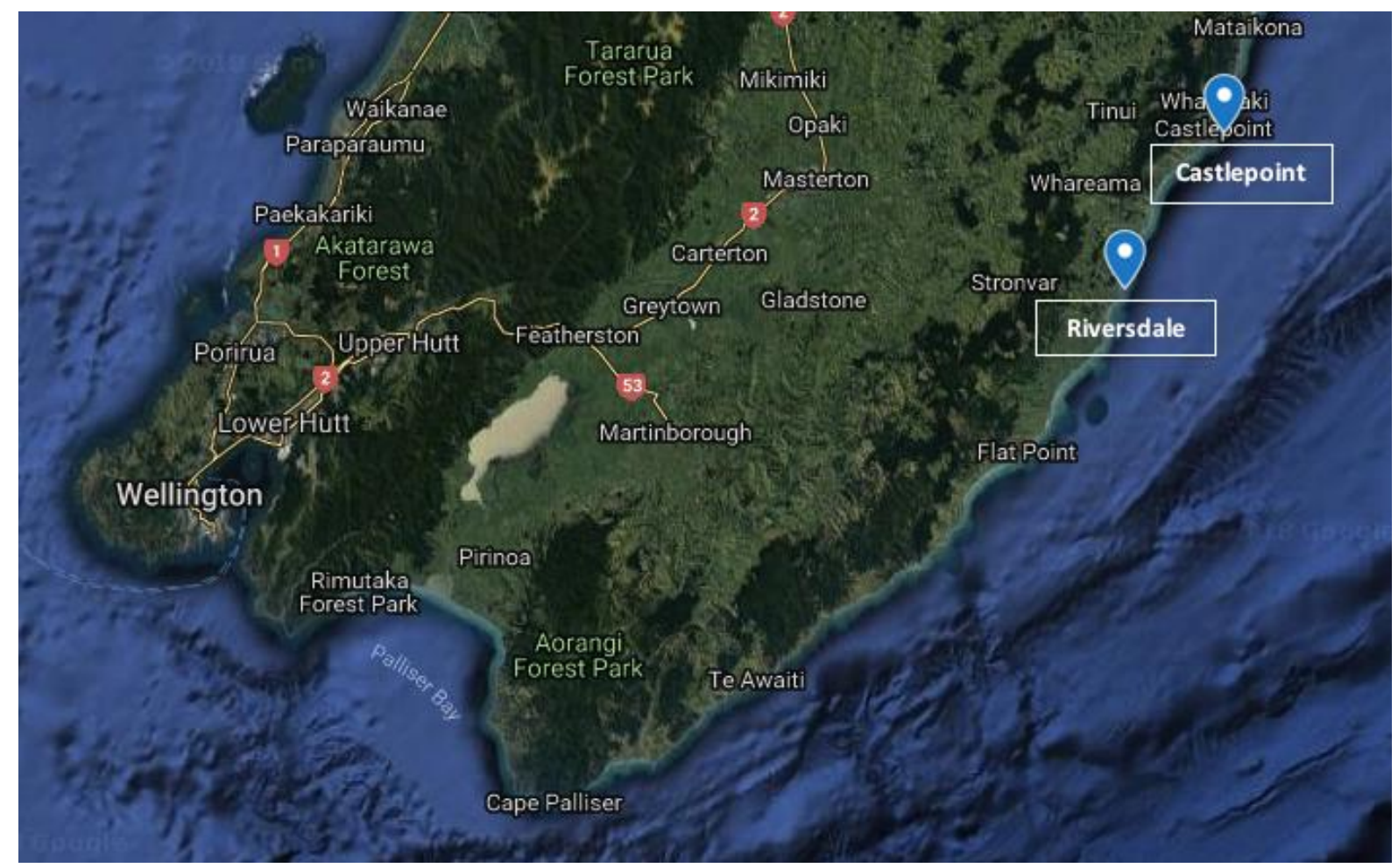

Figure 3.2. NIWA collection sites for Jasus edwardsii. Map generated from Google Earth. 


\section{Moult experiment.}

Twelve Jasus edwardsii moults were collected prior to the beginning of the doping experiment. They had all been discarded in the same 48-hour period between feedings. Four moults were placed in a bucket containing FSW, four in a bucket of FSW and copper, at a concentration of $20 \mu \mathrm{g} / \mathrm{L}$, and four in a bucket of FSW and copper at a concentration of $200 \mu \mathrm{g} / \mathrm{L}$. The buckets were aerated with aquarium bubblers in order to replicate the doping experiment, and the water (and copper) replaced on Monday, Wednesday, and Friday. This experiment ran for one week, and then the moults were frozen until analysis.

\section{Jasus edwardsii doping experiment.}

Prior to the start of the experiment, four individuals that had not been exposed to any water other than the FSW they were housed in were sacrificed by freezing, to use for baseline analysis.

Stock solutions of $500 \mu \mathrm{g} / \mathrm{L}$ copper sulphate and $250 \mu \mathrm{g} / \mathrm{L}$ neodymium chloride hexahydrate were made and kept refrigerated at VUCEL. To make the treatments for the experiment, amounts of these stock solutions were added to $2 \mathrm{~L}$ of FSW, to make concentrations of $20 \mu \mathrm{g} / \mathrm{L}$ and $200 \mu \mathrm{g} / \mathrm{L}$ copper sulphate, and $0.2 \mu \mathrm{g} / \mathrm{L}$ neodymium chloride. The copper concentrations were decided upon following the pilot study as described above. The neodymium concentration used was two orders of magnitude lower than the higher concentration of copper. This was deemed appropriate because it occurs at very low levels naturally, so accumulation should be observable at low levels, which would reduce the risk of mortality from toxicity.

Two J. edwardsii individuals were put in a tank of $200 \mu \mathrm{g} / \mathrm{L}$ copper sulphate and two in a tank of $0.2 \mu \mathrm{g} / \mathrm{L}$ of neodymium chloride for four days, to ensure they were able to survive the treatments, as these were not able to be tested during the pilot study. Only one of the animals in the neodymium treatment died, so the survival rate was deemed satisfactory for the experiment to commence. 
The doping experiment consisted of three treatments in six buckets (Figure 2.3): two controls of $2 \mathrm{~L}$ of FSW (CA and $\mathrm{CB}$ ), two for treatment 1, each containing $2 \mathrm{~L}$ of $20 \mu \mathrm{g} / \mathrm{L}$ copper sulphate and $0.2 \mu \mathrm{g} / \mathrm{L}$ of neodymium chloride and treatment 2 containing $2 \mathrm{~L}$ of $200 \mu \mathrm{g} / \mathrm{L}$ copper sulphate and $0.2 \mu \mathrm{g} / \mathrm{L}$ of neodymium chloride. There was also a seventh bucket that contained a temperature logger. Each control bucket contained six J. edwardsii, and each other contained eight individuals. The buckets contained aquarium bubblers for aeration, and were kept at $14^{\circ} \mathrm{C}$ in the VUCEL constant temperature lab.

The animals were fed with mussels on Mondays, Wednesdays, and Fridays, and the water changed at the same time. All but four of the animals in the $200 \mu \mathrm{g} / \mathrm{L}$ copper/neodymium treatment had died by the end of the first week. The deceased animals were frozen, and as the four surviving were from the same treatment, two were sacrificed and the remaining two put back into untreated seawater to see if they would recover.

On each Friday, two animals from each of the remaining buckets were sacrificed by freezing. For the control tanks, two animals were sacrificed in the first and fourth weeks, and one in the second and third. The experiment ran for four weeks in total, and the sacrificed animals were stored in the freezer until analysis. During this time, some of the animals moulted. The control animals and doped animals moulted at roughly the same rate, and the shed exoskeletons were removed as soon as possible, within no more than 48 hours of moulting. Due to experimental limitations, only animals from the fourth week of the experiment were used for the analysis. These were four crayfish from the $20 \mu \mathrm{g} / \mathrm{L}$ copper/neodymium treatment, two controls and three of the baseline crayfish. The remaining animals were kept frozen for potential analysis in the future.

\section{Cleaning, drying, and weighing decapod samples.}

All processes took place in a sterile environment, with all equipment and surfaces being cleaned with ethanol after each sample. All the equipment used was plastic, Teflon, or aluminium foil. Cleaning the samples took place in the dry lab 
at VUCEL, and weighing was done in the geochemistry laboratory at Victoria University of Wellington.

For the moult experiment, the entire moult was placed in a Teflon vial. For the doping experiment, the tail muscle was dissected out from the shell, and the gut removed. The organs were dissected out from the muscle, and any shell, were removed. The tail muscle, shell, and organs were placed in separate Teflon vials. The gut that was removed from the tail muscle was included with the organs. Deionised water was added, and the vial placed in an ultrasonic bath for 15 seconds. The DI water was removed using a pre-rinsed transfer pipette. This cleaning step was repeated twice more.

The sample was placed into an aluminium foil drying boat, then into a larger aluminium foil tray with an aluminium foil lid to protect the samples from any potential particulate contamination. The samples were dried at $60^{\circ} \mathrm{C}$ for 90 minutes. Once dry, the drying boat and sample were placed in a ziplock bag and into a desiccator until they were weighed.

Samples were weighed on aluminium foil using a Mettler Toledo 5 decimal place balance. Weights were recorded after 30 seconds to allow for drift, and the samples were placed into clean, labelled $1.5 \mathrm{ml}$ plastic vials.

\section{Chemical processing of decapod samples.}

Methods were the same as for Chapter One.

\section{Mass spectrometer analysis.}

Methods were the same as for Chapter One.

\section{Water sample analysis.}

Methods were the same as for Chapter One. 


\section{Statistical analysis.}

When necessary, data were transformed by logging or taking the square root to meet the assumptions of ANOVA. One-way Analyses of Variance (ANOVA) were run in R3.5.1 (R Core Team, 2016), using R-Studio Version 1.1.456 (RStudio Team, 2018), for the moult experiment. Other metals that met the assumptions of ANOVA were also analysed to ensure that any differences seen were due to the copper treatment, rather than natural variation.

For the doping experiment, two-way ANOVAs were run comparing the baseline and control samples, and the controls and treated samples, for copper and neodymium. To see if other elements were influenced by the copper/neodymium treatment, two-way ANOVAs were also run for metals that met the assumptions of ANOVA. In this case, only ten metals aside from copper and neodymium met the ANOVA assumptions.

Water data were analysed through comparison of trends in Excel. The water sample taken for this experiment was compared to those collected from around the Wellington region for the previous chapter. 


\section{RESULTS}

\section{Uptake of metals in moults}

The two-way ANOVA showed significant differences in the concentration of copper in moulted exoskeletons between the treatments $(\mathrm{df}=2, \mathrm{~F}=126.1$, $\mathrm{p}<0.0001)$. The Tukey test showed that all three treatments, control, $20 \mu \mathrm{g} / \mathrm{L}$ copper and $200 \mu \mathrm{g} / \mathrm{L}$ copper, were significantly different from each other.

The mean copper concentration was higher in moults exposed to the $20 \mu \mathrm{g} / \mathrm{L}$ treatment than in the controls, and even higher in those exposed to the $200 \mu \mathrm{g} / \mathrm{L}$ treatment (Figure 3.3). Comparison of the raw data showed that there was 25 times as much copper in the moults exposed to the $20 \mu \mathrm{g} / \mathrm{L}$ treatment than the controls, and over ten times as much in the $200 \mu \mathrm{g} / \mathrm{L}$ treatment than the $20 \mu \mathrm{g} / \mathrm{L}$ treatment (Figure 3.4).

The moults exposed to increased copper were also observed to be less brittle than the controls, which were prone to disintegration. One of the control moults was unable to be analysed due to its fragility, while those in the $20 \mu \mathrm{g} / \mathrm{L}$ treatment were more robust, and the $200 \mu \mathrm{g} / \mathrm{L}$ moults were stronger.

Seven of the other metals measured met the assumptions of ANOVA and were also analysed. These (neodymium, zinc, calcium, lead, iron, arsenic, molybdenum, and cadmium) were not significantly between any of the treatments (Figure 3.3). 


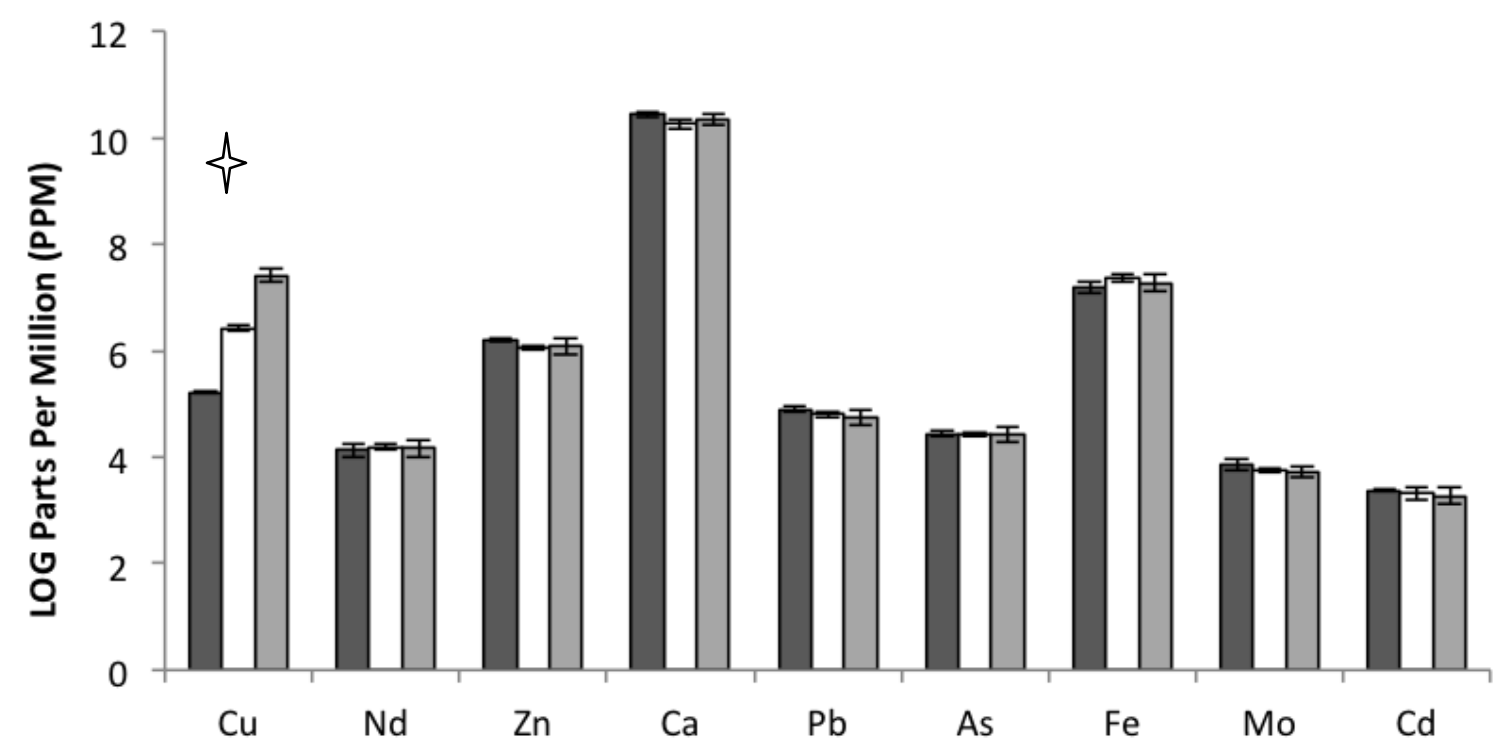

Figure 3.3. Logged concentrations of PPM (+/- SE) of various metals in Jasus edwardsii moults exposed to water doped with two concentrations of copper. Concentrations were logged for ease of comparison. $n=3$ for controls, $n=4$ for $20 \mu \mathrm{g} / \mathrm{L}$ treatment and $\mathrm{n}=4$ for $200 \mu \mathrm{g} / \mathrm{L}$ treatment. Dark grey bars $=$ control, white bars $=20 \mu \mathrm{g} / \mathrm{L}$ copper treatment, light grey bars $=200 \mu \mathrm{g} / \mathrm{L}$ copper treatment. Stars indicate a significant difference between treatments.

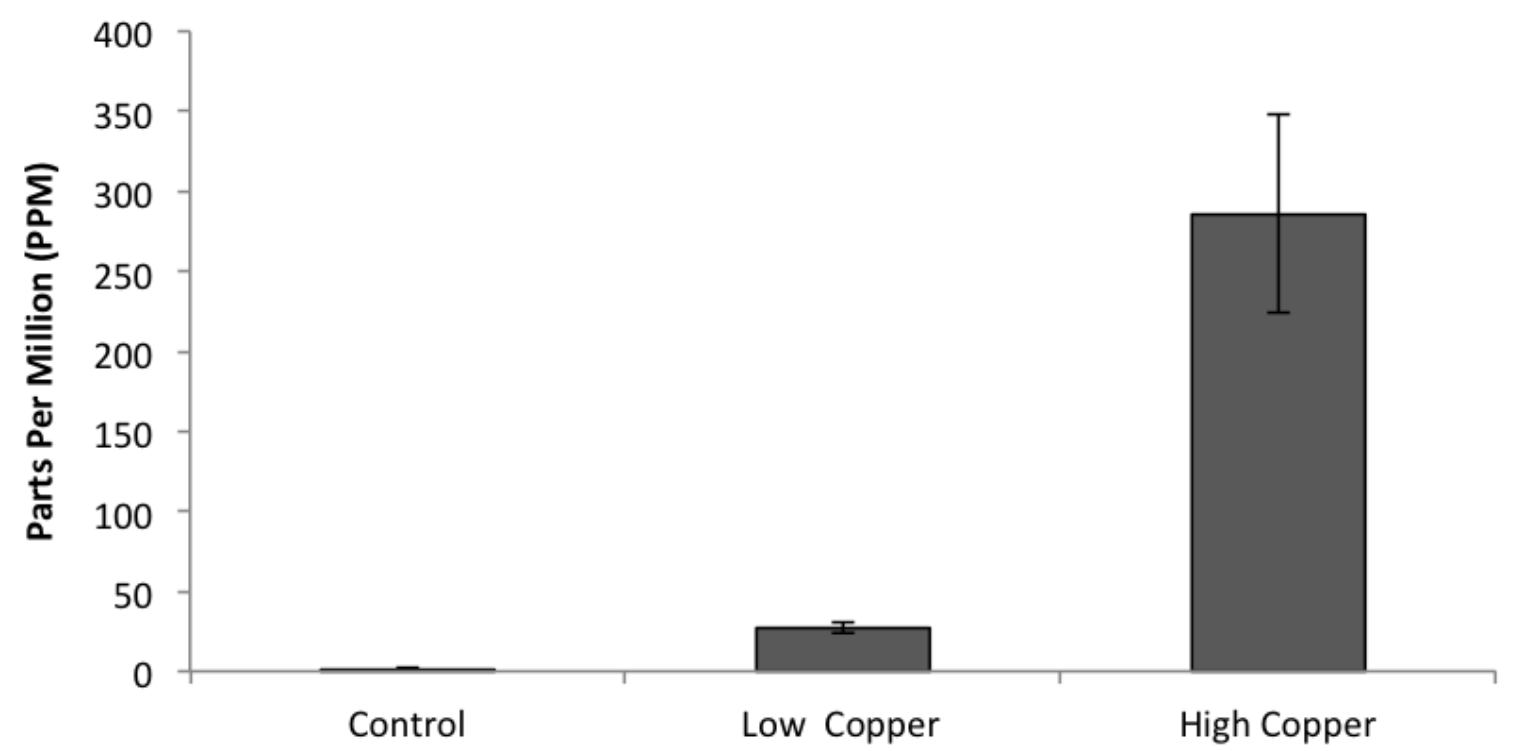

Figure 3.4. Mean concentration in PPM (+/- SE) of copper in Jasus edwardsii moults exposed to water doped with two concentrations of copper (low=20 $\mu \mathrm{g} / \mathrm{L}$ added copper, high $=200 \mu \mathrm{g} / \mathrm{L}$ added copper). $\mathrm{n}=3$ for controls, $\mathrm{n}=4$ for $20 \mu \mathrm{g} / \mathrm{L}$ treatment and $\mathrm{n}=4$ for $200 \mu \mathrm{g} / \mathrm{L}$ treatment. 


\section{$\underline{\text { Results of doping experiment }}$}

\section{Copper}

\section{Comparing animals exposed to the copper/neodymium treatment and control animals.}

There was no significant interaction between the effects of treatment and tissue type (Table 3.1).

There was a significant difference in copper concentration between the control samples and those exposed to the $20 \mu \mathrm{g} / \mathrm{L}$ copper treatment (Table 3.1). Copper concentration was higher in animals exposed to the treatment than in the control samples (Figure 3.5).

There was also a significant difference in copper concentration between different tissues (Table 3.1). The Tukey test showed that shell and organ tissue were significantly different from each other, and neither was different to muscle tissue. There was twice as much copper in the organ tissue of the treatment samples than in their exoskeleton, and more than ten times as much copper in the control organs than control shells (Figure 3.5).

\section{Comparing baseline animals and control animals.}

There was no significant interaction between the effects of treatment and tissue type (Table 3.1).

There was also no significant difference between copper concentrations in the baseline samples, which were not used in the experiment and not exposed to any water other than filtered seawater, and the experimental control samples, although there was a trend for higher copper concentrations in the baseline samples than the controls (Figure 3.6).

Copper concentrations varied significantly across tissue types of the baseline and control samples (Table 3.1). Similar to the experimental animals exposed to elevated copper, organ tissue was significantly higher than shell tissue, with around four times more copper in the baseline organ tissue than baseline shell, 
while muscle tissue was not significantly different from the other tissue types (Figure 3.6).

Table 3.1. Two-way ANOVA tables for copper results. Significant $p$-values are in bold.

\begin{tabular}{|c|c|c|c|c|}
\hline \multicolumn{5}{|c|}{ Copper $20 \mu \mathrm{g} / \mathrm{L}$ and Controls } \\
\hline Factor & DF & $\begin{array}{l}\text { Sum of } \\
\text { Squares }\end{array}$ & F-statistic & $p$-value \\
\hline Treatment & 1 & 3.088 & 10.14 & 0.0079 \\
\hline Tissue Type & 2 & 4.73 & 7.77 & 0.0069 \\
\hline Treatment*Tissue & 2 & 0.631 & 1.04 & 0.384 \\
\hline Error & 12 & & & \\
\hline \multicolumn{5}{|c|}{ Controls and Baseline Samples } \\
\hline Factor & DF & $\begin{array}{l}\text { Sum of } \\
\text { Squares }\end{array}$ & F-statistic & p-value \\
\hline Treatment & 1 & 0.535 & 1.7 & 0.224 \\
\hline Tissue Type & 2 & 7.142 & 11.36 & 0.0035 \\
\hline Treatment* Tissue & 2 & 0.108 & 0.17 & 0.845 \\
\hline Error & 9 & & & \\
\hline
\end{tabular}




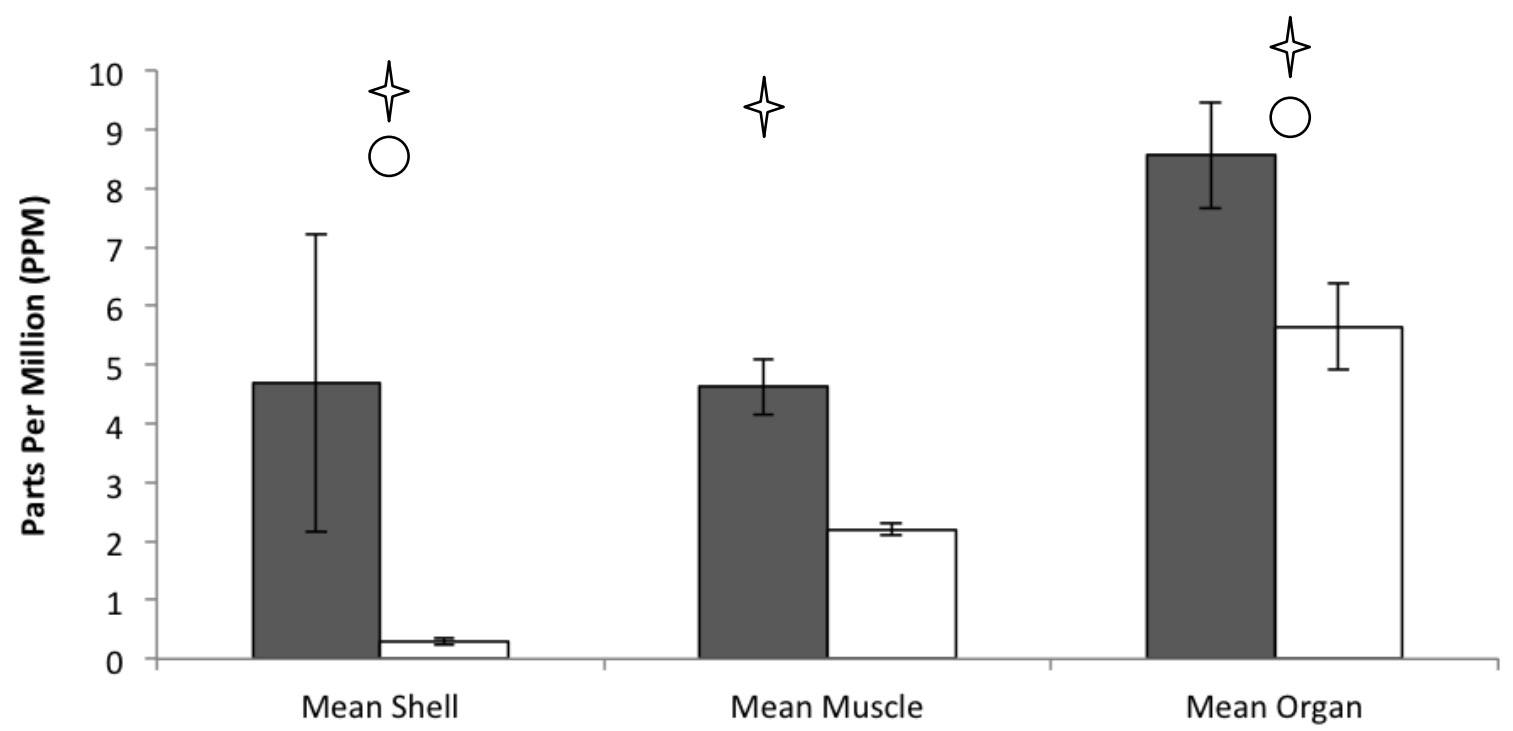

Figure 3.5. Mean copper concentrations in PPM (+/- SE) in three different tissue types, for copper/neodymium treatment samples and control samples. $n=2$ for controls, $n=4$ for treatment samples. Dark grey bars $=20 \mu \mathrm{g} / \mathrm{L}$ treatment samples, white bars $=$ control samples. Stars indicate a significant difference between treatments. Circles indicate a significant difference between tissue types.

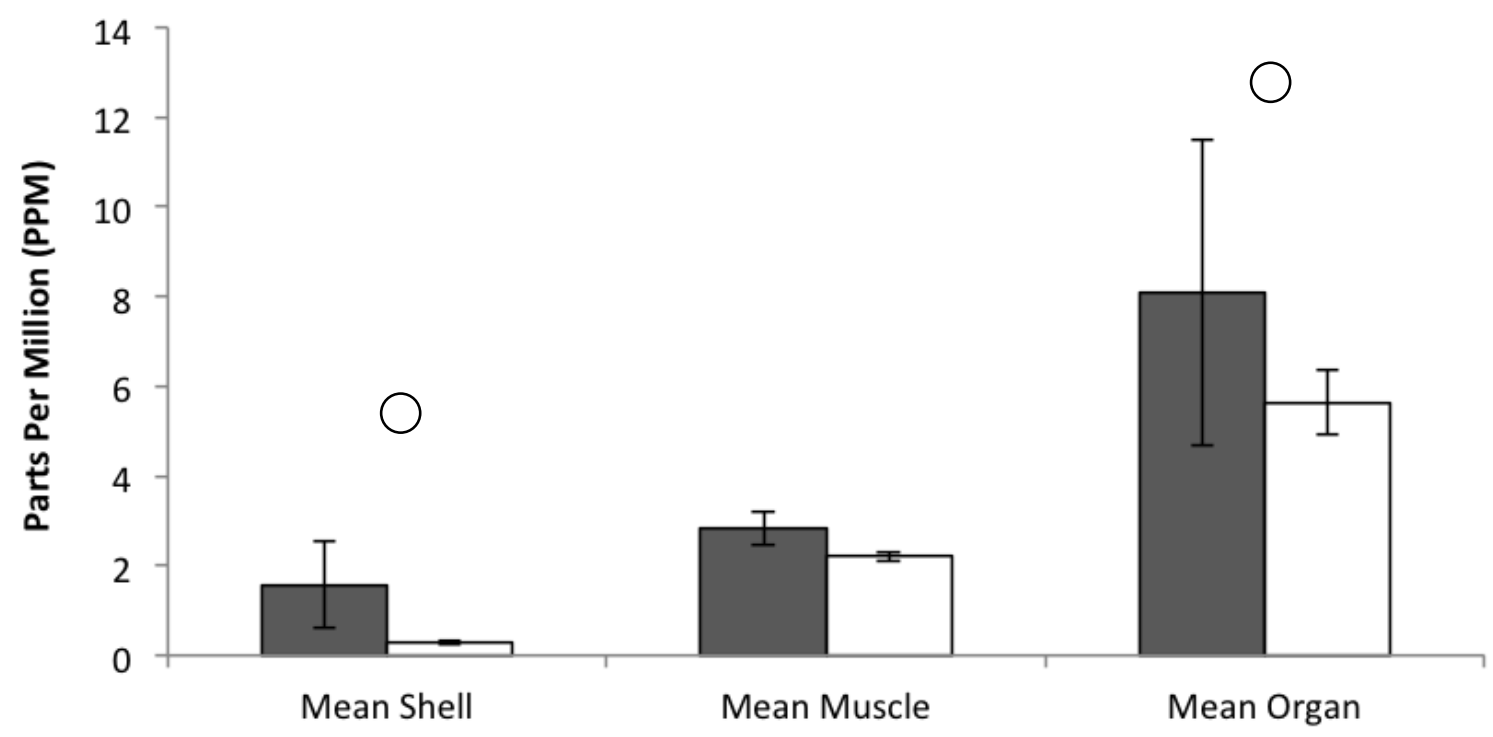

Figure 3.6. Mean copper concentrations in PPM (+/- SE) in three different tissue types for baseline samples and control samples. $n=2$ for controls, $n=3$ for baseline samples. Dark grey bars= baseline samples, white bars $=$ control samples. Circles indicate a significant difference between tissue types. 


\section{Neodymium}

Table 3.2. Two-way ANOVA tables for neodymium results. Significant $p$-values are in bold

\begin{tabular}{|c|c|c|c|c|}
\hline \multicolumn{5}{|c|}{ Neodymium $0.2 \mu / L$ and Controls } \\
\hline Factor & $\mathrm{DF}$ & $\begin{array}{ll}\text { Sum of } \\
\text { Squares }\end{array}$ & F-statistic & p-value \\
\hline Treatment & 1 & 4.54 & 106.39 & $<0.0001$ \\
\hline Tissue Type & 2 & 1.09 & 12.8 & 0.001 \\
\hline Treatment ${ }^{\star}$ Tissue & 2 & 0.474 & 5.56 & 0.0196 \\
\hline Error & 12 & & & \\
\hline \multicolumn{5}{|c|}{ Controls and Baseline Samples } \\
\hline Factor & DF & $\begin{array}{l}\text { Sum of } \\
\text { Squares }\end{array}$ & F-statistic & $p$-value \\
\hline Treatment & 1 & 0.263 & 0.21 & 0.6598 \\
\hline Tissue Type & 2 & 2.52 & 9.92 & 0.0053 \\
\hline Treatment ${ }^{\star}$ Tissue & 2 & 0.03 & 0.12 & 0.887 \\
\hline Error & 9 & & & \\
\hline
\end{tabular}

\section{Comparing animals exposed to the copper/neodymium treatment and control animals.}

There was a significant interaction between the treatments and tissue type for the controls and those exposed to the copper/neodymium treatment (Table 3.2). The animals exposed to the neodymium doped water did however have generally higher concentrations of $\mathrm{Nd}$ than those in the control treatment (Figure 3.7). The interaction likely arises because there was more neodymium in the shell of the doped animals than in their organs or muscle, while the control animals contained more $\mathrm{Nd}$ in their organs than in the other tissue types (Figure 3.7). 


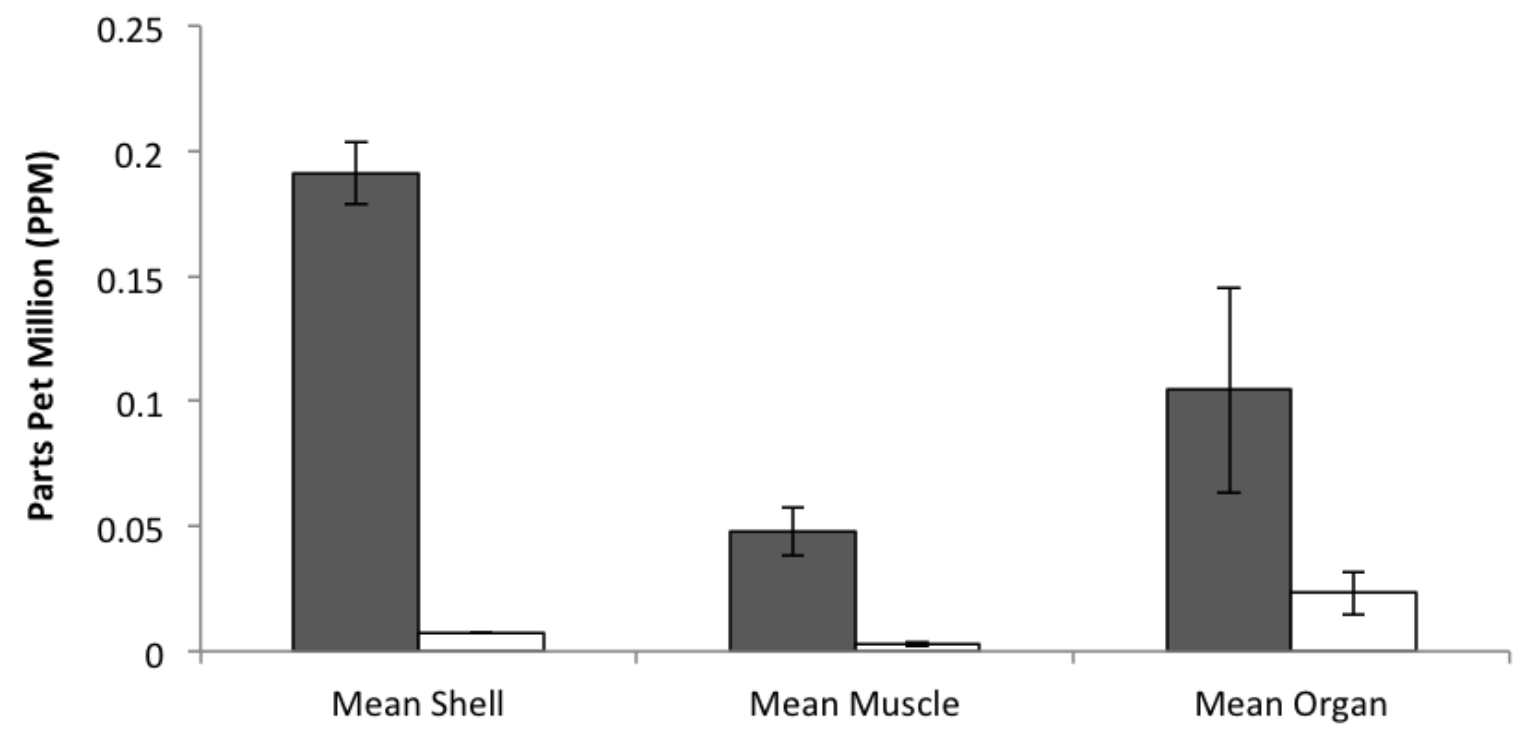

Figure 3.7. Mean neodymium concentrations in PPM (+/- SE) in three different tissue types for copper/neodymium treatment samples and control samples. $n=2$ for controls, $\mathrm{n}=4$ for treatment samples. Dark grey bars $=$ treatment samples, white bars $=$ control samples.

\section{Comparing baseline animals and control animals.}

There was no significant interaction between the treatments and tissue type (Table 3.2).

There was also no significant difference in neodymium concentration between the baseline samples and the control samples (Table 3.2). Neodymium concentrations were slightly higher in the shell and organs of the baseline samples, but not at significant levels (Figure 3.8).

There was a significant difference between the concentrations of neodymium in the tissue types (Table 3.2). The Tukey test showed that the muscle and organ tissue were significantly different from each other, and neither were different from the shell tissue. In the baseline samples, there was up to twenty times as much $\mathrm{Nd}$ in the organ tissue than the muscle, and nearly ten times as much $\mathrm{Nd}$ in the control organs than control muscle (Figure 3.8). The shell also contained more neodymium than the muscle, but less than that of the organs (Figure 3.8). 


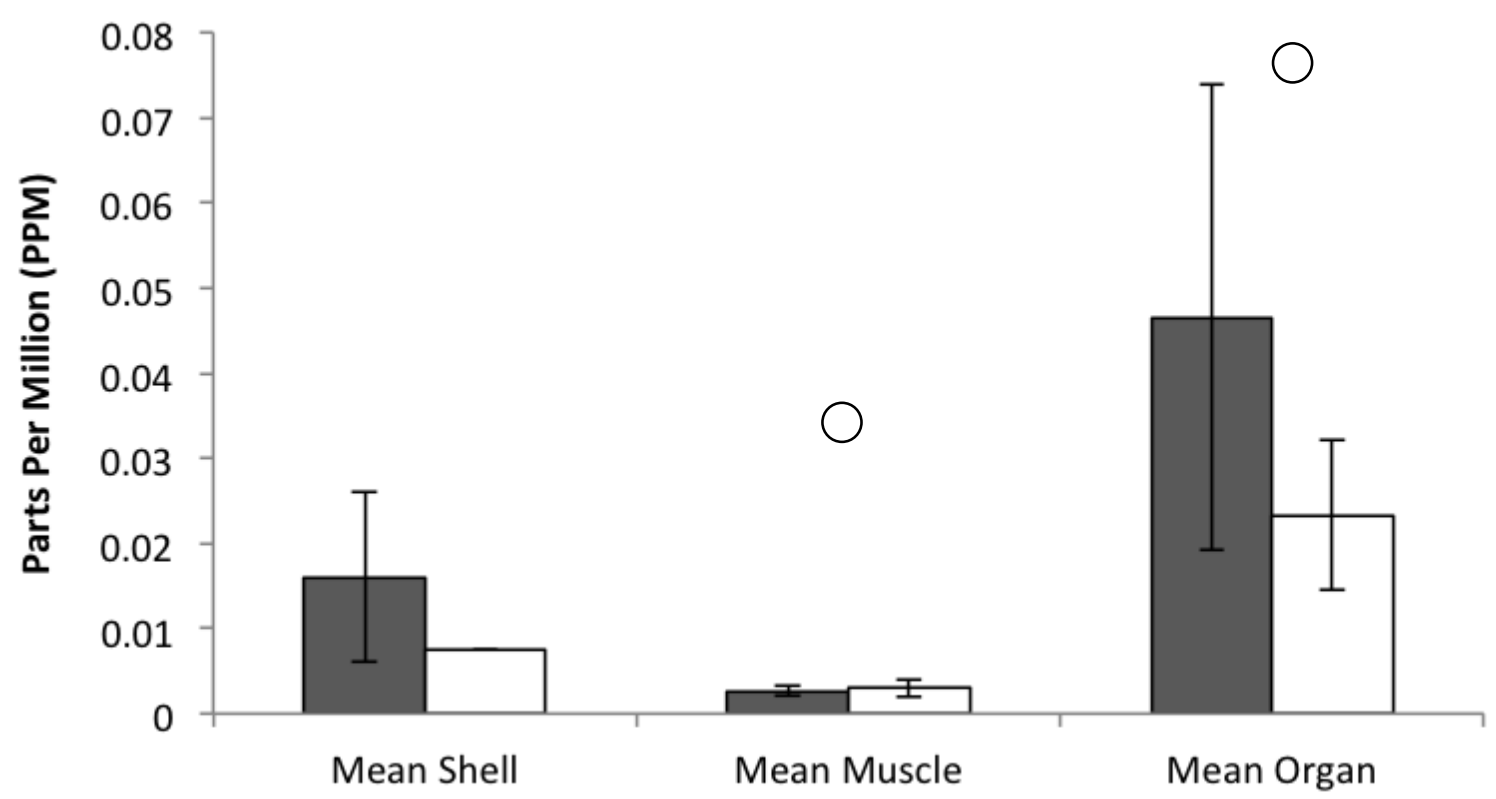

Figure 3.8. Mean neodymium concentrations in PPM (+/- SE) in three different tissue types for baseline samples and control samples. $n=2$ for controls, $n=3$ for baseline samples. Dark grey bars= baseline samples, white bars $=$ control samples. Circles indicate a significant difference between tissue types.

\section{Other elements}

Of the ten other elements that were analysed, seven varied significantly across tissue type, two varied significantly across treatments, and three had significant interactions between the factors.

Tables 3.3i-x. Two-way ANOVA results for the effects of treatment and tissue type and the interaction on the concentration of metals in Jasus edwardsii. Significant $p$-values are in bold.

\section{Caesium (Cs)}

\begin{tabular}{|l|l|l|l|l|}
\hline Factor & DF & $\begin{array}{l}\text { Sum of } \\
\text { Squares }\end{array}$ & F-statistic & p-value \\
\hline Treatment & 2 & 0.0007 & 0.81 & 0.461 \\
\hline Tissue Type & 2 & 0.0154 & 17.82 & $<0.0001$ \\
\hline Treatment ${ }^{\star}$ Tissue & 4 & 0.0069 & 4.03 & $\mathbf{0 . 0 1 6 7}$ \\
\hline Error & 18 & & & \\
\hline
\end{tabular}


Cerium (Ce)

\begin{tabular}{|l|l|l|l|l|}
\hline Factor & DF & $\begin{array}{l}\text { Sum of } \\
\text { Squares }\end{array}$ & F-statistic & p-value \\
\hline Treatment & 2 & 0.031 & 0.11 & 0.901 \\
\hline Tissue Type & 2 & 3.647 & 12.42 & $\mathbf{0 . 0 0 0 4}$ \\
\hline Treatment*Tissue & 4 & 0.085 & 0.14 & 0.963 \\
\hline Error & 18 & & & \\
\hline
\end{tabular}

Iron (Fe)

\begin{tabular}{|l|l|l|l|l|}
\hline Factor & DF & $\begin{array}{l}\text { Sum of } \\
\text { Squares }\end{array}$ & F-statistic & p-value \\
\hline Treatment & 2 & 0.813 & 6.57 & $\mathbf{0 . 0 0 7 2}$ \\
\hline Tissue Type & 2 & 5.6 & 45.31 & $<\mathbf{0 . 0 0 0 1}$ \\
\hline Treatment ${ }^{\star}$ Tissue & 4 & 0.334 & 1.35 & 0.291 \\
\hline Error & 18 & & & \\
\hline
\end{tabular}

\section{Lead (Pb)}

\begin{tabular}{|l|l|l|l|l|}
\hline Factor & DF & $\begin{array}{l}\text { Sum of } \\
\text { Squares }\end{array}$ & F-statistic & $p$-value \\
\hline Treatment & 2 & 0.716 & 7.56 & $\mathbf{0 . 0 0 4 1}$ \\
\hline Tissue Type & 2 & 1.058 & 11.16 & $\mathbf{0 . 0 0 0 7}$ \\
\hline Treatment*Tissue & 4 & 0.389 & 2.05 & 0.13 \\
\hline Error & 18 & & & \\
\hline
\end{tabular}


Lanthanum (La)

\begin{tabular}{|l|l|l|l|l|}
\hline Factor & DF & $\begin{array}{l}\text { Sum of } \\
\text { Squares }\end{array}$ & F-statistic & $p$-value \\
\hline Treatment & 2 & 0.076 & 0.38 & 0.689 \\
\hline Tissue Type & 2 & 5.888 & 29.31 & $<0.0001$ \\
\hline Treatment ${ }^{*}$ Tissue & 4 & 0.163 & 0.41 & 0.802 \\
\hline Error & 18 & & & \\
\hline
\end{tabular}

Manganese (Mn)

\begin{tabular}{|l|l|l|l|l|}
\hline Factor & DF & $\begin{array}{l}\text { Sum of } \\
\text { Squares }\end{array}$ & F-statistic & $p$-value \\
\hline Treatment & 2 & 0.0089 & 0.23 & 0.797 \\
\hline Tissue Type & 2 & 0.911 & 23.39 & $<0.0001$ \\
\hline Treatment ${ }^{\star}$ Tissue & 4 & 0.244 & 3.13 & $\mathbf{0 . 0 4}$ \\
\hline Error & 18 & & & \\
\hline
\end{tabular}

Molybdenum (Mo)

\begin{tabular}{|l|l|l|l|l|}
\hline Factor & DF & $\begin{array}{l}\text { Sum of } \\
\text { Squares }\end{array}$ & F-statistic & p-value \\
\hline Treatment & 2 & 0.004 & 0.05 & 0.948 \\
\hline Tissue Type & 2 & 4.458 & 62.66 & $<0.0001$ \\
\hline Treatment ${ }^{*}$ Tissue & 4 & 0.155 & 1.09 & 0.392 \\
\hline Error & 18 & & & \\
\hline
\end{tabular}


Samarium (Sm)

\begin{tabular}{|l|l|l|l|l|}
\hline Factor & DF & $\begin{array}{l}\text { Sum of } \\
\text { Squares }\end{array}$ & F-statistic & $p$-value \\
\hline Treatment & 2 & 0.083 & 0.37 & 0.695 \\
\hline Tissue Type & 2 & 3.668 & 16.32 & $<0.0001$ \\
\hline Treatment ${ }^{\star}$ Tissue & 4 & 0.171 & 0.38 & 0.819 \\
\hline Error & 18 & & & \\
\hline
\end{tabular}

Uranium (U)

\begin{tabular}{|l|l|l|l|l|}
\hline Factor & DF & $\begin{array}{l}\text { Sum of } \\
\text { Squares }\end{array}$ & F-statistic & $p$-value \\
\hline Treatment & 2 & 0.086 & 0.46 & 0.637 \\
\hline Tissue Type & 2 & 9.217 & 49.62 & $<0.0001$ \\
\hline Treatment ${ }^{*}$ Tissue & 4 & 0.778 & 2.09 & 0.124 \\
\hline Error & 18 & & & \\
\hline
\end{tabular}

\section{Interaction effects.}

There was a significant interaction between treatment and tissue type for caesium, manganese, and rubidium, so the effects cannot be described independently. In the control and baseline samples, caesium and rubidium were most highly accumulated in the muscle tissue, while the animals in the copper/neodymium treatment took up more $\mathrm{Cs}$ and $\mathrm{Rb}$ into their organ tissue (Figure $3.9 \& 3.10$ ). Manganese was taken up at a higher rate into the organ tissue for the control and treatment samples, however the baseline specimens had similar concentrations of $\mathrm{Mn}$ in their shell and organ tissues (Figure 3.11). 


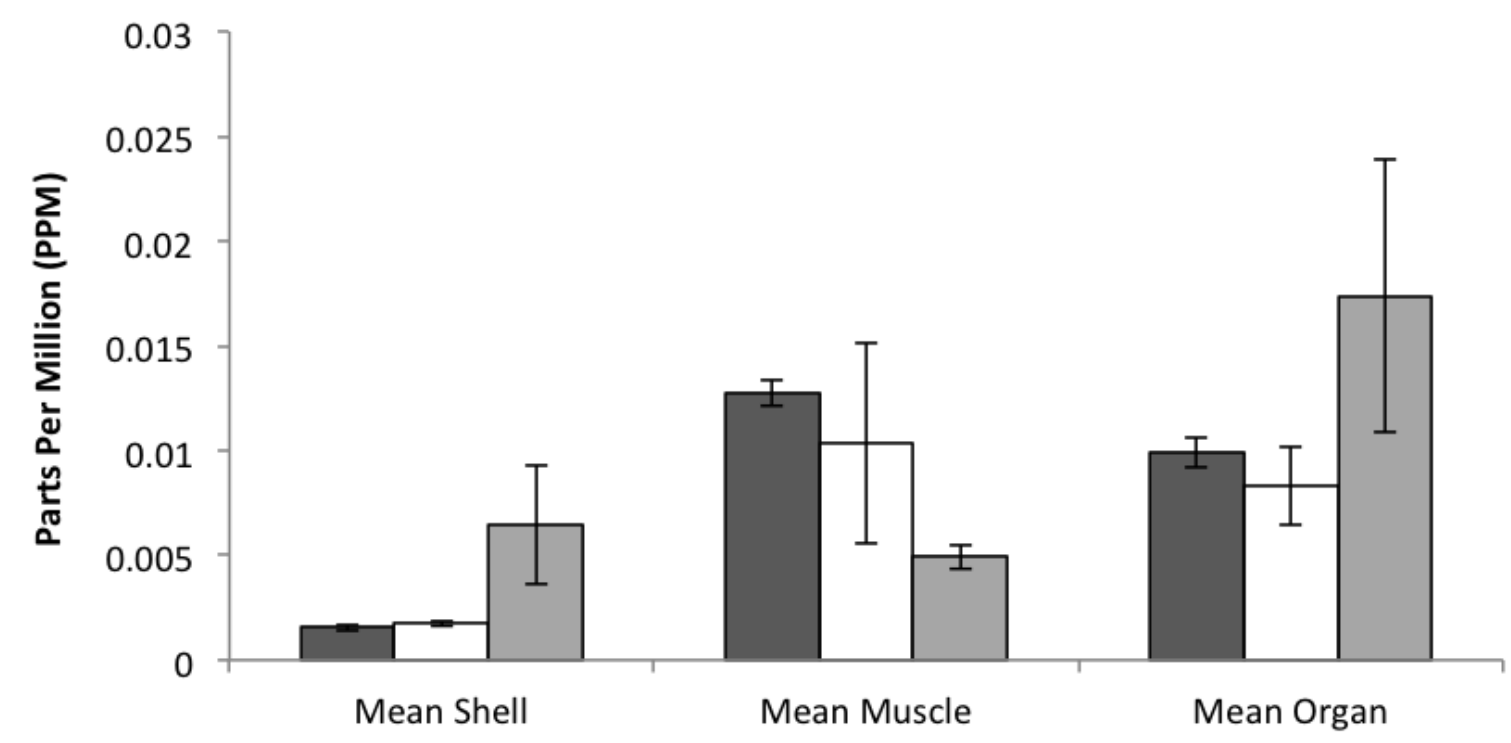

Figure 3.9. Mean caesium concentrations in PPM (+/- SE) in three different tissue types for $J$. edwardsii juveniles exposed to an elevated copper/neodymium treatment, and baseline and control samples. $n=2$ for controls, $n=3$ for baseline samples, $n=4$ for treatment samples. Dark grey bars $=$ metal treatment samples, white bars $=$ control samples, light grey bars= baseline samples.

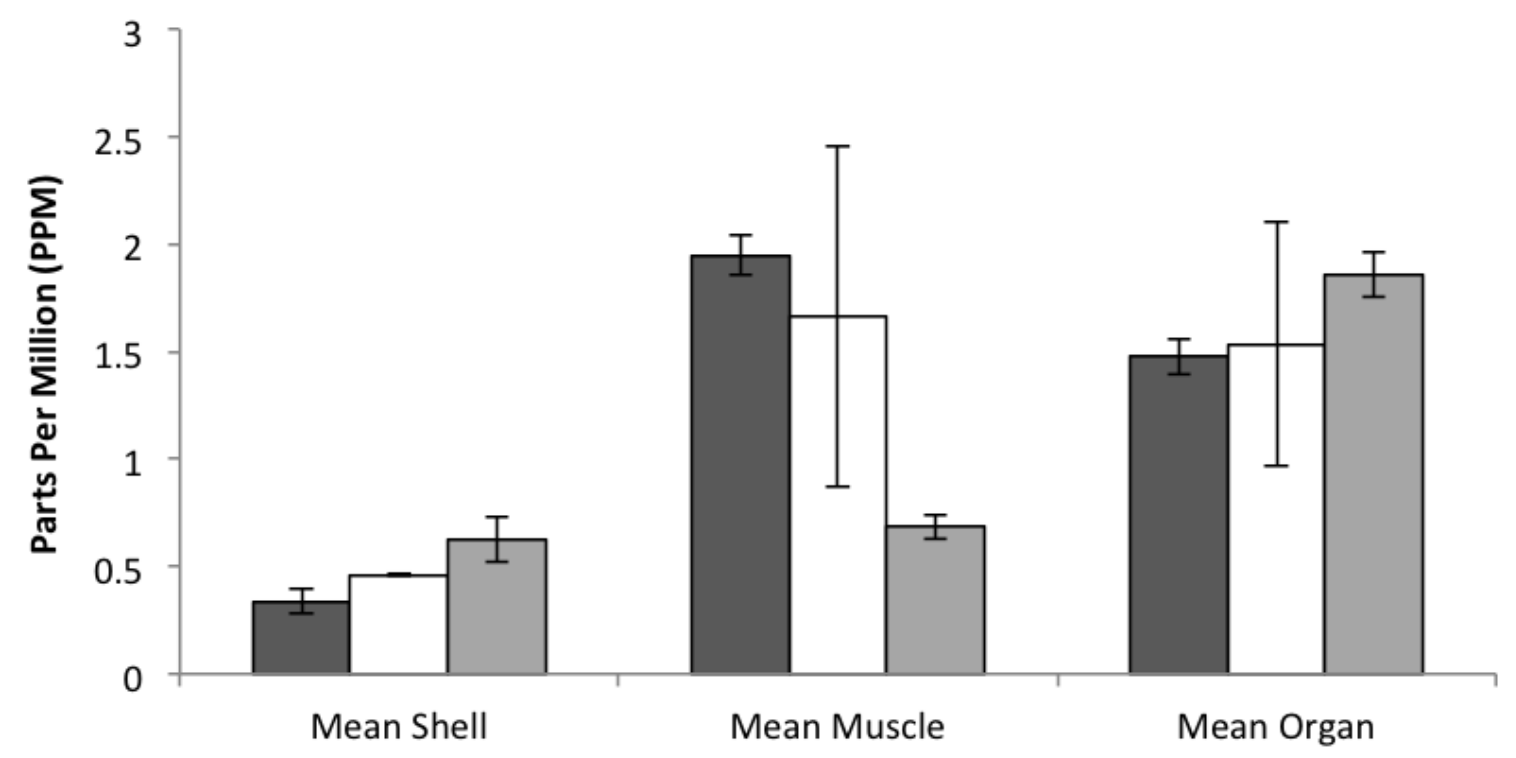

Figure 3.10. Mean rubidium concentrations in PPM (+/- SE) in three different tissue types for $J$. edwardsii juveniles exposed to an elevated copper/neodymium treatment, and baseline and control samples. $n=2$ for controls, $n=3$ for baseline samples, $n=4$ for treatment samples. Dark grey bars $=$ metal treatment samples, white bars $=$ control samples, light grey bars= baseline samples. 


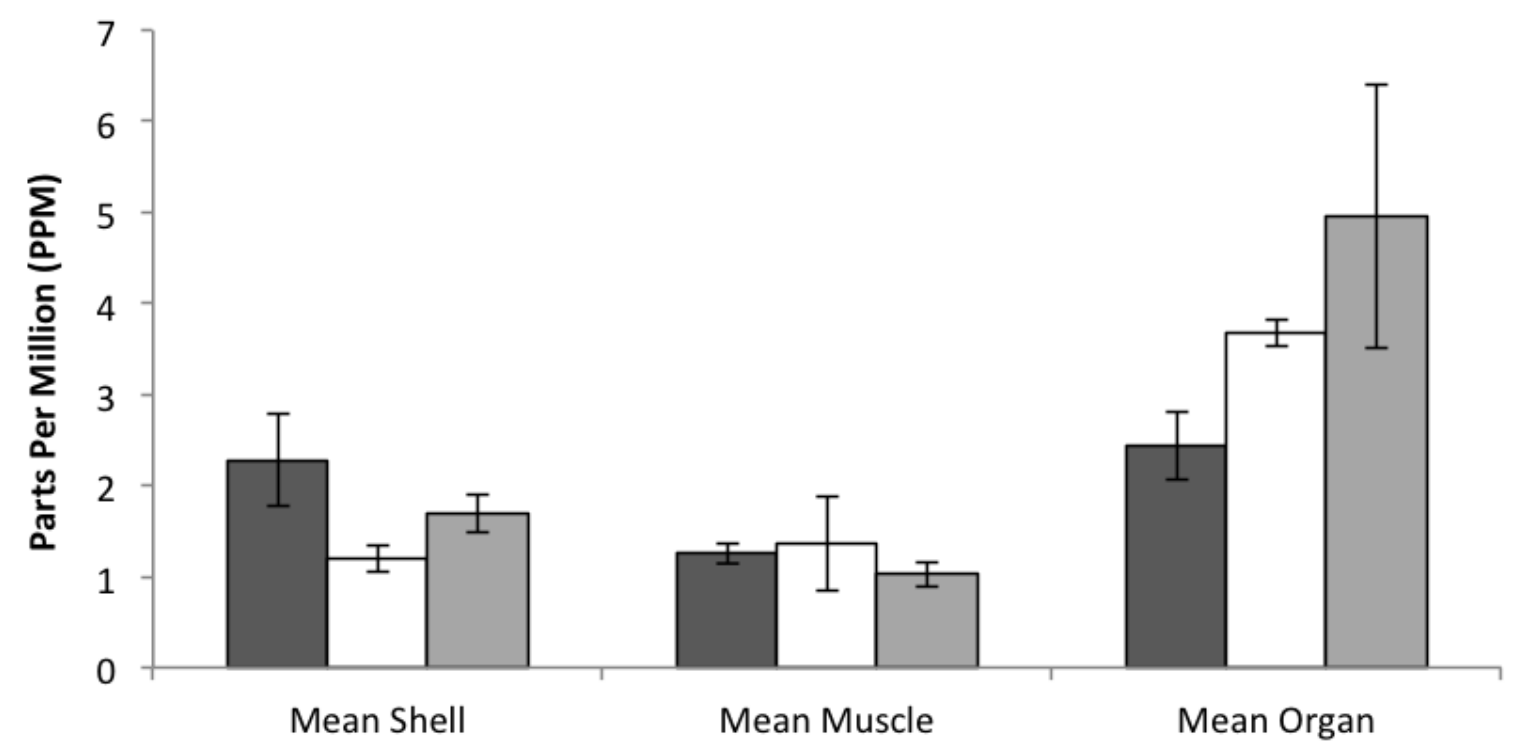

Figure 3.11. Mean manganese concentrations in PPM (+/- SE) in three different tissue types for J. edwardsii juveniles exposed to an elevated copper/neodymium treatment, and baseline and control samples. $n=2$ for controls, $n=3$ for baseline samples, $n=4$ for treatment samples. Dark grey bars $=$ metal treatment samples, white bars $=$ control samples, light grey bars= baseline samples.

\section{Treatment Effects}

Iron and lead were both significantly different between the treatment types. There was a significantly higher concentration of iron in the baseline samples than those in the neodymium/copper treatment, and no difference between the controls and the other treatments (Figure 3.12). In contrast, lead was higher in the $\mathrm{Cu} / \mathrm{Nd}$ treatment samples compared to the baseline, although again, there was no difference between the treatment and controls, or baseline and controls (Figure 3.13). Examination of the raw data of the specimens showed considerable variation in lead concentration between individual crayfish. 


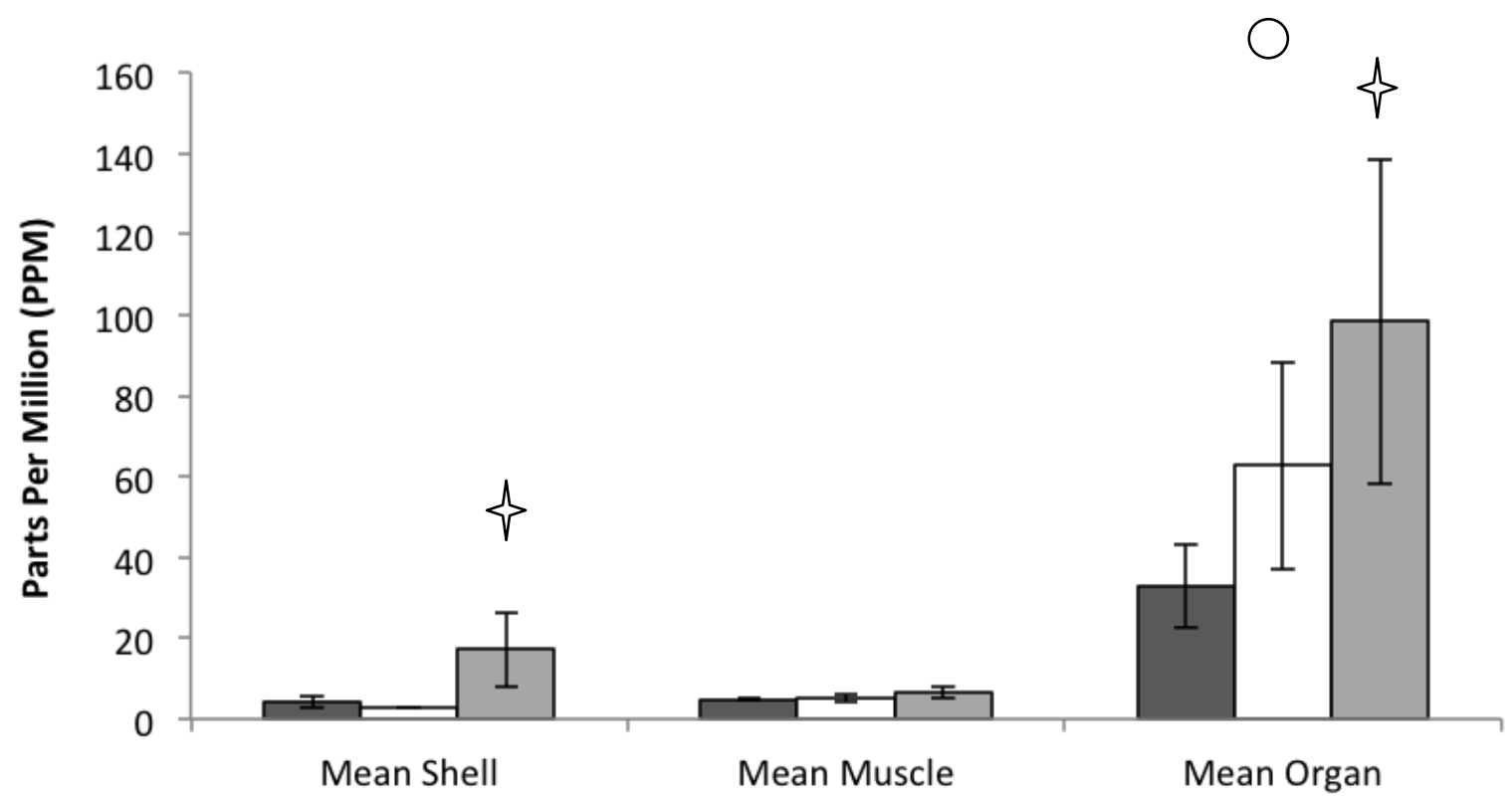

Figure 3.12. Mean iron concentrations in PPM (+/- SE) in three different tissue types for $J$. edwardsii juveniles exposed to an elevated copper/neodymium treatment, and baseline and control samples. $n=2$ for controls, $n=3$ for baseline samples, $n=4$ for treatment samples. Dark grey bars $=$ metal treatment samples, white bars $=$ control samples, light grey bars= baseline samples. Stars indicate a significant difference between treatments. Circles indicate a significant difference between tissue types.

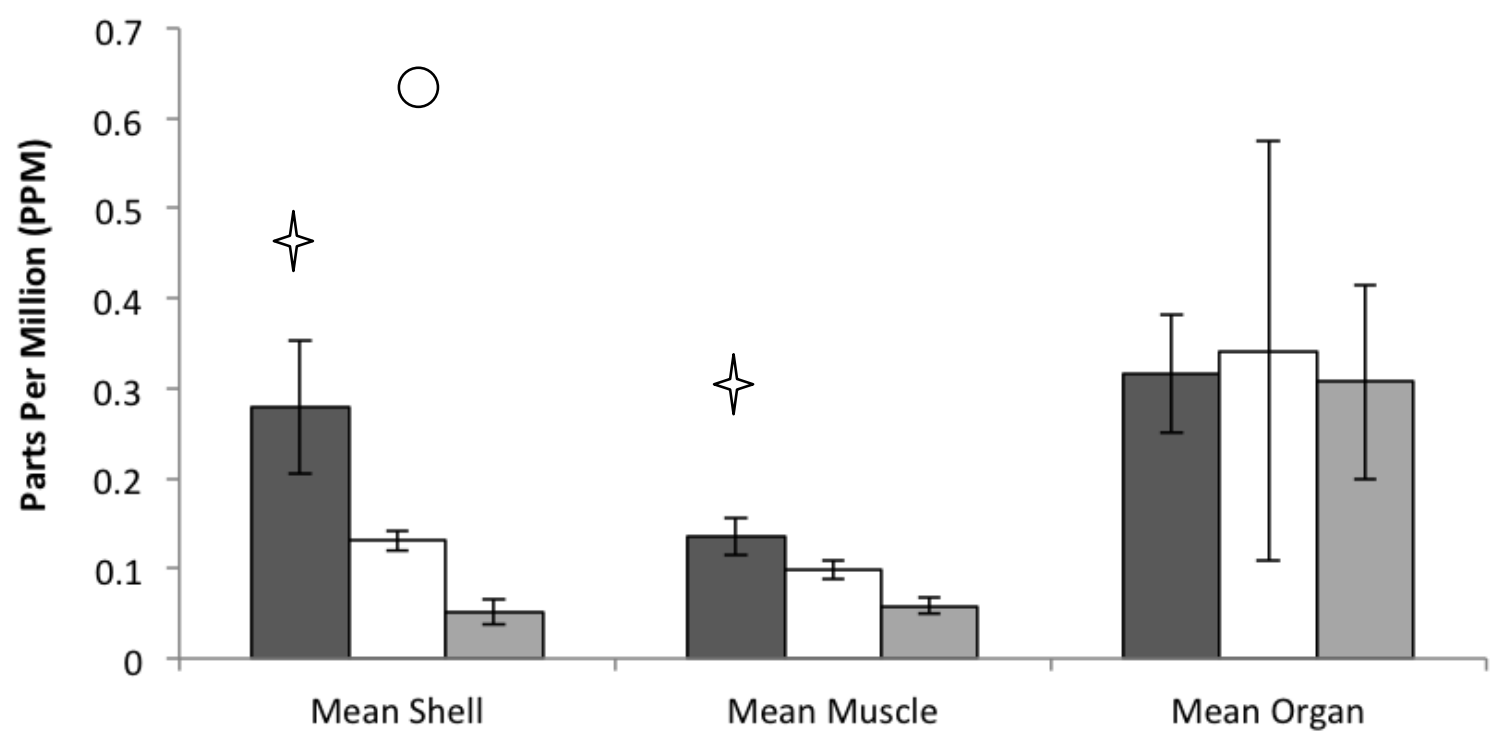

Figure 3.13. Mean lead concentrations in PPM (+/- SE) in three different tissue types for J. edwardsii juveniles exposed to an elevated copper/neodymium treatment, and baseline and control samples. $n=2$ for controls, $n=3$ for baseline samples, $n=4$ for treatment samples. Dark grey bars $=$ metal treatment samples, white bars $=$ control samples, light grey bars= baseline samples. Stars indicate a significant difference between treatments. Circles indicate a significant difference between tissue types. 


\section{Tissue Type Effects.}

All metals were significantly different between tissue types, aside from those with interactions (Figure 3.14). All of the metals were most highly concentrated in the organ tissue, and least in the muscle, with the exception of iron. Iron was highest in the organs, although the shell tissue of the treated samples and the controls was lower in iron than the muscle (Figure 3.12). Lead also was different between treatments, but generally the distribution of lead between tissue types was highest in the organs and lowest, or similar in concentration, in the muscle and shell (Figure 3.13).

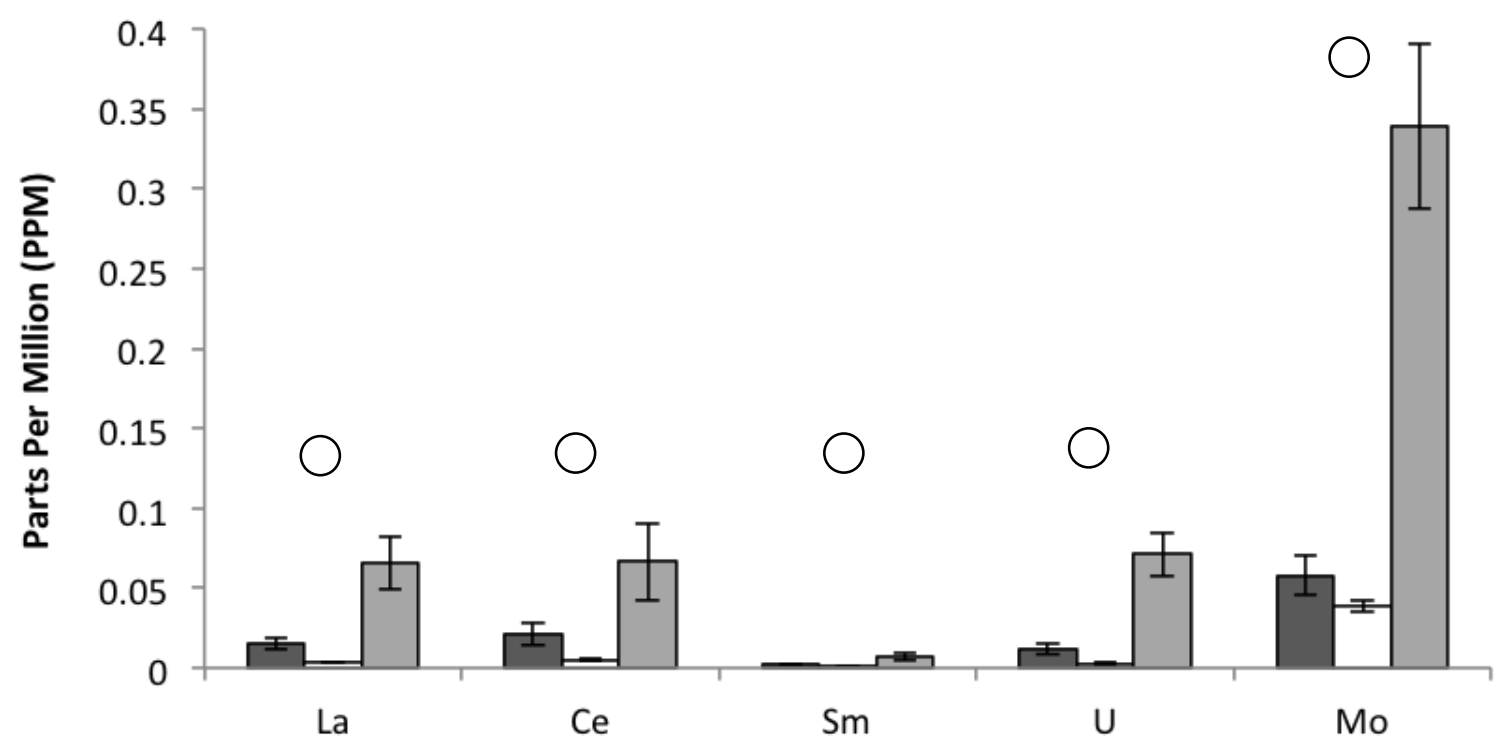

Figure 3.14. Mean concentrations of five metals in PPM (+/- SE), in three different tissue types for $J$. edwardsii juveniles exposed to an elevated copper/neodymium treatment, and baseline and control samples. $n=2$ for controls, $n=3$ for baseline samples, $n=4$ for treatment samples. Dark grey bars $=$ metal treatment samples, white bars $=$ control samples, light grey bars= baseline samples. Circles indicate a significant difference between tissue types. 


\section{Water Sample Analysis.}

The VUCEL water sample was filtered seawater, and the concentration of copper in the VUCEL water is low compared to the water samples from the sites in Chapter One. With the exception of vanadium, the other metals measured were also lower in the VUCEL water. It is most similar to the water sample taken from Tarakena Bay, which is also the site closest in proximity. This sample confirms that the metal concentrations in filtered seawater were low and elevating levels of trace metals would not unintentionally cross a toxicity threshold.

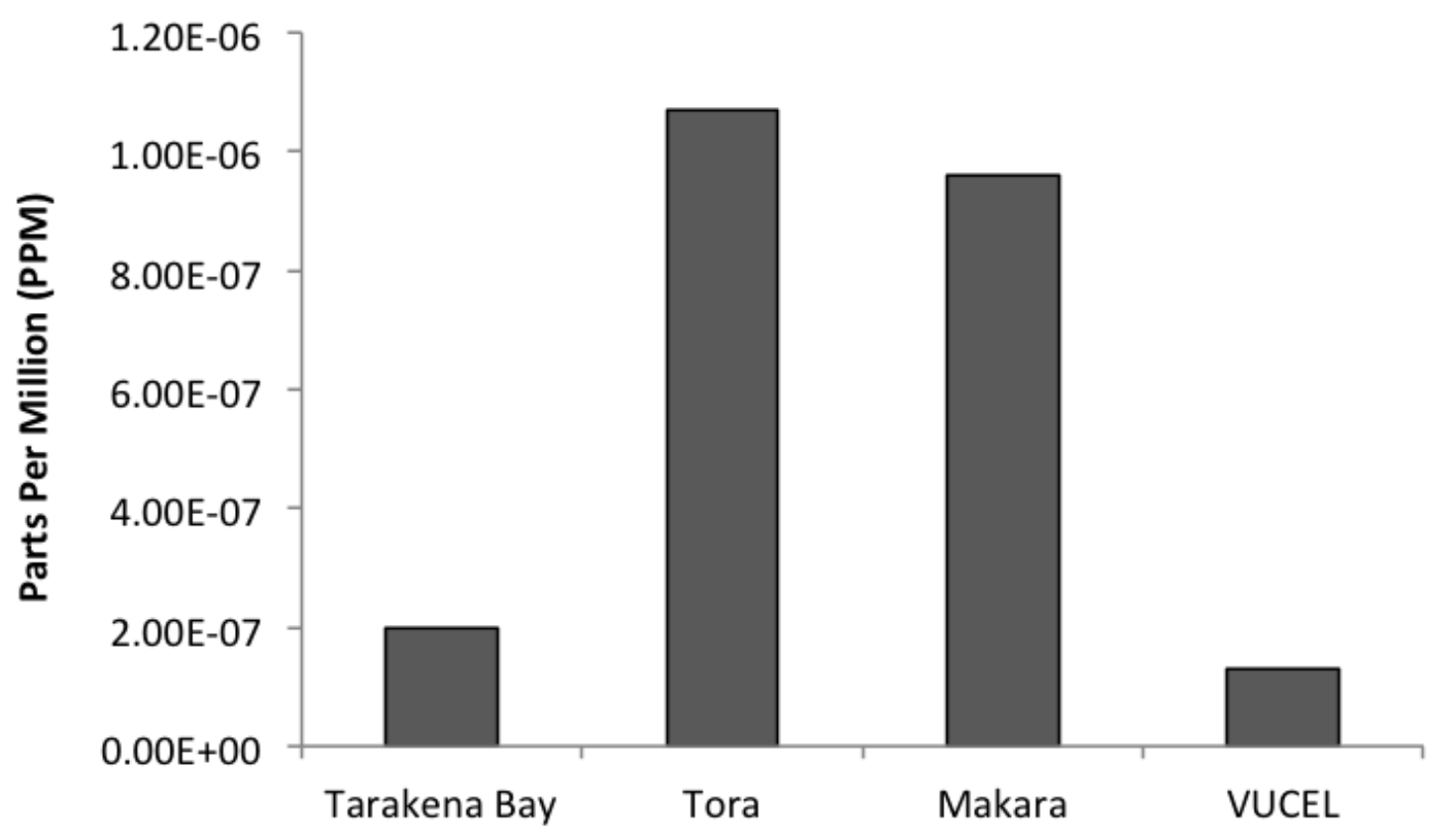

Figure 3.15. Mean scandium concentration in PPB in water samples from four locations. 


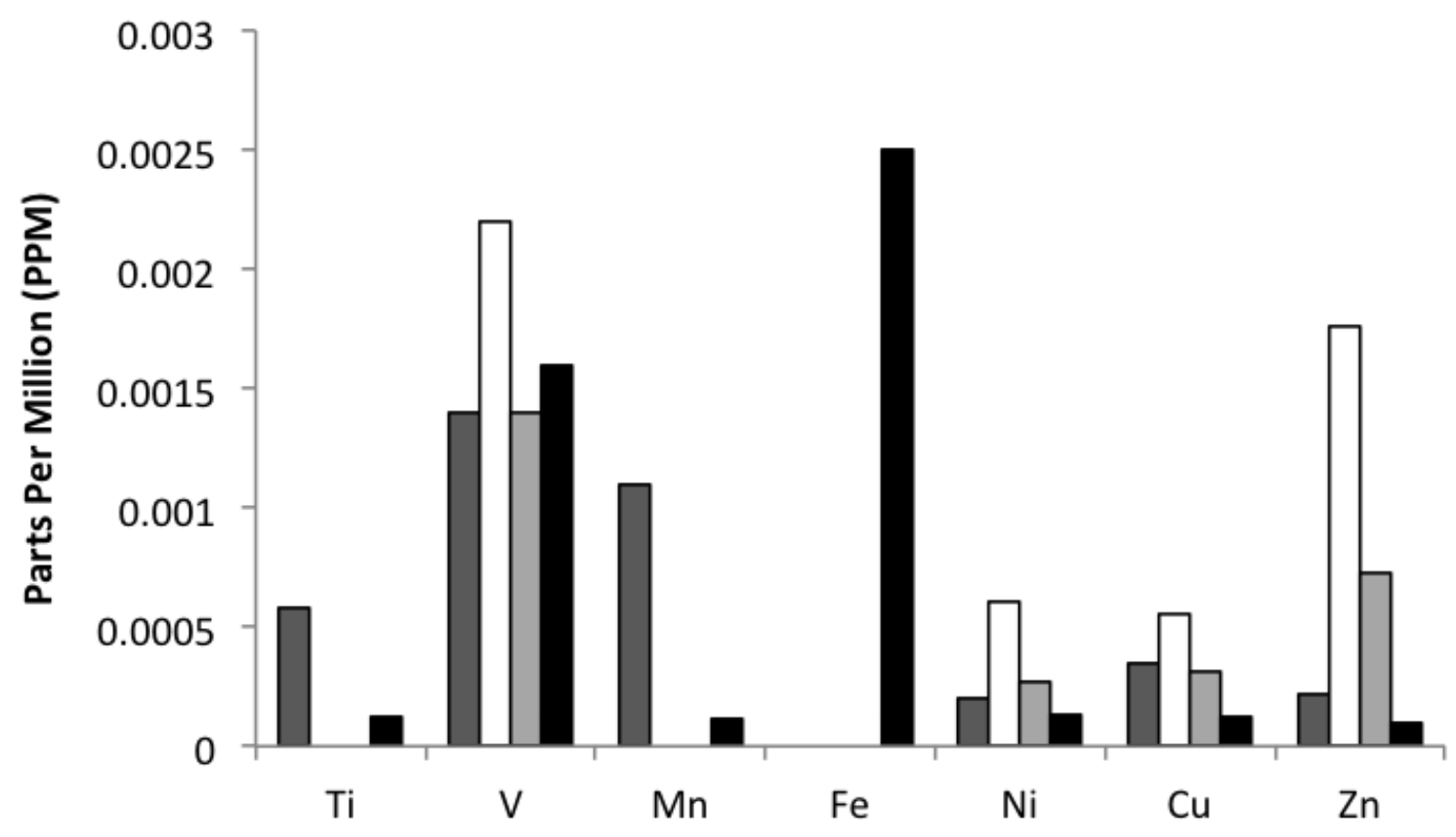

A

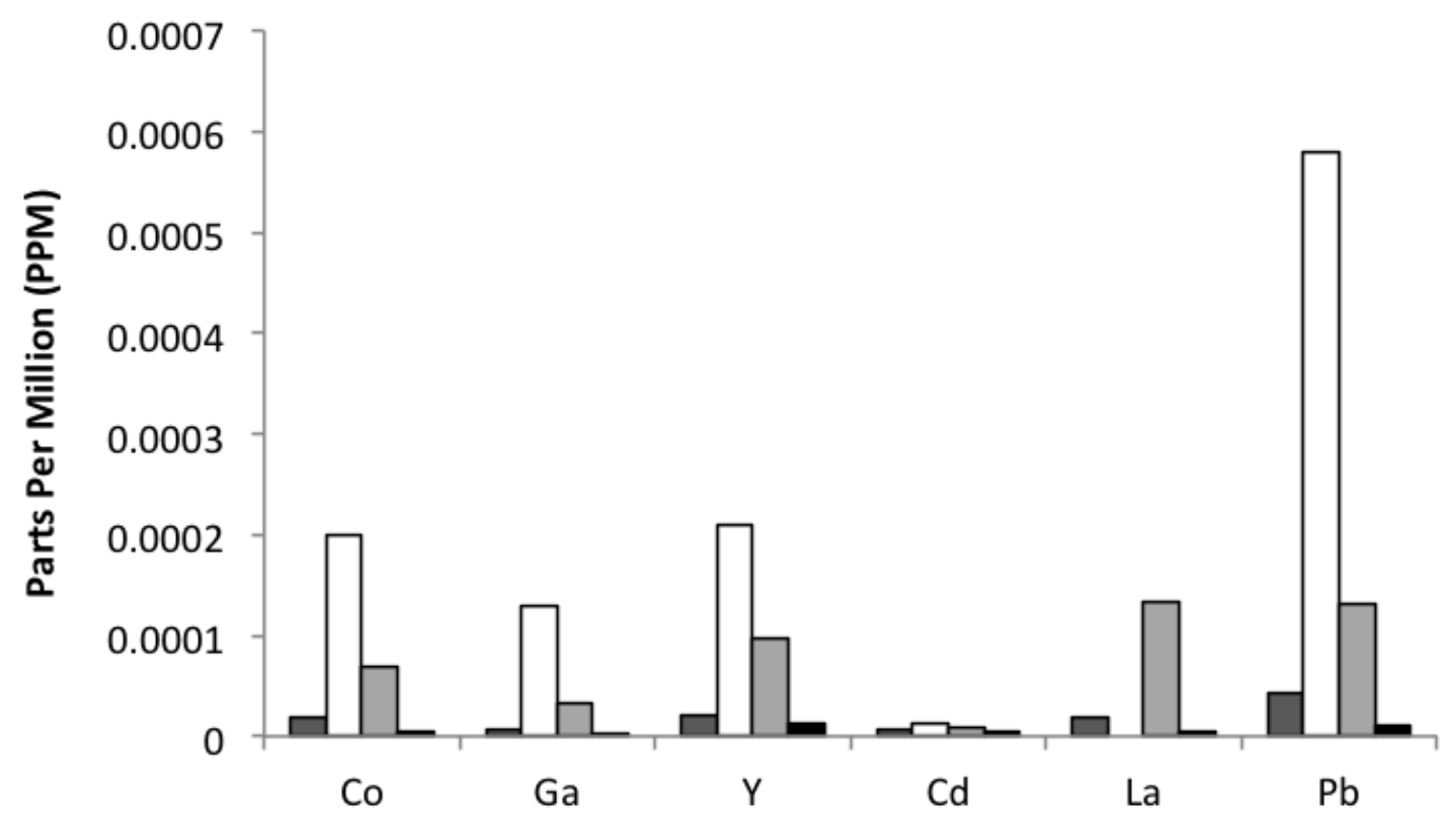

B

Figure 3.16 A and B. Mean trace element concentrations in PPB in water samples from four locations. Dark grey bars= Tarakena Bay, white bars= Tora, light grey bars= Makara, black bars = VUCEL. Absence of a bar indicates the concentration was too high to be accurately measured. 


\section{DISCUSSION}

\section{Moult Experiment}

I hypothesized that there would be significantly more copper absorbed by moults exposed to seawater with a high copper concentration $(200 \mu \mathrm{g} / \mathrm{L})$ than those exposed to the low concentration $(20 \mu \mathrm{g} / \mathrm{L})$, or in the control group. The results of the moult experiment support this hypothesis. The moults exposed to the two elevated copper treatments had significantly higher concentrations of copper than the controls, and there were physical differences in the robustness of the moults as well, that reflected the strength of the copper treatment they were exposed to. There was no difference in concentration in any of the other metals that were analysed, suggesting that the differences in copper in the exoskeletons were due to absorption of copper from the water.

Despite the small sample size, the differences in copper concentration between the treatments were so extreme that it would be expected that more replicates would follow the same trends. It was also valuable to have the information to be able to properly conduct the doping experiment, as it showed that moults left for an extended period of time in the experiment buckets may passively take up excess metals from the water. This could confound results, as the treated buckets were specifically calculated for the experiment and as shed exoskeletons take up metals, the true amount of copper left in the seawater would become unknown if the moults were left alone. It was therefore necessary to monitor the doping experiment tanks frequently and remove any moults as quickly as possible.

The results of this experiment are similar to those for other crustacean species. Shrimp and crawfish shells were found to metals from solutions, and chitosan derived from Cape rock lobsters were also found to absorb copper (Osifo et al., 2009; Beeram et al., 2012; Mohanasrinivasan et al., 2014). Chitosan from snails has also been observed to absorb lead (Edokpayi et al., 2015). These results also have practical applications as a potential bioremediation technique for the 
environment, as well as the aforementioned implication for the doping experiment.

\section{Doping Experiment}

\section{Accumulation of copper}

The hypothesis that there would be no significant difference between the copper treated and control samples was not supported. The samples that were exposed to the $20 \mu \mathrm{g} / \mathrm{L}$ treatment had overall higher concentrations of copper than the controls. The hypothesis that there would be a difference between tissue types for copper was supported. Organ tissue contained significantly more copper than shell, though muscle was not different to either of the other tissue types. There was no significant difference between the baseline animals and the controls. There was a difference between tissue types, as the organs had significantly higher copper concentrations than the shell tissue.

As none of the crayfish in the $20 \mu \mathrm{g} / \mathrm{L}$ treatment were severely impacted by the treatment, it suggests that they were able to bioregulate copper. This is supported by the concentration of copper in the treatment organs relative to those of the baseline. The mean concentrations in the organs are very similar, despite the other tissue types exposed to the $20 \mu \mathrm{g} / \mathrm{L}$ treatment having considerably higher amounts of $\mathrm{Cu}$ compared to the controls and baseline animals. This indicates that although copper levels in the water were high for the animals in the doped water, they were able to regulate it in their organs to a more tolerable concentration. The difference between the elevated treatment animals and the controls could be due to natural variation and future study with a larger sample size could confirm this. The $200 \mu \mathrm{g} / \mathrm{L}$ treatment was planned to confirm that the bioregulation of copper, as this concentration was thought to be too high for the animals to tolerate through detoxification. If this had been the case, comparison with the $20 \mu \mathrm{g} / \mathrm{L}$ treatment was predicted to show significantly more accumulation in all tissue types of the high dosage animals. Although the animals were not able to be analysed due to time constraints, only four being able to survive the 
$200 \mu \mathrm{g} / \mathrm{L}$ treatment for more than a week indicates that they were unable to bioregulate this high concentration. These animals remain in the possession of NIWA to be analysed if possible at a later date.

Other metal doping experiments usually focus on the physiological effects of metals on organisms (Lahman \& Moore, 2015; Ward et al., 2015a; Chandurvelan et al., 2017; Zhao et al., 2019). The majority of trace metal studies focus on adult organisms, and tend to use much higher concentrations - for copper experiments, between $450 \mu \mathrm{g} / \mathrm{L}$ and $3 \mathrm{mg} / \mathrm{L}$ has been used for sublethal concentrations (Lahman \& Moore, 2015; Zhao et al., 2019). A study on adult animals using relatively low copper concentrations (between 125 and $500 \mu \mathrm{g} / \mathrm{L}$ ) yielded similar patterns to this thesis in their results (Zia \& Alikhan, 1989). There is little work on juvenile crustaceans, however studies on juvenile freshwater crayfish showed they are tolerant to sublethal levels of trace metals, which for the species used were over $150 \mu \mathrm{g} / \mathrm{L}$, much higher than what was tolerable for $\mathrm{J}$. edwardsii (Khan et al., 2006; Khan \& Nugegoda, 2007). Another juvenile decapod study on ridgetail white prawns focused solely on lethal concentrations of metals, to investigate the potential effects of pollution (Zhang et al., 2014). This indicates the variability of different species' tolerance and ability to regulate and detoxify metals, and the importance of studying a range of life stages, as well as species.

\section{Bioregulation}

The results of this study suggest that Jasus edwardsii juveniles can regulate elevated levels of copper, which is consistent with the results of many crustacean studies (Anderson \& Brower, 1978; Soedarini et al., 2012). Many marine species are able to bioregulate levels of toxins in their bodies through homeostasis. Metallothionein proteins are arguably the most important part of the homeostasisdetoxification process, and are important for assessing cellular responses to heavy metal exposure (Hogstrand \& Haux, 1990; Viarengo \& Nott, 1993). Cellular homeostasis enables organisms to maintain levels of necessary but potentially harmful elements, such as bioessential metals and nutrients, but it can be disrupted by the effects of heavy metals (Gotze et al., 2014). Homeostasis is a complex process, and relies on systems like the ubiquitin-proteasome system which assists in regulation and protein degradation, and disruption by metals can 
lead to disease and cellular dysfunction (Gotze et al., 2014). If the amount of contaminants being taken up exceeds the amount detoxified or excreted, it results in bioaccumulation in tissue cells. Understanding bioaccumulation of heavy metals in cells of aquatic organisms is important for organism health and the health of their communities, as accumulation of toxic metals, even those that are essential elements, can result in physiological problems, reproductive issues, and increased mortality (Fingerman et al., 1996; Jamiska et al., 2011; Pang et al., 2012; Ward et al., 2015a and b).

\section{Bioaccumulation}

Bioaccumulation distribution patterns vary with species, but the tissue type results of this work generally align with previous trace element research (Beeram et al., 2012; Soedarini et al., 2012; Mazlum et al., 2016; Nicolau et al., 2017). As copper is a bioessential element, it is expected to be taken up preferentially in the organs for use. The animals in the $20 \mu \mathrm{g} / \mathrm{L}$ copper treatment had higher concentrations of copper than the controls in all of their tissues, including the muscle, indicating accumulation of the contaminant. Most studies, on decapods and on other organisms, have found the accumulation is highest in the organ, then the exoskeleton (in the case of crustaceans), with muscle containing the least amount of copper (Guner 2007; Beeram et al., 2012; Soedarini et al., 2012; Mazlum et al., 2016; Nicolau et al., 2017). The results of this experiment showed the highest rate of accumulation of copper was in the organs, but in contrast, this study found that even the undoped animals had more copper in their muscle tissue than in their shells. Bioaccumulation patterns are influenced by a number of factors, so this disparity from other studies may be due to the age of the animals, their moult cycle, or a species difference - while other lobsters have been studied in this way, Jasus edwardsii has not been the focus of this type of research, and it is acknowledged that bioaccumulation rates differ considerably between species and taxa (Fukushima et al., 2001; Cresswell et al., 2014). 


\section{Accumulation of neodymium.}

The hypotheses that neodymium would be significantly higher in the $0.2 \mu \mathrm{g} / \mathrm{L}$ treatment, but that there would be no difference between tissue types, could not be supported as there was a significant interaction between the effects of treatment and tissue. Generally, the animals in the treatment had much higher concentrations of $\mathrm{Nd}$ than the controls. However, $\mathrm{Nd}$ was accumulated at a greater rate into the shell of the treated tissue, while the controls had a greater concentration in the organs. As the trends in the baseline and control animals are the same, it suggests that the differences seen in the experiment were due to the elevated Nd treatment, rather than anomalies.

Neodymium is a non-bioessential element, and there is little other work to place it in a biological context. It naturally occurs in very low concentrations, as seen in the baseline and control samples, so it was expected that even a small dose like $0.2 \mu \mathrm{g} / \mathrm{L}$ would increase the concentration to a level that was significantly different from natural levels overall. However, it was not known how it would be taken up into different tissues, and such a low dose was not expected to be accumulated in the organs for detoxification, or stored elsewhere. It would appear though that even this low dose was enough to have a considerable impact on the animals, without being lethal. Although neodymium has not been studied in biology, geochemical analyses of planktonic foraminifera have indicated that it may be incorporated into calcite structures (Roberts et al., 2012). This might explain why the animals exposed to increased neodymium had significantly higher levels in their exoskeletons, causing the interaction effect. The control and baseline animals, however, appear to take up neodymium into their organs. Many metals are taken up into the pancreas and liver to be used and detoxified. It could be that at natural levels, neodymium is taken up and processed like other nonessential elements, but if there is an excess of neodymium in the water, it begins to be incorporated into the exoskeleton for shedding. It is also possible that with short-term exposure, $\mathrm{Nd}$ is accumulated into the organs for excretion, but with continuous exposure to $\mathrm{Nd}$, the animals redirect it into the exoskeleton to be moulted. The animals analysed in this experiment had been exposed for four weeks to the copper/neodymium treatment, and analysis of the specimens that 
were unable to be analysed for this thesis could provide some further insight into how non-essential elements are accumulated and regulated.

\section{Accumulation of other metals.}

Seven of the ten other metals analysed were significantly different between tissue type, including lead and iron, which were also different between treatments. For those that were different between tissue type only, this indicates that they were not impacted by the presence of copper and neodymium. The majority of the metals analysed were not biologically essential, so the tissue type differences are likely due to being accumulated into the organs for detoxification. Due to the small sample size, it is not possible to tell whether iron and lead being different between the treatment types is due to natural variation, contamination of the samples, or if these metals are affected by the presence of copper or neodymium.

Caesium, manganese, and rubidium all had significant interactions between sample type and tissue type. The tissue which these elements were taken up into depended on the treatment type, which could suggest that these elements were affected by the copper/neodymium treatment. Manganese is an essential element, and was considerably lower in the organs of doped animals than in baseline or control samples. It has also been identified as interacting with trace metals, including copper, in rodents, so could have been influenced by exposure to $\mathrm{Cu}$ (Mercandante et al., 2016; Foster et al., 2017). Caesium and rubidium have no known biological function but are taken up in a similar way to potassium. Whether potassium and copper have an interaction effect in crustaceans is debatable, but it could explain why $\mathrm{Cs}$ and $\mathrm{Rb}$ were influenced by the copper/neodymium treatment (De Schamphelare \& Janssen, 2002).

It was of particular interest to look at the impact on $\mathrm{Mo}$ and $\mathrm{Cu}$ in the experiment animals. Molybdenum and copper are known to have a relationship in animals, in which increased molybdenum can decrease copper concentrations in the body (Wang et al., 2016). This relationship is often used to treat copper toxicity in livestock and other animals (Kusum et al., 2010; Morgan et al., 2014). There was 
significantly more molybdenum in the organ tissue than the shell or muscle, which is to be expected as it is an essential element, however, there was no significant difference between the sample types. The animals exposed to elevated copper did have less molybdenum in their organs than the baseline or control samples, which, although not a significant difference, may be due to the relatively small increase in copper, and could be more pronounced if the treatment was of a higher concentration.

\section{Implications for the environment.}

As the results show, J. edwardsii juveniles are vulnerable to contamination, as they take up both essential and non-essential elements. For ecologically and commercially important species like this, it is especially necessary to have effective environmental health guidelines. The water quality guidelines used in New Zealand were set by the Australian and New Zealand Environment and Conservation Council (ANZECC) and have been updated to the Australian and New Zealand guidelines for fresh and marine water quality. These guidelines use toxicity reports on a range of marine organisms, including crustacean species, to set a guideline value for what is considered the threshold for contamination (Gadd \& Hickey, 2016a; Gadd \& Hicket, 2016b). The guidelines are reviewed frequently, and are intended to be adjustable for site-specific use, however, they are not legally binding and the testing of contaminants is done on adult animals. As juveniles are smaller and more vulnerable, they may respond differently to the effects of heavy metal pollution.

Although these guides are thorough, and are conservative in their recommendations, J. edwardsii, despite being of commercial and cultural importance, is not one of the species included in the analyses. Since the fishery is so valuable, and trace metal uptake is so variable, it may be prudent to include $J$. edwardsii in future reviews of water contamination guidelines (Fukushima et al., 2001; Cresswell et al., 2014; Chiswell \& Booth, 2017). Adult J. edwardsii are found at depths of 5-200 metres, so may be less susceptible to anthropogenic sources of contamination, however juvenile crayfish settle closer to the shore, 
and populations have been found near ports and power stations (Booth, 1989; Freeman et al., 2012; Stanley et al., 2015). High doses of metals can cause oxidative damage and affect biological processes of crustaceans even at sublethal levels, although often they are able to recover (Truchot \& Rtal 1998; Lahman et al., 2015). However, this has not been tested for J. edwardsii, and juvenile animals may be less able to tolerate even sublethal effects - physical effects of sub-lethal doses of copper have been observed in spiny lobsters (Maharajan et al., 2011). It may be necessary for these regulations to be improved in areas known for decapod populations, or in areas with naturally elevated levels of contaminants.

The evidence for passive uptake of metals by J. edwardsii exoskeletons also has implications for environmental management. One of the most common uses for chitosan is in water treatment, particularly in chelation of heavy metals, in which a material binds with molecules in order to remove them from substances, such as waste material from factories or farms (Osifo et al., 2009). Remediation of wastewater and contaminated sites is important for habitat restoration, industrial projects, and cleaning up pollution. Other remediation methods include using microorganisms, chemical techniques and complex systems, which can be expensive, time consuming, and impractical (Ngamlerdpokin et al., 2011; Wilson \& Albano, 2013; Taiwo et al., 2016). Biological remediation techniques with readily available materials are becoming more viable for large-scale applications (Kidgell et al., 2014). Chitosan is usually a waste product, as the shells of edible crustaceans in particular are discarded, making it easily accessible and economically viable (Osifo et al., 2009). The many applications of chitin from crustacean shells gives great economic potential to species that are already of significance in fisheries and aquaculture, and the value of chitin products is expected to increase (Nguyen et al., 2017).

\section{Implications for biomonitoring.}

The differences in metal concentration between tissue types have implications for the use of decapods for monitoring. During the statistical analysis of this chapter, it was found that even animals that shared a habitat could be highly variable in 
their chemical profile. This could potentially confound monitoring results, if not considered carefully.

It is important to consider that the concentration in different tissue types, of metals with certain roles, changes depending on a number of factors. This could be a reason for the aforementioned chemical variation in animals that were housed in the same environment. The moult cycle, for example, changes the distribution of copper throughout the body of crustaceans (Engel \& Brouwer, 1991; Pratoomchat et al. 2002). Relative concentrations of metals in certain tissues also vary depending on temperature (Engel \& Brouwer, 1987). Regular variation like this must be considered when using animals as bioindicators, as it can provide an inaccurate picture of an animal's chemical profile.

It is imperative for monitoring to use a range of tissue types, to be able to properly assess levels of trace elements in the environment. This chapter has shown that uptake of both essential and non-essential metals is significantly different across tissue types, and analysis of only certain tissues, especially edible muscle, which was consistently low in trace elements, can be misleading and provide an inaccurate picture of the levels of trace metals in the environment.

\section{Conclusions.}

Uptake of trace metals into body tissues is important to understand as it affects the health of organisms, and has implications for monitoring. This chapter addressed how essential and non-essential metals are accumulated in different tissues of Jasus edwardsii. The results showed that this species accumulates contaminants in its organs, and can bioregulate elevated concentrations of trace elements. They also showed that non-essential elements, like neodymium, behave differently to bioessential metals like copper - $\mathrm{Cu}$ was consistently higher in the organ tissue, including when the concentration was increased by the treatment, however excess $\mathrm{Nd}$, while accumulated in the organs at natural levels, was taken up into the shell. This study has considerable implications for the environment. It provided evidence for the use of crayfish moults as wastewater remediation devices, which has potential for environmental management. In 
particular, it emphasised the variability in trace metal accumulation patterns, and the need for using a range of species and tissue types to establish toxicity thresholds and monitoring programs. 


\section{General Discussion}

\section{Implications of this research for the New Zealand environment.}

The current research has contributed trace element data for three native decapod species, and provides valuable information that addresses a knowledge gap in a New Zealand context. It contributes to the wider CAIME project, which aims to establish this biomonitoring method for the New Zealand coastal environment.

The baseline data collection chapter of the thesis provides a range of ecosystem data that can be used for the CAIME monitoring objective, and shows variation across the Wellington region and between trophic levels. The results showed some limited differences between sites; however there was geographic variation in the concentration of cadmium in the animals, which is an extremely toxic metal, even in low doses. Although it was not clear what caused animals from Tora to have comparatively elevated $\mathrm{Cd}$ levels, it emphasises the importance of monitoring contaminants even in relatively isolated locations. It also shows the necessity of taking into consideration the connectivity of ecosystems - cadmium is a fertiliser byproduct that is regularly monitored in soil, and may be elevated due to agricultural runoff from the coast and the Awhea River, and it is worth monitoring in aquatic environments as well (Ministry of Primary Industries, 2008).

Chapter One also provided data on trophic level variation of trace elements, which highlighted the importance of diet in accumulation of metals, and showed that trophic levels are affected differently, and metal contamination may be more detrimental to certain species than others (Wang \& Rainbow, 2000; Wang \& Ke, 2002; Briand et al., 2018).

The results of Chapter Two show that Jasus edwardsii accumulates both essential and non-essential metals, however despite it being a commercially successful species it was not included as a target species in the water quality guidelines used in New Zealand and Australia. These results show how variable uptake of metal contaminants is, and that bioaccumulation rates vary between species and types of metal, which, combined with the ability of invertebrates to detoxify metals themselves (to an extent), makes it hard to establish toxicity 
thresholds (Rizo et al., 2010; Rainbow et al., 2015). It is therefore important to analyse a range of species when setting contamination guidelines. The results of this thesis stress the necessity of including a range of species in environmental health guidelines, and in monitoring programs.

\section{Implications of this research for biomonitoring.}

This thesis has contributed to the body of research on biomonitoring by assessing species at different trophic levels, and identifying the necessity of using a range of species and tissue types when monitoring the environment.

Although the decapod species used in Chapter One were similar in size and habitat, there was considerable variation in their trace element chemistry. Toxicity of trace metals varies depending on a number of factors, including whether or not the element has a biological function, and the species of animal being investigated (Rainbow et al., 2015). Therefore, it is not possible to claim that there is a general body burden threshold at which metals become toxic (Rainbow et al., 2015). Research suggests that there may be a threshold at which metabolically available metal exceeds safe levels, which is a proportion of the total accumulated amount in the body (Rainbow \& Luoma, 2011). For the purposes of monitoring safe levels of contaminants in the environment, it may be necessary to establish different thresholds for different species, as although this threshold of metabolically available metals may be similar between families or orders of organisms, it will still vary depending on the environment of the animal, and the proportion of the total body concentration (Rainbow \& Luoma, 2011).

Chapter One also addressed the limitation of being unable to identify differences in trace element chemistry of separate tissue types, which was investigated in Chapter Two, and shown to be important for accurate biomonitoring. Many monitoring studies, particularly of important fishery species, focus on muscle tissue since these are consumed. However, this thesis has provided evidence that using a range of tissue types is more effective for monitoring, as trace metals are taken up differentially into different tissues, with organs typically containing the highest concentration of metals and edible muscle tissue having the lowest. 


\section{Limitations of this research.}

Small sample sizes were the most significant limitation to this study. This was the result of the availability of Jasus edwardsii, and the numbers of samples that could be analysed using the ICP-MS. The steps in the dissolution process preceding the ICP-MS require waiting for $\mathrm{HNO}_{3}$ to dry, and can take several hours, usually overnight. There is a physical limitation on lab space that restricts how many samples can be processed at once, and the cost of the chemicals used for the preparation of the samples and the standards, and the cost of argon gas also limit the number of samples that can be analysed. A small sample size is not ideal as it can make it difficult to obtain a robust result from the analysis. However, as most of the elements met the assumptions of the statistical tests, it can be inferred that the results are satisfactory despite the small sample size.

There is also natural variation in the number of animals that settle each month, so the experiment was limited by the number of $J$. edwardsii that could be collected at the same time. It was preferred that the animals all be around the same age so that they were of a similar size, and from the same area to ensure there was no geographical variation. This meant the experiment sample size was restricted by how many $J$. edwardsii were collected on one trip to the Wairarapa where they were all sourced from. Variation in growth rate was also a limiting factor animals that were too small would not have been able to be dissected with the tools available, or have enough muscle or organ tissue extracted. This again limited the number of animals that could be used in the experiment.

\section{Suggestions for future study.}

The limitations of this study lend themselves to a number of possibilities for future research. There were a number of samples that could not be run, and the animals in the $200 \mu \mathrm{g} / \mathrm{L}$ copper treatment could be assessed to understand how high doses of heavy metals are accumulated in different tissues, and whether animals can recover from copper exposure. The animals that were not able to be analysed for this thesis are in the possession of NIWA, and are intended to be analysed at a later date. A significant amount of trace element data from the ICP- 
MS analysis were not analysed for this research, as it did not meet statistical assumptions, but may be useful in further understanding the relationships between different trace metals if included in a larger dataset. Although the baseline data collection was limited by the number of samples that could be run, it will be valuable to compare the results of this study to similar data from the baseline analysis of other samples in the CAIME project. The baseline collection includes a wide range of decapods and amphipods from around New Zealand, from the NIWA collection as well as fresh samples. The data from the species used in this project are an addition to the CAIME baseline study, and so even though the sample size was small, the results contribute to this dataset and can be used for future analyses.

The limited number of samples that could be run also meant that it was not possible to analyse the trace metal content of the crayfish food source, Mytilus edulis. This would be useful to examine further, in order to assess whether trace metal concentration in the mussels has any effect on the concentration in the target species. Research on amphipods has suggested that crustaceans may accumulate more nutrients, including copper, from their diet than from their environment (Weeks \& Rainbow, 1993). This would be particularly useful for species like Jasus edwardsii, as it is a major fishery species. Analysing the food source would also provide additional trophic level research, which was shown in this thesis to be highly variable and therefore important to understand, as the possibility of further developing an aquaculture industry for this and other seafood species is a popular issue, so knowledge of how diet affects the levels of contaminants in these animals is extremely important.

In future doping experiments, obtaining a larger sample size may require collection from a number of sites. In this case, it would be useful to run a pilot study to test how long it takes for the animals to adjust to laboratory water, by comparing the chemical profile of animals straight from the collection site with those that have been living in lab water. In addition, it would be of interest to test for variation in heavy metal tolerance and uptake between animals from different sites, especially those with different sources of contamination, levels of pollution, or geological features. This would be of particular use for fishery species like $J$. 
edwardsii and other edible crustaceans, as many of these are widespread in New Zealand and therefore may have different tolerances to levels of contamination, which is vital information for the food industry.

Although the sites used for chapter one of this research were mostly coarse sand and gravel consisting largely of greywacke, and therefore unlikely to have any significant differences in contaminant levels in the sediment, it may be preferable to include ICP-MS analysis of the sediment in future study, to gather environmental information and assess any differences in sediment metal concentrations. This would be key information for research that includes sites with known differences in geology or levels of pollutants. It also may help to explain differences between metal concentration in the animal and seawater data, like that of titanium where the water analysis was at odds with the trends seen in the animal analysis.

\section{Conclusions.}

This thesis aimed to investigate the use of decapods as bioindicators of environmental quality through baseline data collection and analysis of trace metal uptake.

Data collection on the concentration of thirty metals in two species, across three sites saw differences between species for the majority of elements, with most being higher in Heterozius rotundifrons than Petrolisthes elongatus. This could be due to accumulation of metals from the diet of $H$. rotundifrons. Few significant differences were seen between sites, which was mainly due to the similar geology of the area but it is notable that the different levels of urbanisation did not cause a significant effect between sites. This may be due to the exposed nature of all three sites, which would not allow for many contaminants to be retained in the sediment, and would cause mixing and homogeneity of trace elements in the seawater. Collection of these data contributed to the CAIME project's database of crustacean trace element data. 
This thesis also investigated accumulation of biologically essential and nonessential trace metals into different tissue types. Copper is accumulated predominantly in the organs, where it performs a number of biological functions, and is detoxified at high levels. Neodymium, a non-essential element, was more complex, accumulating differently into tissues depending on whether the concentration was elevated in the water or not. This furthers understanding of how elements are accumulated into different tissue types, which is important for biomonitoring and animal health, and contributes information on Jasus edwardsii, which is commercially and culturally valuable. It shows that non-essential elements, which are often toxic, may accumulate differently to those with a biological function, which monitoring methods must consider.

This thesis has contributed trace metal data on native New Zealand decapods, which has been little studied in this context, and which is important for assessing the health of organisms and the environment through biomonitoring. 


\section{$\underline{\text { References }}$}

Alikhan, M. A., Bagatto, G., \& Zia, S. (1990). The crayfish as a "biological indicator" of aquatic contamination by heavy metals. Water Research, 24(9), 1069-1076.

Alonso-Hernández, C. M., Gómez-Batista, M., Díaz-Asencio, M., EstévezAlvares, J., \& Padilla-Alvares, R. (2012). Total arsenic in marine organisms from Cienfuegos bay (Cuba). Food Chemistry, 130(4), 973-976.

Al-Subiai, S. N., Moody, A. J., Mustafa, S. A., \& Jha, A. N. (2011). A multiple biomarker approach to investigate the effects of copper on the marine bivalve mollusc, Mytilus edulis. Ecotoxicology and Environmental Safety, 74(7), 19131920.

Anderson, R. V., \& Brower, J. E. (1978). Patterns of trace metal accumulation in crayfish populations. Bulletin of Environmental Contamination and Toxicology, 20(1), 120-127.

Arulkumar, A., Paramasivam, S., \& Rajaram, R. (2017). Toxic heavy metals in commercially important food fishes collected from Palk Bay, Southeastern India. Marine Pollution Bulletin, 119(1), 454-459.

Babbucci, M., Buccoli, S., Cau, A., Cannas, R., Goñi, R., Díaz, D., Marcato, S., Zane, L., \& Patarnello, T. (2010). Population structure, demographic history, and selective processes: contrasting evidences from mitochondrial and nuclear markers in the European spiny lobster Palinurus elephas (Fabricius, 1787). Molecular Phylogenetics and Evolution, 56(3), 1040-1050.

Baker, D. J., Hartley, A. J., Butchart, S. H., \& Willis, S. G. (2016). Choice of baseline climate data impacts projected species' responses to climate change. Global Change Biology, 22(7), 2392-2404.

Bardeggia, M., \& Alikhan, M. A. (1991). The relationship between copper and nickel levels in the diet, and their uptake and accumulation by Cambarus bartoni (Fabricius)(Decapoda, Crustacea). Water Research, 25(10), 1187-1192.

Beeram, S., Morris, A., Hardaway, C. J., Richert, J. C., \& Sneddon, J. (2012). Studies of whole crawfish shells for the removal of chromium, lead, and selenium ions in solution. Instrumentation Science \& Technology, 40(6), 618-639.

Begg, J.G., \& Johnston, M.R. (Compilers)(2000). Geology of the Wellington area.1:250,000 geological map 10.1 sheet +64 p. Lower Hutt: Institute of Geological \& Nuclear Sciences. Institute of Geological \& Nuclear Sciences

Bergey, L. L., \& Weis, J. S. (2007). Molting as a mechanism of depuration of metals in the fiddler crab, Uca pugnax. Marine Environmental Research, 64(5), 556-562.

Bertrand, L., Monferrán, M. V., Mouneyrac, C., \& Amé, M. V. (2018). Native crustacean species as a bioindicator of freshwater ecosystem pollution: A multivariate and integrative study of multi-biomarker response in active river monitoring. Chemosphere, 206, 265-277.

Blott, S. J. (2010). GRADISTAT: a grain size distribution and statistics package for the analysis of unconsolidated sediments. Version 8.0 
Bonsignore, M., Manta, D. S., Mirto, S., Quinci, E. M., Ape, F., Montalto, V., Gristina, M., Traina, A., \& Sprovieri, M. (2018). Bioaccumulation of heavy metals in fish, crustaceans, molluscs and echinoderms from the Tuscany coast. Ecotoxicology and Environmental Safety, 162, 554-562.

Booth, J. D. (1989). Occurrence of the puerulus stage of the rock lobster, Jasus edwardsii at the New Plymouth Power Station, New Zealand. New Zealand Journal of Marine and Freshwater Research, 23(1), 43-50.

Borrell, A., Tornero, V., Bhattacharjee, D., \& Aguilar, A. (2016). Trace element accumulation and trophic relationships in aquatic organisms of the Sundarbans mangrove ecosystem (Bangladesh). Science of the Total Environment, 545, 414423.

Bou-Olayan, A. H., Al-Yakoob, S., \& Al-Hossaini, M. (1995). Arsenic in shrimp from Kuwait. Bulletin of Environmental Contamination and Toxicology, 54(4), 584590.

Bravo, I., Focaracci, F., Cerfolli, F., \& Papetti, P. (2016). Relationships between trace elements in Posidonia oceanica shoots and in sediment fractions along Latium coasts (northwestern Mediterranean Sea). Environmental Monitoring and Assessment, 188(3), 157.

Briand, M. J., Bustamante, P., Bonnet, X., Churlaud, C., \& Letourneur, Y. (2018). Tracking trace elements into complex coral reef trophic networks. Science of the Total Environment, 612, 1091-1104.

Brix, K. V., Keithly, J., Santore, R. C., DeForest, D. K., \& Tobiason, S. (2010). Ecological risk assessment of zinc from stormwater runoff to an aquatic ecosystem. Science of the Total Environment, 408(8), 1824-1832.

Buettner, K. M., \& Valentine, A. M. (2011). Bioinorganic chemistry of titanium. Chemical Reviews, 112(3), 1863-1881.

Burton, C. A., Hoefen, T. M., Plumlee, G. S., Baumberger, K. L., Backlin, A. R., Gallegos, E., \& Fisher, R. N. (2016). Trace elements in stormflow, ash, and burned soil following the 2009 Station Fire in Southern California. PloS one, $11(5)$, e 0153372.

Caro, A., Chereau, G., Briant, N., Roques, C., Freydier, R., Delpoux, S., Escalas, A., \& Elbaz-Poulichet, F. (2015). Contrasted responses of Ruditapes decussatus (filter and deposit feeding) and Loripes lacteus (symbiotic) exposed to polymetallic contamination (Port-Camargue, France). Science of the Total Environment, 505, 526-534.

Cebrian, E., \& Uriz, M. J. (2007). Contrasting effects of heavy metals and hydrocarbons on larval settlement and juvenile survival in sponges. Aquatic Toxicology, 81(2), 137-143.

Celi, M., Filiciotto, F., Vazzana, M., Arizza, V., Maccarrone, V., Ceraulo, M., Mazzola, S., \& Buscaino, G. (2014). Shipping noise affecting immune responses of European spiny lobster (Palinurus elephas). Canadian Journal of Zoology, 93(2), 113-121.

Chandurvelan, R., Marsden, I. D., Gaw, S., \& Glover, C. N. (2017). Acute and sub-chronic effects of sub-lethal cadmium exposure on energy metabolism in the 
freshwater shrimp, Paratya curvirostris. Ecotoxicology and Environmental Safety, 135, 60-67.

Chiswell, S. M., \& Booth, J. D. (2008). Sources and sinks of larval settlement in Jasus edwardsii around New Zealand: Where do larvae come from and where do they go?. Marine Ecology Progress Series, 354, 201-217.

Chiswell, S. M., \& Booth, J. D. (2017). Evolution of long larval life in the Australasian rock lobster Jasus edwardsii. Marine Ecology Progress Series, 576, 69-87.

Chou, C. L., Paon, L. A., Moffatt, J. D., \& King, T. (2003). Selection of bioindicators for monitoring marine environmental quality in the Bay of Fundy, Atlantic Canada. Marine Pollution Bulletin, 46(6), 756-762.

Cid, N., Ibáñez, C., Palanques, A., \& Prat, N. (2010). Patterns of metal bioaccumulation in two filter-feeding macroinvertebrates: exposure distribution, inter-species differences and variability across developmental stages. Science of the Total Environment, 408(14), 2795-2806.

Company, R., Serafim, A., Lopes, B., Cravo, A., Kalman, J., Riba, I., DelValls, t.A., Blasco, J., Delgado, J., Sarmiento, A.M., Nieto, J. M.,Shepherd, T.J., Nowell, G., \& Bebianno, M.J. (2011). Source and impact of lead contamination on $\delta$ aminolevulinic acid dehydratase activity in several marine bivalve species along the Gulf of Cadiz. Aquatic Toxicology, 101(1), 146-154.

Cresswell, T., Smith, R. E., Nugegoda, D., \& Simpson, S. L. (2014). Comparing trace metal bioaccumulation characteristics of three freshwater decapods of the genus Macrobrachium. Aquatic Toxicology, 152, 256-263.

Cui, L., Newcombe, C., Urgast, D. S., Raab, A., Krupp, E. M., \& Feldmann, J. (2011). Assessing the toxicity of arsenic-bearing sulfide minerals with the bioindicator Corophium volutator. Environmental Chemistry, 8(1), 52-61.

Depledge, M. H., \& Bjerregaard, P. (1989). Haemolymph protein composition and copper levels in decapod crustaceans. Helgoländer Meeresuntersuchungen, 43(2), 207.

Deruytter, D., Vandegehuchte, M. B., Garrevoet, J., De Laender, F., Vergucht, E., Delbeke, K., Blust, R., De Schamphelaere, K.A.C., Vincze, L., \& Janssen, C. R. (2015). Salinity and dissolved organic carbon both affect copper toxicity in mussel larvae: Copper speciation or competition cannot explain everything. Environmental Toxicology and Chemistry, 34(6), 1330-1336.

de Schamphelaere, K. A., \& Janssen, C. R. (2002). A biotic ligand model predicting acute copper toxicity for Daphnia magna: the effects of calcium, magnesium, sodium, potassium, and $\mathrm{pH}$. Environmental Science \& Technology, 36(1), 48-54.

de Souza, G. N., Oliveira, C. A., Tardem, A. S., \& Soares-Gomes, A. (2017). Counting and measuring ghost crab burrows as a way to assess the environmental quality of beaches. Ocean \& Coastal Management, 140, 1-10.

Downs, P. W., Singer, M. S., Orr, B. K., Diggory, Z. E., \& Church, T. C. (2011). Restoring ecological integrity in highly regulated rivers: the role of baseline data and analytical references. Environmental Management, 48(4), 847-864. 
Eddy, T. D., Pitcher, T. J., MacDiarmid, A. B., Byfield, T. T., Tam, J. C., Jones, T. T., Bell. J. J., \& Gardner, J. P. (2014). Lobsters as keystone: Only in unfished ecosystems?. Ecological Modelling, 275, 48-72.

Edgar, G. J., Bustamante, R. H., Farina, J. M., Calvopina, M., Martinez, C., \& Toral-Granda, M. V. (2004). Bias in evaluating the effects of marine protected areas: the importance of baseline data for the Galapagos Marine Reserve. Environmental Conservation, 31(3), 212-218.

Edokpayi, J., Odiyo, J., Popoola, E., Alayande, O., \& Msagati, T. (2015). Synthesis and characterization of biopolymeric chitosan derived from land snail shells and its potential for $\mathrm{Pb} 2+$ removal from aqueous solution. Materials, 8(12), 8630-8640.

El Gammal, M. A. M., Al-madan, A., \& Fita, N. (2016). Shrimp, Crabs and Squids as bio-indicators for heavy metals in Arabian Gulf, Saudi Arabia. International Journal of Fisheries and Aquatic Studies, 4(6), 200-207.

Engel, D. W., \& Brouwer, M. (1987). Metal regulation and molting in the blue crab, Callinectes sapidus: metallothionein function in metal metabolism. The Biological Bulletin, 173(1), 239-251.

Engel, D. W., \& Brouwer, M. (1991). Short-term metallothionein and copper changes in blue crabs at ecdysis. The Biological Bulletin, 180(3), 447-452.

Fabris, G., Turoczy, N. J., \& Stagnitti, F. (2006). Trace metal concentrations in edible tissue of snapper, flathead, lobster, and abalone from coastal waters of Victoria, Australia. Ecotoxicology and Environmental Safety, 63(2), 286-292.

Fingerman, M., Devi, M., Reddy, P. S., \& Katyayani, R. (1996). Impact of heavy metal exposure on the nervous system and endocrine-mediated processes in crustaceans. Zoological Studies, 35(1), 1-8.

Foster, M. L., Bartnikas, T. B., Maresca-Fichter, H. C., Mercadante, C., Dash, M., Miller, C., \& Dorman, D. C. (2017). Interactions of manganese with iron, zinc, and copper in neonatal $\mathrm{C} 57 \mathrm{BL} / 6 \mathrm{~J}$ and parkin mice following developmental oral manganese exposure. Data In Brief, 15, 908-915.

Freeman, D. J., Breen, P. A., \& MacDiarmid, A. B. (2012). Use of a marine reserve to determine the direct and indirect effects of fishing on growth in a New Zealand fishery for the spiny lobster Jasus edwardsii. Canadian Journal of Fisheries and Aquatic Sciences, 69(5), 894-905.

Frisch, A. J., \& Hobbs, J. P. A. (2011). Effects of autotomy on long-term survival and growth of painted spiny lobster (Panulirus versicolor) on the Great Barrier Reef, Australia. Marine Biology, 158(7), 1645-1652.

Fukunaga, A., \& Anderson, M. J. (2011). Bioaccumulation of copper, lead and zinc by the bivalves Macomona liliana and Austrovenus stutchburyi. Journal of Experimental Marine Biology and Ecology, 396(2), 244-252.

Gadd, J., Hickey, C.W. (2016a). Guidelines for the protection of aquatic ecosystems, toxicant trigger values: Copper - Marine. Australian and New Zealand guidelines for fresh and marine water quality. Draft September 2016. Council of Australian Governments Standing Council on Environment and Water, Canberra, ACT, Australia. 
Gadd, J., Hickey, C.W. (2016b). Guidelines for the protection of aquatic ecosystems, toxicant trigger values: Zinc - Marine. Australian and New Zealand guidelines for fresh and marine water quality. Draft September 2016. Council of Australian Governments Standing Council on Environment and Water, Canberra, $A C T$, Australia.

Gardner, J. P., Zbawicka, M., Westfall, K. M., \& Wenne, R. (2016). Invasive blue mussels threaten regional scale genetic diversity in mainland and remote offshore locations: the need for baseline data and enhanced protection in the Southern Ocean. Global Change Biology, 22(9), 3182-3195.

Giacomin, M., Jorge, M. B., \& Bianchini, A. (2014). Effects of copper exposure on the energy metabolism in juveniles of the marine clam Mesodesma mactroides. Aquatic Toxicology, 152, 30-37.

Gomiero, A., \& Viarengo, A. (2014). Effects of elevated temperature on the toxicity of copper and oxytetracycline in the marine model, Euplotes crassus: a climate change perspective. Environmental Pollution, 194, 262-271.

Goretti, E., Pallottini, M., Ricciarini, M. I., Selvaggi, R., \& Cappelletti, D. (2016). Heavy metals bioaccumulation in selected tissues of red swamp crayfish: An easy tool for monitoring environmental contamination levels. Science of the Total Environment, 559, 339-346.

Götze, S., Bose, A., Sokolova, I. M., Abele, D., \& Saborowski, R. (2014). The proteasomes of two marine decapod crustaceans, European lobster (Homarus gammarus) and Edible crab (Cancer pagurus), are differently impaired by heavy metals. Comparative Biochemistry and Physiology Part C: Toxicology \& Pharmacology, 162, 62-69.

Greco, L. L., Sánchez, M. V., Nicoloso, G. L., Medesani, D. A., \& Rodríguez, E. M. (2001). Toxicity of cadmium and copper on larval and juvenile stages of the estuarine crab Chasmagnathus granulata (Brachyura, Grapsidae). Archives of Environmental Contamination and Toxicology, 41(3), 333-338.

Grinham, A., Kvennefors, C., Fisher, P. L., Gibbes, B., \& Albert, S. (2014). Baseline arsenic levels in marine and terrestrial resources from a pristine environment: Isabel Island, Solomon Islands. Marine Pollution Bulletin, 88(1-2), 354-360.

Gristina, M., Sinopoli, M., Fiorentino, F., Garofalo, G., \& Badalamenti, F. (2011). Shelter selection of the spiny lobster Palinurus elephas under different levels of Octopus vulgaris predation threat. Marine Biology, 158(6), 1331-1337.

Gundacker, C. (2000). Comparison of heavy metal bioaccumulation in freshwater molluscs of urban river habitats in Vienna. Environmental Pollution, 110(1), 6171.

Guner, U. (2007). Freshwater crayfish Astacus leptodactylus (Eschscholtz, 1823) accumulates and depurates copper. Environmental monitoring and Assessment, 133(1-3), 365.

Hao, Y., Chen, L., Zhang, X., Zhang, D., Zhang, X., Yu, Y., \& Fu, J. (2013). Trace elements in fish from Taihu Lake, China: Levels, associated risks, and trophic transfer. Ecotoxicology and Environmental Safety, 90, 89-97. 
Hazlett, B. A., \& Bach, C. E. (2010). Individuality in the predator defense behaviour of the crab Heterozius rotundifrons. Behaviour, 587-597.

Hazlett, B. A., Bach, C. E., Thompson, G. A., \& McLay, C. L. (2005). Movement of male Heterozius rotundifrons (Crustacea: Decapoda: Brachyura) depends upon local sex ratio. New Zealand Journal of Marine and Freshwater Research, 39(1), 157-163.

Hinojosa, I. A., Green, B. S., Gardner, C., Hesse, J., Stanley, J. A., \& Jeffs, A. G. (2016). Reef sound as an orientation cue for shoreward migration by pueruli of the rock lobster, Jasus edwardsii. PloS one, 11(6), e0157862.

His, E., Beiras, R., \& Seaman, M. N. L. (1999). The assessment of marine pollution-bioassays with bivalve embryos and larvae. Advances in Marine Biology, 37, 1-178.

Hogstrand, C., \& Haux, C. (1990). Metallothionein as an indicator of heavy-metal exposure in two subtropical fish species. Journal of Experimental Marine Biology and Ecology, 138(1-2), 69-84.

Huang, P., Li, J., Zhang, S., Chen, C., Han, Y., Liu, N., Xiao, Y., Wang, H., Zhang, M., Yu, Q., Liu, Y., \& Liu, Y. (2011). Effects of lanthanum, cerium, and neodymium on the nuclei and mitochondria of hepatocytes: accumulation and oxidative damage. Environmental Toxicology and Pharmacology, 31(1), 25-32.

Huang, S. F., Li, Z. Y., Wang, X. Q., Wang, Q. X., \& Hu, F. F. (2010). Cerium caused life span shortening and oxidative stress resistance in Drosophila melanogaster. Ecotoxicology and Environmental Safety, 73(1), 89-93.

Jack, L., Wing, S. R., Hu, Y., \& Roberts, M. (2011). Natural trace elemental markers for adult red rock lobsters Jasus edwardsii vary among replicate distinct water masses. Marine Ecology Progress Series, 443, 141-151.

Jakimska, A., Konieczka, P., Skóra, K., \& Namieśnik, J. (2011). Bioaccumulation of Metals in Tissues of Marine Animals, Part I: the Role and Impact of Heavy Metals on Organisms. Polish Journal of Environmental Studies, 20(5).

Jara-Marini, M. E., Tapia-Alcaraz, J. N., Dumer-Gutiérrez, J. A., García-Rico, L., García-Hernández, J., \& Páez-Osuna, F. (2013). Comparative bioaccumulation of trace metals using six filter feeder organisms in a coastal lagoon ecosystem (of the central-east Gulf of California). Environmental Monitoring and Assessment, 185(2), 1071-1085.

Jenkins, C. (2013). Statistical aspects of monitoring and verification. International Journal of Greenhouse Gas Control, 13, 215-229.

Jensen, M. A., Carter, C. G., Adams, L. R., \& Fitzgibbon, Q. P. (2013). Growth and biochemistry of the spiny lobster Sagmariasus verreauxi cultured at low and high density from hatch to puerulus. Aquaculture, 376, 162-170.

Kay, M. C., Lenihan, H. S., Guenther, C. M., Wilson, J. R., Miller, C. J., \& Shrout, S. W. (2012). Collaborative assessment of California spiny lobster population and fishery responses to a marine reserve network. Ecological Applications, 22(1), 322-335. 
Khan, S., \& Nugegoda, D. (2007). Sensitivity of juvenile freshwater crayfish Cherax destructor (Decapoda: Parastacidae) to trace metals. Ecotoxicology and Environmental Safety, 68(3), 463-469.

Khan, M. A. Q., Ahmed, S. A., Catalin, B., Khodadoust, A., Ajayi, O., \& Vaughn, M. (2006). Effect of temperature on heavy metal toxicity to juvenile crayfish, Orconectes immunis (Hagen). Environmental Toxicology: An International Journal, 21(5), 513-520.

Kidgell, J. T., de Nys, R., Hu, Y., Paul, N. A., \& Roberts, D. A. (2014). Bioremediation of a complex industrial effluent by biosorbents derived from freshwater macroalgae. PloS one, 9(6), e94706.

Kikuchi, M., Akamatsu, T., \& Takase, T. (2015). Passive acoustic monitoring of Japanese spiny lobster stridulating sounds. Fisheries Science, 81(2), 229-234.

Kobayashi, N. I., Sugita, R., Nobori, T., Tanoi, K., \& Nakanishi, T. M. (2016). Tracer experiment using $42 \mathrm{~K}+$ and $137 \mathrm{Cs}+$ revealed the different transport rates of potassium and caesium within rice roots. Functional Plant Biology, 43(2), 151160.

Krishna, A. K., \& Mohan, K. R. (2013). Metal contamination and their distribution in different grain size fractions of sediments in an industrial development area. Bulletin of Environmental Contamination and Toxicology, 90(2), 170-175.

Kuklina, I., Kouba, A., Buřič, M., Horká, I., Ďuriš, Z., \& Kozák, P. (2014). Accumulation of heavy metals in crayfish and fish from selected Czech reservoirs. BioMed Research International, 2014.

Kusum, R. R., Verma, P. K., Pankaj, N. K., Kant, V., Kumar, J., \& Srivastava, A. K. (2010). Haematological profile of subacute oral toxicity of molybdenum and ameliorative efficacy of copper salt in goats. Toxicology International, 17(2), 82.

Lee, J.M., \& Begg, J.G. (Compilers)(2002). Geology of the Wairarapa area.1:250,000 geological map 10.1 sheet +64 p. Lower Hutt: Institute of Geological \& Nuclear Sciences. Institute of Geological \& Nuclear Sciences

Lefcort, H., Thomson, S. M., Cowles, E. E., Harowicz, H. L., Livaudais, B. M., Roberts, W. E., \& Ettinger, W. F. (1999). Ramifications of predator avoidance: predator and heavy-metal-mediated competition between tadpoles and snails. Ecological Applications, 9(4), 1477-1489.

Lahman, S. E., Trent, K. R., \& Moore, P. A. (2015). Sublethal copper toxicity impairs chemical orientation in the crayfish, Orconectes rusticus. Ecotoxicology and Environmental Safety, 113, 369-377.

Liao, Z., Cao, H., Dai, X., Xing, C., Xu, X., Nie, G., \& Zhang, C. (2018). Molybdenum and Cadmium exposure influences the concentration of trace elements in the digestive organs of Shaoxing duck (Anas platyrhyncha). Ecotoxicology and Environmental Safety, 164, 75-83.

Liu, J., Cao, L., \& Dou, S. (2017). Bioaccumulation of heavy metals and health risk assessment in three benthic bivalves along the coast of Laizhou Bay, China. Marine Pollution Bulletin, 117(1), 98-110.

Loflen, C. L., Buck, T., Bonnema, A., \& Heim, W. A. (2018). Pollutant bioaccumulation in the California spiny lobster (Panulirus interruptus) in San 
Diego Bay, California, and potential human health implications. Marine Pollution Bulletin, 128, 585-592.

Lorei García-Echauri, L., \& Jeffs, A. (2018). Swimming energetics of the postlarvae of the spiny lobster Jasus edwardsii in New Zealand. Bulletin of Marine Science, 94(3), 821-833.

Lucia, M., Bocher, P., Chambosse, M., Delaporte, P., \& Bustamante, P. (2014). Trace element accumulation in relation to trophic niches of shorebirds using intertidal mudflats. Journal of Sea Research, 92, 134-143.

Ma, W., He, Y., Yan, T., \& Wang, L. (2014). Tissue-specific copper accumulation, zinc levels, induction, and purification of metallothionein in freshwater crab Sinopotamon henanense exposed to subacute waterborne copper. Environmental Toxicology, 29(4), 407-417.

MacFarlane, G. R., Booth, D. J., \& Brown, K. R. (2000). The semaphore crab, Heloecius cordiformis: bio-indication potential for heavy metals in estuarine systems. Aquatic Toxicology, 50(3), 153-166.

Maffucci, F., Caurant, F., Bustamante, P., \& Bentivegna, F. (2005). Trace element ( $\mathrm{Cd}, \mathrm{Cu}, \mathrm{Hg}, \mathrm{Se}, \mathrm{Zn})$ accumulation and tissue distribution in loggerhead turtles (Caretta caretta) from the Western Mediterranean Sea (southern Italy). Chemosphere, 58(5), 535-542.

Maharajan, A., Rajalakshmi, S., Vijayakumaran, M., \& Kumarasamy, P. (2012). Sublethal effect of copper toxicity against histopathological changes in the spiny lobster, Panulirus homarus (Linnaeus, 1758). Biological Trace Element Research, 145(2), 201-210.

Maharajan, A., Vaseeharan, B., Rajalakshmi, S., Vijayakumaran, M., Kumarasamy, P., \& Chen, J. C. (2011). Effect of copper on morphology, weight, and chromosomal aberrations in the spiny lobster, Panulirus homarus (Linnaeus, 1758). Biological Trace Element Research, 144(1-3), 769-780.

Manimaran, K., Karthikeyan, P., Ashokkumar, S., Prabu, V. A., \& Sampathkumar, P. (2012). Effect of copper on growth and enzyme activities of marine diatom, Odontella mobiliensis. Bulletin of Environmental Contamination and Toxicology, 88(1), 30-37.

Martins, C. D. M. G., Barcarolli, I. F., de Menezes, E. J., Giacomin, M. M., Wood, C. M., \& Bianchini, A. (2011). Acute toxicity, accumulation and tissue distribution of copper in the blue crab Callinectes sapidus acclimated to different salinities: in vivo and in vitro studies. Aquatic Toxicology, 101(1), 88-99.

Mazlum, Y., Yılmaz, A. B., \& Yanar, A. (2016). Uptake and distribution of different copper compound in tissues of crayfish (Astacus leptodactylus). Fresenius Environmental Bulletin, 25(6), 1858-66.

McLay, C.1988. Brachyura and crab-like Anomura of New Zealand. Leigh Laboratory Bulletin, 22,1-463.

McLeod, C., Kiermeier, A., Stewart, I., Tan, J., Turnbull, A., \& Madigan, T. (2018). Paralytic shellfish toxins in Australian Southern Rock Lobster (Jasus edwardsii): Acute human exposure from consumption of hepatopancreas. Human and Ecological Risk Assessment: An International Journal, 24(7), 1872-1886. 
McMeans, B. C., Borgå, K., Bechtol, W. R., Higginbotham, D., \& Fisk, A. T. (2007). Essential and non-essential element concentrations in two sleeper shark species collected in arctic waters. Environmental Pollution, 148(1), 281-290.

Mercadante, C. J., Herrera, C., Pettiglio, M. A., Foster, M. L., Johnson, L. C., Dorman, D. C., \& Bartnikas, T. B. (2016). The effect of high dose oral manganese exposure on copper, iron and zinc levels in rats. Biometals, 29(3), 417-422.

Ministry of Primary Industries (2008). Report One: Cadmium in New Zealand Agriculture. Retrieved from https://www.mpi.govt.nz/protection-andresponse/environment-and-natural-resources/land-and-soil/cadmium/

Mochida, K., Amano, H., Onduka, T., Kakuno, A., \& Fujii, K. (2011). Toxicity and metabolism of copper pyrithione and its degradation product, 2, 2'dipyridyldisulfide in a marine polychaete. Chemosphere, 82(3), 390-397.

Mohanasrinivasan, V., Mishra, M., Paliwal, J. S., Singh, S. K., Selvarajan, E., Suganthi, V., \& Devi, C. S. (2014). Studies on heavy metal removal efficiency and antibacterial activity of chitosan prepared from shrimp shell waste. 3 Biotech, 4(2), 167-175.

Morcillo, P., Esteban, M. Á., \& Cuesta, A. (2016). Heavy metals produce toxicity, oxidative stress and apoptosis in the marine teleost fish SAF-1 cell line. Chemosphere, 144, 225-233.

Morgan, P. L., Grace, N. D., \& Lilley, D. P. (2014). Using sodium molybdate to treat chronic copper toxicity in dairy cows: a practical approach. New Zealand Veterinary Journal, 62(3), 167-170.

Moura, J. F., Tavares, D. C., Lemos, L. S., Acevedo-Trejos, E., Saint'Pierre, T. D., Siciliano, S., \& Merico, A. (2018). Interspecific variation of essential and nonessential trace elements in sympatric seabirds. Environmental Pollution, 242, 470-479.

Fukushima, M., Tamate, H., \& Nakano, Y. (2001). Trace elements in several species of crustaceans of Amami Island Group in Japan determined by activation analysis. Journal of Radioanalytical and Nuclear Chemistry, 249(2), 481-486.

Ngamlerdpokin, K., Kumjadpai, S., Chatanon, P., Tungmanee, U., Chuenchuanchom, S., Jaruwat, P., Lertsathitphongs, P., \& Hunsom, M. (2011). Remediation of biodiesel wastewater by chemical-and electro-coagulation: A comparative study. Journal of Environmental Management, 92(10), 2454-2460.

Nguyen, T. T., Barber, A. R., Corbin, K., \& Zhang, W. (2017). Lobster processing by-products as valuable bioresource of marine functional ingredients, nutraceuticals, and pharmaceuticals. Bioresources and Bioprocessing, 4(1), 27.

Nicolau, L., Monteiro, S. S., Pereira, A. T., Marçalo, A., Ferreira, M., Torres, J., Vingada, J., \& Eira, C. (2017). Trace elements in loggerhead turtles (Caretta caretta) stranded in mainland Portugal: Bioaccumulation and tissue distribution. Chemosphere, 179, 120-126.

Nunez-Nogueira, G., Rainbow, P. S., \& Smith, B. D. (2006). Assimilation efficiency of zinc and cadmium in the decapod crustacean Penaeus indicus. Journal of Experimental Marine Biology and Ecology, 332(1), 75-83. 
Núñez-Nogueira, G., Fernández-Bringas, L., Ordiano-Flores, A., Gómez-Ponce, A., de León-Hill, C. P., \& González-Farías, F. (2012). Accumulation and regulation effects from the metal mixture of $\mathrm{Zn}, \mathrm{Pb}$, and $\mathrm{Cd}$ in the tropical shrimp Penaeus vannamei. Biological Trace Element Research, 150(1-3), 208-213.

Osifo, P. O., Neomagus, H. W., Everson, R. C., Webster, A., \& vd Gun, M. A. (2009). The adsorption of copper in a packed-bed of chitosan beads: Modeling, multiple adsorption and regeneration. Journal of Hazardous Materials, 167(1-3), 1242-1245.

Paganini, C. L., \& Bianchini, A. (2009). Copper accumulation and toxicity in isolated cells from gills and hepatopancreas of the blue crab (Callinectes sapidus). Environmental Toxicology and Chemistry, 28(6), 1200-1205.

Pais, M. P., Henriques, S., Costa, M. J., \& Cabral, H. N. (2012). A critical approach to the use of published data for baseline characterisation of marine fish assemblages: An exercise on Portuguese coastal waters. Ocean \& Coastal Management, 69, 173-184.

Pang, C., Selck, H., Misra, S. K., Berhanu, D., Dybowska, A., Valsami-Jones, E., \& Forbes, V. E. (2012). Effects of sediment-associated copper to the depositfeeding snail, Potamopyrgus antipodarum: a comparison of $\mathrm{Cu}$ added in aqueous form or as nano-and micro-CuO particles. Aquatic Toxicology, 106, 114-122.

Pastorinho, M. R., Telfer, T. C., \& Soares, A. M. (2009). Amphipod susceptibility to metals: cautionary tales. Chemosphere, 75(11), 1423-1428.

Peraza-Castro, M., Sauvage, S., Sánchez-Pérez, J. M., \& Ruiz-Romera, E. (2016). Effect of flood events on transport of suspended sediments, organic matter and particulate metals in a forest watershed in the Basque Country (Northern Spain). Science of the Total Environment, 569, 784-797.

Phillips, B. F., \& Booth, J. D. (1994). Design, use, and effectiveness of collectors for catching the puerulus stage of spiny lobsters. Reviews in Fisheries Science, 2(3), 255-289.

Pratoomchat, B., Sawangwong, P., Pakkong, P., \& Machado, J. (2002). Organic and inorganic compound variations in haemolymph, epidermal tissue and cuticle over the molt cycle in Scyllaserrata (Decapoda). Comparative Biochemistry and Physiology Part A: Molecular \& Integrative Physiology, 131(2), 243-255.

Puig, M., Pla, A., Seguí, X., \& Darbra, R. M. (2017). Tool for the identification and implementation of Environmental Indicators in Ports (TEIP). Ocean \& Coastal Management, 140, 34-45.

Qiu, Y. W. (2015). Bioaccumulation of heavy metals both in wild and mariculture food chains in Daya Bay, South China. Estuarine, Coastal and Shelf Science, 163, 7-14.

Ragi, A. S., Leena, P. P., Cheriyan, E., \& Nair, S. M. (2017). Heavy metal concentrations in some gastropods and bivalves collected from the fishing zone of South India. Marine Pollution Bulletin, 118(1-2), 452-458.

Rainbow, P. S., Liu, F., \& Wang, W. X. (2015). Metal accumulation and toxicity: the critical accumulated concentration of metabolically available zinc in an oyster model. Aquatic Toxicology, 162, 102-108. 
Rainbow, P. S., \& Luoma, S. N. (2011). Metal toxicity, uptake and bioaccumulation in aquatic invertebrates-modelling zinc in crustaceans. Aquatic Toxicology, 105(3-4), 455-465.

Rainbow, P. S., Poirier, L., Smith, B. D., Brix, K. V., \& Luoma, S. N. (2006). Trophic transfer of trace metals from the polychaete worm Nereis diversicolor to the polychaete $\mathrm{N}$. virens and the decapod crustacean Palaemonetes varians. Marine Ecology Progress Series, 321, 167-181.

Rainbow, P. S., \& Smith, B. D. (2013). Accumulation and detoxification of copper and zinc by the decapod crustacean Palaemonetes varians from diets of fieldcontaminated polychaetes Nereis diversicolor. Journal of Experimental Marine Biology and Ecology, 449, 312-320.

R-Core-Team. 2016. R: A Language and Environment for Statistical Computing. R Foundation for Statistical Computing, Vienna, Austria. URL https://www.Rproject.org/.

Relman, A. S. (1956). The physiological behavior of rubidium and cesium in relation to that of potassium. The Yale Journal of Biology and Medicine, 29(3), 248.

Rim, K. T., Koo, K. H., \& Park, J. S. (2013). Toxicological evaluations of rare earths and their health impacts to workers: a literature review. Safety and Health at Work, 4(1), 12-26.

Rizo, O. D., Reumont, S. O., Fuente, J. V., Arado, O. D., Pino, N. L., Rodríguez, K. A., Lopez, J.O.A., Rudnikas, A.G., \& Carballo, G. A. (2010). Copper, zinc and lead bioaccumulation in marine snail, Strombus gigas, from Guacanayabo Gulf, Cuba. Bulletin of Environmental Contamination and Toxicology, 85(3), 330-333.

Roberts, N. L., Piotrowski, A. M., Elderfield, H., Eglinton, T. I., \& Lomas, M. W. (2012). Rare earth element association with foraminifera. Geochimica et Cosmochimica Acta, 94, 57-71.

RStudio. Team (2018). RStudio: Integrated Development for R. RStudio, Inc., Boston, MA. URL http://www.rstudio.com/.

Sabullah, M. K., Ahmad, S. A., Shukor, M. Y., Gansau, A. J., Syed, M. A., Sulaiman, M. R., \& Shamaan, N. A. (2015). Heavy metal biomarker: Fish behavior, cellular alteration, enzymatic reaction and proteomics approaches. International Food Research Journal, 22(2).

Sary, A. A., \& Mohammadi, M. (2012). Lead bioaccumulation and toxicity in tissues of economically fish species from river and marine water. Bulletin of Environmental Contamination and Toxicology, 89(1), 82-85

Schaller, J., \& Planer-Friedrich, B. (2017). The filter feeder Dreissena polymorpha affects nutrient, silicon, and metal (loid) mobilization from freshwater sediments. Chemosphere, 174, 531-537.

Signa, G., Mazzola, A., Di Leonardo, R., \& Vizzini, S. (2017). Element-specific behaviour and sediment properties modulate transfer and bioaccumulation of trace elements in a highly-contaminated area (Augusta Bay, Central Mediterranean Sea). Chemosphere, 187, 230-239. 
Silliman, B. R., \& Bertness, M. D. (2002). A trophic cascade regulates salt marsh primary production. Proceedings of the National Academy of Sciences, 99(16), 10500-10505.

Smart, A. C., Harper, D. M., Malaisse, F., Schmitz, S., Coley, S., \& De Beauregard, A. C. G. (2002). Feeding of the exotic Louisiana red swamp crayfish, Procambarus clarkii (Crustacea, Decapoda), in an African tropical lake: Lake Naivasha, Kenya. In Lake Naivasha, Kenya (pp. 129-142). Springer, Dordrecht.

Soedarini, B., Klaver, L., Roessink, I., Widianarko, B., Van Straalen, N. M., \& Van Gestel, C. A. M. (2012). Copper kinetics and internal distribution in the marbled crayfish (Procambarus sp.). Chemosphere, 87(4), 333-338.

Soegianto, A., Charmantier-Daures, M., Trilles, J. P., \& Charmantier, G. (1999). Impact of copper on the structure of gills and epipodites of the shrimp Penaeus japonicus (Decapoda). Journal of Crustacean Biology, 19(2), 209-223.

Soto-Jiménez, M. F., Arellano-Fiore, C., Rocha-Velarde, R., Jara-Marini, M. E., Ruelas-Inzunza, J., Voltolina, D., Frias-Espericueta, M.G., Quintero-Alvarez, J.M., \& Páez-Osuna, F. (2011). Biological responses of a simulated marine food chain to lead addition. Environmental Toxicology and Chemistry, 30(7), 1611-1617.

Stanley, J. A., Hesse, J., Hinojosa, I. A., \& Jeffs, A. G. (2015). Inducers of settlement and moulting in post-larval spiny lobster. Oecologia, 178(3), 685-697.

Stark, J. S., Snape, I., \& Riddle, M. J. (2003). The effects of petroleum hydrocarbon and heavy metal contamination of marine sediments on recruitment of Antarctic soft-sediment assemblages: a field experimental investigation. Journal of Experimental Marine Biology and Ecology, 283(1), 21-50.

Stockdale, A., Tipping, E., Lofts, S., \& Mortimer, R. J. (2016). Effect of ocean acidification on organic and inorganic speciation of trace metals. Environmental Science \& Technology, 50(4), 1906-1913.

Suarez-Serrano, A., Alcaraz, C., Ibanez, C., Trobajo, R., \& Barata, C. (2010). Procambarus clarkii as a bioindicator of heavy metal pollution sources in the lower Ebro River and Delta. Ecotoxicology and Environmental Safety, 73(3), 280286.

Suttle, N. F. (1974). Recent studies of the copper-molybdenum antagonism. Proceedings of the Nutrition Society, 33(3), 299-305.

Taiwo, A. M., Gbadebo, A. M., Oyedepo, J. A., Ojekunle, Z. O., Alo, O. M., Oyeniran, A. A., Onalaja, O.J., Ogunjimi, D., \& Taiwo, O. T. (2016). Bioremediation of industrially contaminated soil using compost and plant technology. Journal of Hazardous Materials, 304, 166-172.

Tomlinson, S., Mathialagan, P. D., \& Maloney, S. K. (2014). Special K: testing the potassium link between radioactive rubidium ( $86 \mathrm{Rb}$ ) turnover and metabolic rate. Journal of Experimental Biology, 217(7), 1040-1045.

Truchot, J. P., \& Rtal, A. (1998). Effects of long-term sublethal exposure to copper on subsequent uptake and distribution of metal in the shore crab Carcinus maenas. Journal of Crustacean Biology, 18(2), 224-231.

Uthus, E. O. (1992). Evidence for arsenic essentiality. Environmental Geochemistry and Health, 14(2), 55-58. 
Venter, J. A., \& Conradie, W. (2015). A checklist of the reptiles and amphibians found in protected areas along the South African Wild Coast, with notes on conservation implications. Koedoe, 57(1), 1-25.

Viarengo, A., \& Nott, J. A. (1993). Mechanisms of heavy metal cation homeostasis in marine invertebrates. Comparative Biochemistry and Physiology Part C: Comparative Pharmacology, 104(3), 355-372.

Vinichuk, M., Rosén, K., Johanson, K. J., \& Dahlberg, A. (2011). Correlations between potassium, rubidium and cesium (133Cs and 137Cs) in sporocarps of Suillus variegatus in a Swedish boreal forest. Journal of Environmental Radioactivity, 102(4), 386-392.

Walker, T. R., \& Grant, J. (2015). Metal (loid) s in sediment, lobster and mussel tissues near historical gold mine sites. Marine Pollution Bulletin, 101(1), 404-408.

Walker, T. R., MacAskill, D., \& Weaver, P. (2013). Environmental recovery in Sydney Harbour, Nova Scotia: Evidence of natural and anthropogenic sediment capping. Marine Pollution Bulletin, 74(1), 446-452.

Wang, W. X., \& Ke, C. (2002). Dominance of dietary intake of cadmium and zinc by two marine predatory gastropods. Aquatic Toxicology, 56(3), 153-165.

Wang, T., Long, X., Cheng, Y., Liu, Z., \& Yan, S. (2014). The potential toxicity of copper nanoparticles and copper sulphate on juvenile Epinephelus coioides. Aquatic Toxicology, 152, 96-104.

Wang, W. X., \& Rainbow, P. S. (2000). Dietary uptake of Cd, Cr, and $\mathrm{Zn}$ by the barnacle Balanus trigonus: influence of diet composition. Marine Ecology Progress Series, 204, 159-168.

Wang, H. W., Zhou, B. H., Zhang, S., Guo, H. W., Zhang, J. L., Zhao, J., \& Tian, E. J. (2016). Reproductive toxicity in male mice after exposure to high molybdenum and low copper concentrations. Toxicology and Industrial Health, 32(9), 1598-1606.

Ward, T. J., Gaertner, K. E., Gorsuch, J. W., \& Call, D. J. (2015a). Survival, reproduction and growth of the marine amphipod, Leptocheirus plumulosus, following laboratory exposure to copper-spiked sediment. Bulletin of Environmental Contamination and Toxicology, 95(4), 434-440.

Ward, T. J., Gaertner, K. E., Gorsuch, J. W., \& Call, D. J. (2015b). Survival and growth of the marine polychaete, Neanthes arenaceodentata, following laboratory exposure to copper-spiked sediment. Bulletin of Environmental Contamination and Toxicology, 95(4), 428-433.

Weeks, J. M., \& Rainbow, P. S. (1993). The relative importance of food and seawater as sources of copper and zinc to talitrid amphipods (Crustacea; Amphipoda; Talitridae). Journal of Applied Ecology, 722-735.

Weeks, J. M., Rainbow, P. S., \& Moore, P. G. (1992). The loss, uptake and tissue distribution of copper and zinc during the moult cycle in an ecological series of talitrid amphipods (Crustacea: Amphipoda). Hydrobiologia, 245(1), 15-25.

Wei, K., \& Yang, J. (2016). Copper-induced oxidative damage to the prophenoloxidase-activating system in the freshwater crayfish Procambarus clarkii. Fish \& Shellfish Immunology, 52, 221-229. 
Weinstein, J. E., West, T. L., \& Bray, J. T. (1992). Shell disease and metal content of blue crabs, Callinectes sapidus, from the Albemarle-Pamlico estuarine system, North Carolina. Archives of Environmental Contamination and Toxicology, 23(3), 355-362.

White, S. L., \& Rainbow, P. S. (1982). Regulation and accumulation of copper, zinc and cadmium by the shrimp Palaemon elegans. Marine Ecology Progress Series, 8(95), 101.

Wilson, P. C., \& Albano, J. P. (2013). Novel flow-through bioremediation system for removing nitrate from nursery discharge water. Journal of Environmental Management, 130, 192-198.

Yap, C. K., Ismail, A., Omar, H., \& Tan, S. G. (2004). Toxicities and tolerances of $\mathrm{Cd}, \mathrm{Cu}, \mathrm{Pb}$ and $\mathrm{Zn}$ in a primary producer (Isochrysis galbana) and in a primary consumer (Perna viridis). Environment International, 29(8), 1097-1104.

Zaaboub, N., Oueslati, W., Amine Helali, M., Abdeljaouad, S., Javier Huertas, F., \& Lopez Galindo, A. (2014). Trace elements in different marine sediment fractions of the Gulf of Tunis (Central Mediterranean Sea). Chemical Speciation \& Bioavailability, 26(1), 1-12.

Zaharescu, D. G., Hooda, P. S., Burghelea, C. I., Polyakov, V., \& Palanca-Soler, A. (2016). Climate change enhances the mobilisation of naturally occurring metals in high altitude environments. Science of the Total Environment, 560, 7381.

Zha, H., Cheng, Z., Chen, J., Hu, R., Che, Y., Cui, Y., Ling, W., \& Hong, F. (2011). The toxicological effects in brain of mice following exposure to cerium chloride. Biological Trace Element Research, 144(1-3), 872-884.

Zhang, C., Li, F., \& Xiang, J. (2014). Acute effects of cadmium and copper on survival, oxygen consumption, ammonia-N excretion, and metal accumulation in juvenile Exopalaemon carinicauda. Ecotoxicology and Environmental Safety, 104, 209-214.

Zhao, D., Zhang, X., Li, X., Ru, S., Wang, Y., Yin, J., \& Liu, D. (2019). Oxidative damage induced by copper in testis of the red swamp crayfish Procambarus clarkii and its underlying mechanisms. Aquatic Toxicology, 207, 120-131.

Zia, S., \& Alikhan, M. A. (1989). Copper uptake and regulation in a coppertolerant decapod Cambarus bartoni (Fabricius)(Decapoda, Crustacea). Bulletin of Environmental Contamination and Toxicology, 42(1), 103-110. 